University of Louisville

ThinkIR: The University of Louisville's Institutional Repository

Electronic Theses and Dissertations

$12-2011$

\title{
Characterization of DNA-binding proteins as clinically relevant biomarkers of breast cancer behavior.
}

Traci L. Kruer 1979-

University of Louisville

Follow this and additional works at: https://ir.library.louisville.edu/etd

\section{Recommended Citation}

Kruer, Traci L. 1979-, "Characterization of DNA-binding proteins as clinically relevant biomarkers of breast cancer behavior." (2011). Electronic Theses and Dissertations. Paper 778.

https://doi.org/10.18297/etd/778

This Doctoral Dissertation is brought to you for free and open access by ThinkIR: The University of Louisville's Institutional Repository. It has been accepted for inclusion in Electronic Theses and Dissertations by an authorized administrator of ThinkIR: The University of Louisville's Institutional Repository. This title appears here courtesy of the author, who has retained all other copyrights. For more information, please contact thinkir@louisville.edu. 


\title{
CHARACTERIZATION OF DNA-BINDING PROTEINS AS CLINICALLY RELEVANT BIOMARKERS OF BREAST CANCER BEHAVIOR
}

\author{
By \\ Traci L. Kruer \\ B.A. Purdue University, 2001 \\ M.S. University of Louisville, 2011
}

\begin{abstract}
A Dissertation
Submitted to the Faculty of the

School of Medicine of the University of Louisville in Partial Fulfillment of the Requirements

for the Degree of
\end{abstract}

Doctor of Philosophy

Department of Biochemistry and Molecular Biology

University of Louisville

Louisville, KY

December 2011 


\title{
CHARACTERIZATION OF DNA-BINDING PROTEINS AS CLINICALLY RELEVANT BIOMARKERS OF BREAST CANCER BEHAVIOR
}

\author{
By \\ Traci L. Kruer \\ B.A. Purdue University, 2001 \\ M.S. University of Louisville, 2011 \\ A Dissertation Approved on
}

November 17, 2011

By the following Dissertation Committee:

James L. Wittliff, Dissertation Director

Anees Chagpar

Paula Bates

William Dean

Steven R. Ellis 


\section{ACKNOWLEDGEMENTS}

I would like to thank my mentor Dr. James L. Wittliff for his support and guidance over the last few years. I appreciate the opportunities he has given me to grow as a scientist. I would also like to thank my committee members, Dr. William Dean, Dr. Steve Ellis, Dr. Paula Bates and Dr. Anees Chagpar, for their feedback and advice. I would like to thank my colleagues in the lab, Dr. Irina Smolenkova, Dr. Sarah Andres and Mitzie Wittliff, for both their support in the lab and their friendship. I also owe special thanks to Dr. Tim Cummins and Dr. David Powell for their assistance with the mass spectrometry experiments, which were crucial to my dissertation project. I would also like to thank Aaron denDekker for reading and critiquing this dissertation and for his assistance with my defense preparation. I would like to acknowledge the NIH/NCI, Phi Beta Psi Charity Trust, the University of Louisville Research on Women Program, the Commonwealth of Kentucky Clinical Translational Research Program, the Institute for Molecular Diversity and Drug Design and the Department of Defense Breast Cancer Research Program for funding me and this project.

Most importantly, I would like to thank my family and especially my husband Dr. Alan Kerr for believing in me. Without their love and patience, I couldn't have accomplished this. Alan always encouraged me to keep going even during tough times, and I can't express enough how much I love and appreciate him. 


\title{
ABSTRACT \\ CHARACTERIZATION OF DNA-BINDING PROTEINS AS CLINICALLY RELEVANT BIOMARKERS OF BREAST CANCER BEHAVIOR
}

\author{
Traci L. Kruer
}

November 17, 2011

While investigating estrogen response element (ERE) binding properties of ER $\alpha$ in de-identified human breast cancer extracts, additional proteins were observed that recognized ERE sequences (ERE-BP). In order to unravel the apparent role of these proteins, our goal was to compare properties of these novel ERE-BP with those of ER $\alpha$, determine their identity and evaluate their clinical relevance in breast cancer behavior. ERE-BP were present in various tissue types including breast, ovarian, uterine and colon cancers and normal tissues. These proteins were present in both cytoplasm and nuclei although higher binding activities were detected in nuclear extracts. ERE-BP did not supershift with numerous anti-ER $\alpha$ or ER $\beta$ antibodies recognizing different ER epitopes suggesting that they are not fragments of either ER $\alpha$ or ER $\beta$. ERE-BP competed with rhER $\alpha$ for binding to the VitA2-ERE yet overall exhibited significantly different sequence specificity compared to that of human ER $\alpha$. The ERE-BP we observed in breast cancer extracts were not specific for ERE sequences. To further support this conclusion, various estrogens had no effect on the ERE-binding of these proteins in contrast to rhER $\alpha$. Furthermore, ERE-BP activities were not correlated with levels of expression of 
in either ER $\alpha$ - or ERE-mediated transcription. An immune-based method was established for purifying ERE-BP from tissue extracts and proteins were identified by mass spectrometry. Ku70 (XRCC6) and Ku80 (XRCC5) were determined to be the most likely candidates for the identity of ERE-BP. Supershift assays confirmed that ERE-BP/ERE complexes observed by EMSA were specifically recognized by antibodies to the $\mathrm{Ku} 70 / \mathrm{Ku} 80$ heterodimer $(\mathrm{Ku})$. Western blotting with $\mathrm{Ku} 70 / \mathrm{Ku} 80$ antibodies confirmed their presence in breast cancer extracts. Increased Ku DNA-binding activities in cytosols of breast biopsies correlated with higher grade tumors, positive lymph node status and decreased patient survival. Also increased Ku DNA-binding activities in cancers from patients receiving adjuvant chemotherapy correlated with decreased survival, suggesting Ku DNA-binding activities may be used to predict response to treatment. Collectively, our results suggest that Ku DNA-binding activities in cytosols prepared from carcinoma biopsies are useful biomarkers for assessing breast cancer recurrence and response to therapy. 


\section{TABLE OF CONTENTS}

PAGE

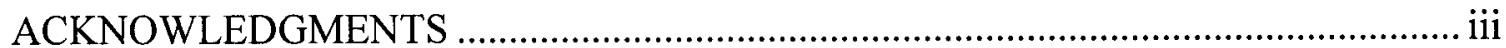

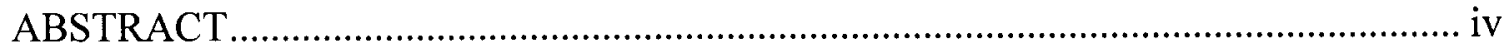

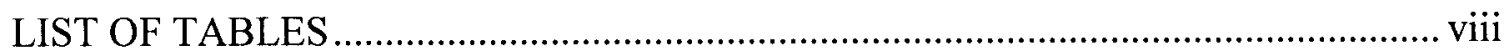

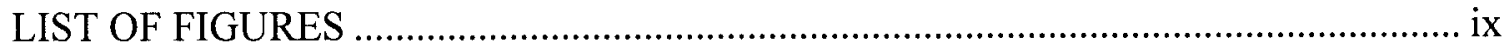

CHAPTER

I. INTRODUCTION and PRELIMINARY RESULTS

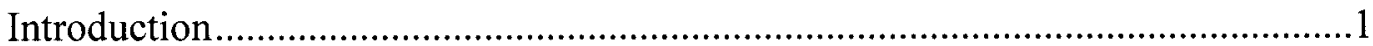

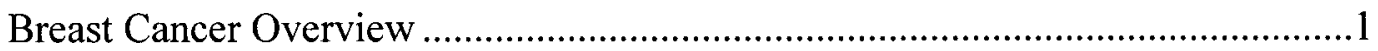

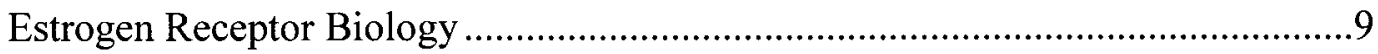

Molecular Pathogenesis of Breast Cancer ............................................................10

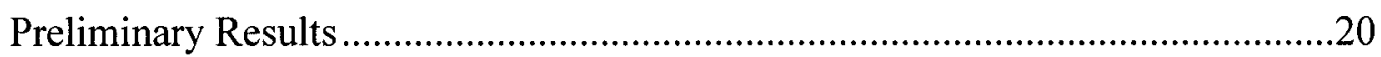

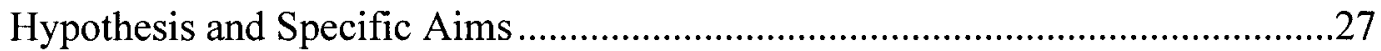

II. CHARACTERIZATION AND DISTRIBUTION OF CANDIDATE ESTROGEN RESPONSE ELEMENT BINDING PROTEINS IN HUMAN BREAST

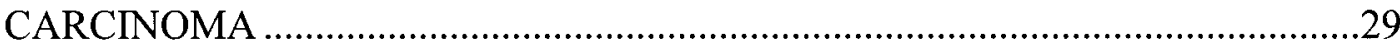

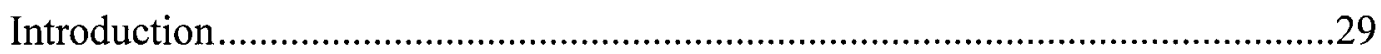

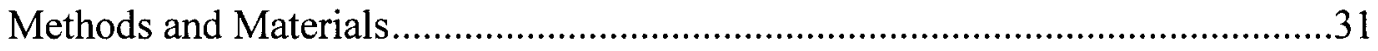

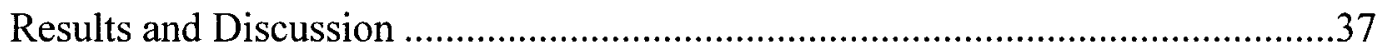

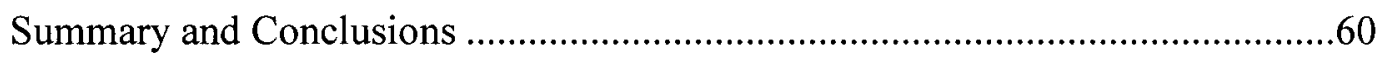

III. PURIFICATION AND IDENIFICATION OF DNA-BINDING PROTEINS BY IMMUNO-BASED METHODS AND MASS SPECTROMETRY ........................63 


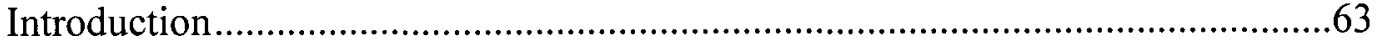

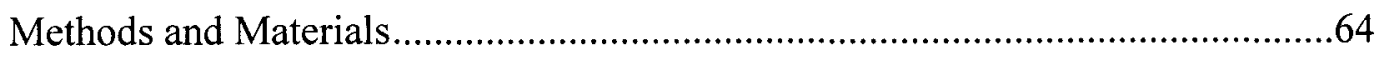

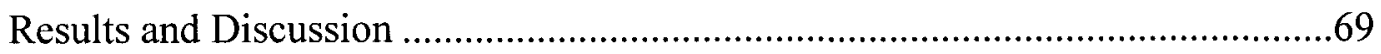

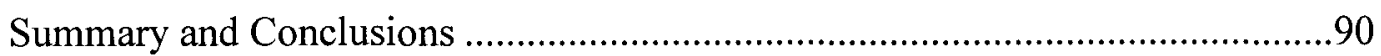

IV. CLINICAL UTILITY OF THE DNA-BINDING PROTEIN KU AS A BIOMARKER OF BREAST CARCINOMA BEHAVIOR ..................................94

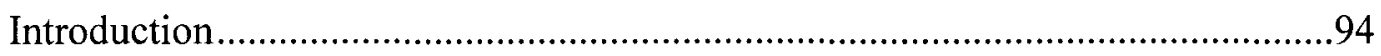

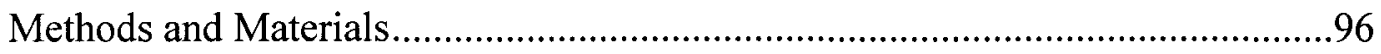

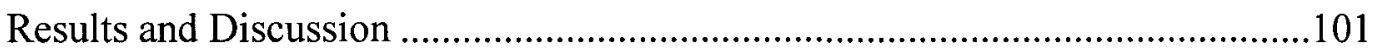

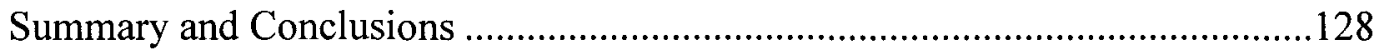

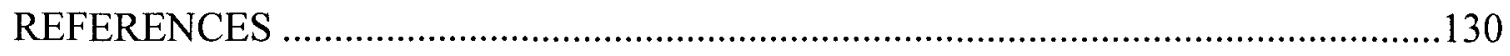

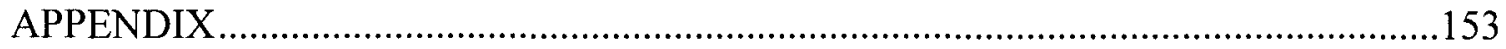

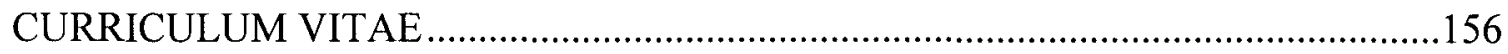




\section{TABLE}

\section{LIST OF TABLES}

1. Representative genes known to contain ERE sequences that were evaluated in microarray analyses of LCM-procured human breast carcinoma cells 59

2. Correlation of cytosolic ERE-BP levels with candidate genes containing ERE sequences known to be expressed in breast carcinoma cells

3. List of proteins in the final purified sample that were identified by mass spectrometry. .76

4. Characteristics of the overall patient population with associated clinical data .....99

5. Association of cytosolic $\mathrm{Ku}$ DNA-binding activities with various patient characteristics. 105

6. Influence of $\mathrm{Ku}$ DNA-binding activity in frozen breast cytosols from breast carcinomas for predicting the disease-free and overall survival of patients

7. Comparison of clinical parameters between the two prognostic groups in a subset of patients receiving adjuvant chemotherapy only

8. List of DNA sequences 153

9. List of abbreviations 154 


\section{LIST OF FIGURES}

\section{FIGURE}

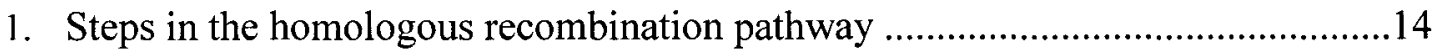

2. Steps in the nonhomologous end joining pathway ..........................................16

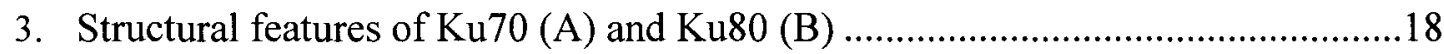

4. Distribution of ERE-binding proteins in breast cancer cytosols.........................22

5. Correlation of ERE-BP binding activity with ER and PR status ........................24

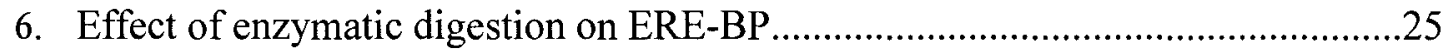

7. Overall survival probabilities of breast cancer patients as a function of ERE-BP

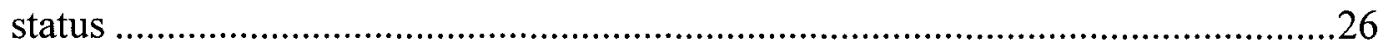

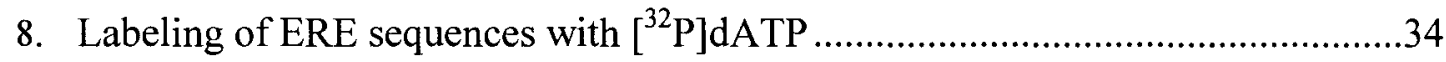

9. Method for estimating ERE-binding protein activities in breast cancer biopsies

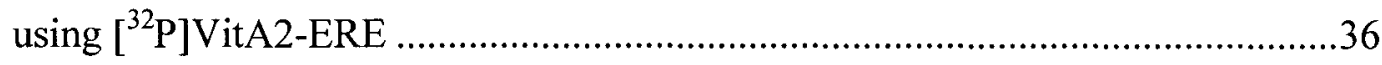

10. ERE-binding proteins from extracts of human tissue reference specimens and animal tissues associated with VitA2-ERE (A) and pS2-ERE (B) .......................38

11. ERE-binding proteins from extracts of frozen human tissue specimens associated

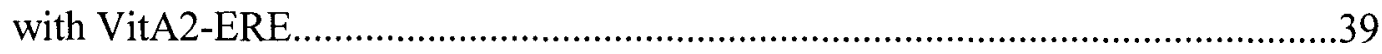

12. Comparison of ERE-BP activities in cytosolic and nuclear extracts ...................42

13. Influence of $\mathrm{hER} \alpha$ antibodies recognizing different sequence domains on the cytosolic ERE-BP assessed by super-shift assay. 
14. Influence of hER $\beta$ antibodies recognizing different sequence domains on cytosolic ERE-BP assessed by super-shift assay

15. Supershift assay using antibodies to known ERE-binding proteins

16. Competition of rhER $\alpha$ recognition of VitA2-ERE by ERE-BP in human breast cancer extracts

17. ERE-BP binding to a variety of hormone response element sequences

18. Competition of VitA2-ERE recognition by ERE-BP using various unlabeled response element sequences

19. Specificity of ERE-BP binding to VitA2-ERE 52

20. Representative ERE titration of $\operatorname{rhER} \alpha(\mathrm{A})$ and ERE-BP (B) in the presence of $1 \mu \mathrm{M}$ diethylstilbestrol

21. Titration of rhER $\alpha$ with increasing concentrations of $\left[{ }^{32} \mathrm{P}\right]$ VitA2-ERE in the presence of various therapeutic estrogens

22. Titration of an ERE-BP preparation from a breast cancer reference specimen with increasing concentrations of $\left[{ }^{32} \mathrm{P}\right] \mathrm{VitA} 2-\mathrm{ERE}$ in the presence of various

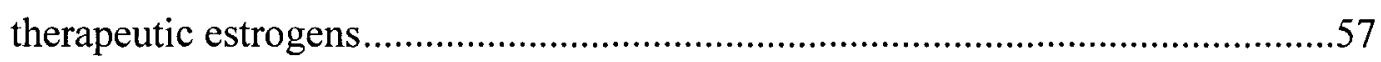

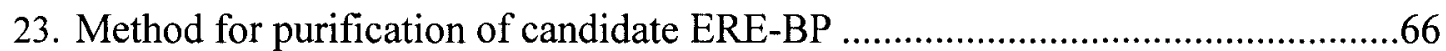

24. Removal of high abundant proteins from nuclear extracts of a uterine cancer reference powder.

25. Influence of various biotinylated DNA sequences on the "pull-down" of candidate ERE-BP from nuclear extracts. .72

26. Purification of ERE-BP for analysis by mass spectrometry 
27. Determination of molecular weight of ERE-BP in reference specimens of human breast and uterine carcinomas .80

28. Western blot analyses of proteins eluted during the purification of ERE-BP with NeutrAvidin beads .81

29. Recognition of ERE-BP by an antibody detecting heterodimers of $\mathrm{Ku} 70 / \mathrm{Ku} 80 . .83$

30. Influence of antibodies to double strand breaks repair proteins on candidate EREbinding proteins .85

31. Influence of various antibodies to $\mathrm{Ku} 70 / \mathrm{Ku} 80$ on ERE-BP in frozen cytosols from breast cancer.

32. Comparison of Ku DNA-binding activities and protein levels .89

33. Correlation of $\mathrm{Ku}$ DNA-binding activities and protein levels .91

34. REMARK diagram describing the patient population used to investigate the clinical relevance of $\mathrm{Ku}$ .98

35. Reproducibility of EMSA measurement of Ku DNA-binding activities 102

36. Inter-relationships of cytosolic Ku DNA-binding activities in breast cancers and various patient characteristics

37. Disease-free and overall survival probabilities of the study population as a function of known prognostic indicators 107

38. Disease-free and overall survival probabilities of the study population as a function of ER and PR status of the breast carcinomas 108

39. Disease-free and overall survival probabilities as a function of $\mathrm{Ku}$ DNA-binding activity in breast carcinomas. 
40. Disease-free and overall survival probabilities as a function of $\mathrm{Ku} 70$ and $\mathrm{Ku} 80$ protein levels

41. Disease-free and overall survival probabilities as a function of XRCC5 (Ku80) or XRCC6 $(\mathrm{Ku} 70)$ gene expression levels in breast carcinomas

42. Disease-free and overall survival probabilities as a function of both $\mathrm{Ku}$ DNAbinding activity and ER/PR status of breast carcinomas

43. Disease-free and overall survival probabilities as a function of both $\mathrm{Ku}$ DNAbinding activity and nodal status of breast carcinomas 120

44. Disease-free and overall survival probabilities as a function of $\mathrm{Ku}$ DNA-binding activity in cytosols of breast cancers from a sub-population of patients receiving no adjuvant therapy 121

45. Disease-free and overall survival probabilities as a function of $\mathrm{Ku}$ DNA-binding activity in cytosols of breast cancers from a sub-population of patients receiving adjuvant chemotherapy 


\section{CHAPTER I}

\section{INTRODUCTION AND PRELIMINARY RESULTS}

\section{Breast Cancer Overview}

Carcinoma of the breast cancer is the most common cancer affecting women in the United States with over 200,000 new cases estimated in 2010 and more than 39,000 deaths [1]. It is the second most common cause of cancer death in women, and the main cause of death in women ages 40 to 59 , although the incidence has been decreasing by $1.8 \%$ per year from 1999-2007 [1;2]. Current risk estimates suggest that a woman who lives to the age of 90 has a 1 in 8 chance of developing breast cancer [3].

\section{Breast cancer etiology and risk factors}

The most common risk factors for developing breast cancer are age, benign breast disease, young age of menarche, late age of first live birth, a first-degree relative with breast cancer and race $[1 ; 4 ; 5]$. Additional risk factors include excessive estrogen exposure, radiation exposure, environmental toxins, smoking, diet, obesity and exercise [3;5-9]. The effects of these are not fully understood.

Breast cancers may be divided into sporadic and hereditary cases. Only $13 \%$ of women with breast cancer report a family history in a first-degree relative [4]. Approximately $3 \%$ of all breast cancers and $25 \%$ of those classified as hereditary cancers 
can be attributed to mutations in the genes BRCA1 and BRCA2 [3]. Both of these genes act as tumor suppressors and are involved in DNA repair and cell cycle control [3]. A key function for BRCA1 and BRCA2 is to prevent genomic instability from progressing after DNA damage occurs [10]. BRCA1 and BRCA2 are highly penetrant and have a large effect on risk but are rare. Approximately $10 \%$ of hereditary breast cancers are attributed to mutations in other known genes [11]. These genes include CHEK2, p53, PTEN and ATM $[3 ; 12 ; 13]$. CHEK2 gene encodes a cell cycle checkpoint kinase protein and functions to repair DNA damage by activating BRCA1 [14]. The p53 gene encodes a well studied transcription factor that is involved in the Gl checkpoint of the cell cycle and mutations in this gene increase the risk of genomic instability in the cell [13]. Furthermore, the PTEN gene encodes a protein tyrosine phosphatase whose inactivation results in elevated Akt activity and abnormal growth regulation [15-17]. Lastly, the ATM gene encodes a protein kinase that phosphorylates BRCAl in response to DNA damage [13]. These genes are moderately penetrant and their combined effects are not fully understood.

Sporadic breast carcinomas comprise the majority of all breast cancer cases. For sporadic breast cancer, the major risk factors are related to estrogen exposure [3]. Hormone replacement therapy increases the risk of developing breast cancer [18], and combined hormonal therapy with estrogen and progestins may further increase breast cancer risk [19]. The majority of sporadic breast cancers occur in post-menopausal women and more than $60 \%$ of the lesions over-express the estrogen receptor $[3 ; 20]$. Many studies have examined the mechanisms by which estrogens influence differentiation and proliferation of cells that may result in aberrant signaling through 
estrogen-dependent pathways, thought to be a major mechanism for hormone receptor positive breast cancers [20-24]. However, additional mechanisms play a role in sporadic cancers as a significant number of breast carcinomas are ER negative [25;26]. Clearly, breast cancer is a complex disease determined by environmental and genetic components.

Prognostic and predictive factors of breast cancer

The 5-year survival rates for women with breast cancer vary from $98 \%$ for patients with localized disease at diagnosis to $23 \%$ for patients with distant disease at diagnosis [1]. Several major indicators are used at the time of diagnosis to determine prognosis of a breast cancer patient and are integrated into the American Joint Committee on Cancer (AJCC) staging system [27]. These prognostic indicators provide information on clinical outcome independent of therapy and are related to cancer growth, invasion and metastatic potential [28]. The major prognostic factors of breast cancer are invasive carcinoma, distant metastases, axillary lymph node metastases, tumor size, locally advanced disease and inflammatory carcinoma [3]. The most significant of these factors in the absence of distant metastases is lymph node status [3;29]. For node negative patients, the 10 -year disease-free survival rate is $70 \%$ to $80 \%$ [3]. For patients with up to three positive nodes, the 10 -year survival rate drops to $35 \%$ to $40 \%$ [3]. This rate drops to $10 \%$ to $15 \%$ for breast cancer patients with more than 10 positive nodes. The second most important prognostic factor is tumor size [3]. The 5-year survival rate for a woman with a carcinoma less than $1 \mathrm{~cm}$ in diameter is approximately $92.6 \%$; however the 5-year survival rate for a woman with a carcinoma greater than $5 \mathrm{~cm}$ in diameter drops to $62.9 \%$ [30]. 
These major prognostic factors are integrated into the AJCC staging system [27] and are divided into stages 0-IV. Stage 0 consists of ductal carcinoma (DCIS) in situ or lobular carcinoma in situ (LCIS). These have not invaded beyond the basement membrane and have not yet metastasized [3;27]. The 5-year survival rate of patients with these carcinomas is $92 \%$ [3]. Stage I carcinomas are locally invasive tumors less than 2 $\mathrm{cm}$ in diameter without nodal involvement [3;27]. The 5-year survival rate is $87 \%$ [3]. Stage II carcinomas are invasive tumors less than $5 \mathrm{~cm}$ in diameter with up to three positive lymph nodes or invasive tumors greater than $5 \mathrm{~cm}$ in diameter without nodal involvement. The 5-year survival rate of patients with these cancers is $75 \%$ [3]. Stage III breast carcinomas consist of invasive tumors less than $5 \mathrm{~cm}$ in diameter with at least 4 positive axillary lymph nodes as well as invasive tumors greater than $5 \mathrm{~cm}$ in diameter with positive lymph nodes, invasive tumors with 10 or more positive lymph nodes, invasive tumors with involvement of the internal mammary lymph nodes, skin, or chest wall and inflammatory cancer [3]. The 5-year survival rate for these cancers is $46 \%$ [3]. Stage IV breast cancers are invasive tumors of any size with the presence of distant metastases. The 5-year survival rate for patients with these cancers is only $13 \%$ [3].

There are also several minor factors that provide useful clinical information regarding prognosis. These include histologic subtypes (e.g. ductal, tubular, mucinous, medullary, lobular, papillary and cribiform), tumor grade, lymphovascular invasion, proliferation rate and DNA content $[3 ; 12 ; 13]$. Tumor grade is a measure of tumor differentiation that takes into account tubule formation, nuclear pleomorphism and mitotic counts [31]. The 10-year survival rates are $85 \%, 60 \%$ and $15 \%$ for welldifferentiated (grade I), moderately differentiated (grade II) and poorly differentiated 
(grade III) tumors, respectively [3]. Observation of tumor cells within the lymphatics or capillaries (lymphovascular invasion) is associated with increased lymph node involvement and poorer prognosis [3]. Proliferation rate can be measured by flow cytometry (S-phase fraction), thymidine labeling index or immunohistochemical detection of cellular proteins (e.g., cyclins, Ki-67) [3]. High proliferation rates are associated with a poorer prognosis [32]. The DNA content of a cell is also correlated with prognosis while aneuploid tumors are indicative of poor prognosis [3;33;34].

Certain molecular factors in breast carcinoma biopsies are used to predict the liklihood of a patient responding to a specific treatment. The three most commonly used predictive factors are the estrogen receptor (ER), progesterone receptor (PR) and human epidermal growth factor receptor 2 (HER2) status [3;35]. ER and PR are members of the nuclear hormone receptor superfamily and function as ligand dependent transcription factors [36]. It is reported that $60-70 \%$ of breast cancers express ER [12;20;35]. Furthermore, patients with tumors that over-express ER and/or PR are most likely to respond to endocrine therapy [20;24-26;35;37]. Many studies report that $80 \%$ of patients with tumors that are ER+/PR+ respond to endocrine therapy [3]. Approximately forty percent of patients with tumors that are positive for one of these receptors respond to endocrine therapy, whereas only $10 \%$ of ER-/PR- tumors respond $[3 ; 12 ; 25 ; 26]$.

Originally ER and PR were measured a ligand binding assay (LBA) that was developed into an FDA-approved assay [23;38-40]. In this assay, ligand (17 $\beta$-estradiol for ER, progestin (R5020) for PR) labeled with either [ ${ }^{125}$ Iodine] or $\left[{ }^{3} \mathrm{H}\right.$-tritium] is incubated with cytosols prepared from tissue biopsies under conditions allowing the ligand to bind to the receptor. Free steroid is separated by addition of dextran-coated 
charcoal and removed by centrifugation. The amount of receptor-bound labeled steroid hormone in the supernatant is then measured using a scintillation counter [23;38-40]. The results are used to create a Scatchard plot [41]. From this plot, the concentration of the receptor protein in the cytosol is determined and generally expressed as femtomoles of receptor per $\mathrm{mg}$ protein (fmol/mg protein). The cutoff value approved by the FDA for ER or PR positivity using this assay is $\geq 10 \mathrm{fmol} / \mathrm{mg}$ protein [35]. Importantly, a $\mathrm{Kd}$ value estimating the affinity of the ligand for the receptor protein is also derived.

Beginning in the 1980 's, ER and PR levels were also quantified by enzyme immunoassay (EIA). This is an antibody based method that also requires the use of cytosols from fresh tissues [42]. In this assay, cytosols are incubated with a monoclonal antibody attached to a polystyrene bead. The protein/antibody-bead complex is separated by centrifugation, resuspended and incubated with a secondary antibody conjugated to the enzyme horseradish peroxidase. A colorimetric substrate is added and converted to yield a color change that can be measured by spectrophotometry and the values are plotted on a standard curve for quantification [42-44]. The cutoff approved by the FDA for ER and PR positivity using this assay is $\geq 15 \mathrm{fmol} / \mathrm{mg}$ protein [35]. The advantage of both LBA and EIA is that the receptors are measured quantitatively $[20 ; 45]$. The LBA is the only procedure that determines the affinity of the receptor for its ligand, usually expressed as the $\mathrm{Kd}$ value. However, both assays require fresh-frozen specimens and a considerable amount of tissue.

Currently, the predominate assay used for clinical measurement of ER and PR levels is immunohistochemistry (IHC) [35]. IHC is also an antibody based assay and can be performed on either frozen or formalin-fixed, paraffin-embedded (FFPE) tissue 
sections mounted on glass slides [46;47]. Sections are incubated with monoclonal antibodies followed by incubation with a secondary antibody conjugated to the enzyme horseradish peroxidase. A colorimetric substrate is then added which is converted to a colored product that is detected by microscopy and the amount of ER or PR protein can be semi-quantified based on the number of positive cells and the intensity of staining. The advantage of IHC over EIA or LBA is that it can be performed on a variety of specimens and requires very little tissue. The disadvantage of IHC is assay variability and lack of standardization [48-50].

The HER2 gene encodes a transmembrane glycoprotein with intrinsic tyrosine kinase activity [51]. This protein belongs to the epidermal growth factor receptor (EGFR) family of receptors and is involved in the signal transduction pathways controlling cell growth and differentiation [52]. Amplification of the HER2 gene has been correlated with both shorter disease-free and overall survival in breast cancer [53]. Tumors that overexpress HER2 are less likely to respond to certain chemotherapies than tumors with normal HER2 levels [54]. However, these tumors are more likely to respond to therapies that target HER2 itself (e.g. trastuzumab) [55]. HER2 may be measured by IHC, PCR or fluorescence in situ hybridization (FISH) [12;13].

\section{Treatment of breast cancer}

Surgical removal of the tumor is the standard initial treatment for primary breast cancers with no evidence of distant metastases. This therapeutic approach may be breastconserving or involve surgical removal of the entire breast [56]. Surgery may then be followed with adjuvant radiation therapy, chemotherapy, endocrine therapy (e.g. 
tamoxifen) or targeted therapy (e.g. trastuzumab) depending on the size of the tumor, lymph node involvement, presence of ER, PR and HER2 and other risk factors for recurrence.

\section{Endocrine therapy}

Due to the estrogen-dependent nature of many breast cancers, endocrine therapies have been developed to prevent tumors from responding to stimulation by endogenous estrogens. In the 1950 's, ovarian ablation was the standard therapy for women with breast cancer. This therapy was most effective in women with ER+ and/or PR+ tumors [57]. In the early 1970 's, it was reported that ER+ tumors were more likely to respond to endocrine ablation than ER- tumors [58]. Several studies reported that approximately $60 \%$ of patients with ER+ tumors responded to endocrine therapy, while only $8 \%$ of patients with ER- tumors responded to the same therapy $[59 ; 60]$. These observations led to the development of tamoxifen for the treatment of breast cancer [61-64]. Currently, tamoxifen is the most commonly used endocrine therapy for breast cancers that are ER and/or PR positive. Fifty to eighty percent of these tumors respond to tamoxifen, while only $5-10 \%$ of ER-/PR-tumors respond [65-68]. Tamoxifen is a selective estrogen receptor modulator (SERM) and acts as an inhibitor of growth and proliferation of breast cancer cells by competitive antagonism of ER [69]. Another SERM, raloxifene, is used for reduction in risk of invasive breast cancer in postmenopausal women [70]. Another class of endocrine therapy for treatment of breast cancer is composed of aromatase inhibitors (e.g. anastrozole, letrozole, exemestane). Aromatase inhibitors work by 
inhibiting aromatase, the enzyme which converts androgenic precursors into estrogens $[67 ; 71]$.

\section{Estrogen Receptor Biology}

ER is a member of the nuclear hormone receptor superfamily and acts as a liganddependent transcription factor [72]. Two ER isoforms, ER $\alpha$ and ER $\beta$, mediate estrogen actions in target tissues [73]. The structure of these ER proteins can be divided into six functional domains. The $\mathrm{N}$-terminal $\mathrm{A} / \mathrm{B}$ domain contains a transactivation function (AF) which promotes the transcriptional activation of target genes $[74 ; 75]$. The $\mathrm{C}$ region contains the DNA-binding domain, which is responsible for ERE recognition and dimerization $[75 ; 76]$. ER binds to the ERE through two type II zinc fingers formed by the coordination of a zinc atom with four cysteine residues [75-78]. The D region joins the DNA-binding and ligand-binding domains and is referred to as the hinge region [74;75]. This region allows the receptor to bend and alter conformation and also contains a putative nuclear localization sequence $[75 ; 79 ; 80]$. The E region contains the ligandbinding domain and is responsible for hormone binding and activation of transcription [74;75]. The C-terminal $\mathrm{F}$ domain modifies the interaction of ER with coregulators and plays a role in the response to agonist and antagonist ligands [81-83].

The DNA-binding domains of ER $\alpha$ and ER $\beta$ share 97\% homology; however the ligand-binding domains share only $59 \%$ homology [84;85]. Although both isoforms are expressed in breast tissue, currently the biological and clinical roles of ER $\beta$ are being evaluated [84;86]. A clinical application of ER $\beta$ has not yet been accepted for the 
management of breast cancer, although its expression has reported to be associated with better survival in breast cancer patients treated with adjuvant tamoxifen [86;87].

In the classical pathway of estrogen action, ER alters the expression of target genes by binding to regions upstream of general promoters known as estrogen response elements (ERE). This mechanism affects the expression of genes involved in cell growth, proliferation and differentiation $[74 ; 88]$. Some examples of target genes containing ERE sequences are progesterone receptor, lactoferrin, $\mathrm{pS} 2$, cathepsin D and BRCA1 [88]. When $17 \beta$-estradiol $\left(E_{2}\right)$ or another estrogenic ligand binds to $E R$, it induces a conformational change in the receptor protein leading to dimerization and binding to an ERE sequence [75;89]. The consensus ERE is a 13 bp palindromic inverted repeat with the sequence 5'-GGTCAnnnTGACC-3'; however ER $\alpha$ can also bind to imperfect ERE sequences $[88 ; 90 ; 91]$. The ERE was first discovered in the 5'-flanking regions of Xenopus laevis estrogen controlled vitellogenin genes [88;92]. After ERE binding, a protein complex is formed as either coactivator (e.g. SRC-1, TIF1, TIF2, TFIIB) or corepressor proteins (e.g. NCoR, SMRT, SHP, REA) bind to the dimer, culminating in either recruitment of general transcription factors to promote transcription of the adjacent gene or histone deacetylases to negatively effect ER-mediated transcription [93-96].

\section{Molecular Pathogenesis of Breast Cancer}

The progression of breast cancer is a multistep process that involves a series of genetic changes leading to the conversion of normal cells into carcinoma cells [97]. In order for normal cells to become cancerous, they must acquire basic traits that include sustaining proliferative signaling, insensitivity to growth suppressors, evasion of 
apoptosis, replicative immortality, sustained angiogenesis and tissue invasion [97]. Genomic instability is a major underlying cause of normal cells acquiring these premalignant traits. Genomic instability refers to an increased rate of alterations in the genome throughout the life cycle of a cell [98]. Normal cells minimize the risk of these alterations through high-fidelity DNA replication, accurate chromosome segregation during mitosis, cell cycle checkpoints and repair of DNA damage [99]. Maintenance of genomic integrity following DNA damage is crucial for tumor suppression. This is especially important in breast tissue because of the extensive differentiation, proliferation and apoptosis that occurs during development in utero, puberty, monthly pre-menopausal cycles and pregnancy [100-102].

\section{DNA damage and repair}

DNA damage may be caused by endogenous factors (e.g. oxidative damage, errors of replication) or environmental factors (e.g mutagenic chemical exposure, food contaminants, ionizing radiation) $[100 ; 103 ; 104]$. Among the most dangerous forms of DNA damage are double strand breaks (DSBs). DSBs occur when both strands of the DNA double helix are broken simultaneously. This allows the DNA ends to dissociate making repair difficult and permitting recombination with improper sites in the genome [105]. As a result, chromosomal aberrations may occur that increase the rate of cancer development. Therefore, defects in DNA-damage repair pathways are potential initiating events of carcinogenesis [105-107].

Repair of DSBs occurs through at least two mechanisms: homologous recombination and nonhomologous end joining [108]. During homologous 
recombination, the DNA strand with the DSB uses an undamaged DNA strand with which it shares extensive sequence homology as a template [105-108]. Homologous recombination is generally an accurate mechanism of repair if the template used for repair is identical to the original DNA sequence $[107 ; 108]$. Homologous recombination is mediated through the RAD52 group of proteins that is composed of RAD50, RAD51, RAD52, RAD54, RAD55, RAD57, MRE11 and NBS1 [107-110]. Homologous recombination proceeds by recognition and resection of the DSB ends to form 3'-OH single-stranded tails, strand invasion and exchange with a homologous DNA duplex and resolution of recombination intermediates [108;111].

The first step of homologous recombination involves degradation of the 5'-end of the DNA strand to produce $3^{\prime}-\mathrm{OH}$ single-stranded tails that are able to invade a homologous DNA duplex [108] (Figure 1). The complex of proteins responsible for this series of reactions is composed of MRE11, RAD50 and NBS1 (known as the MR(X)N complex) [109]. In the next step of homologous recombination, one strand of homologous DNA duplex is displaced by the invasive strand, resulting in the formation of a heteroduplex DNA known as a D-loop [108;111]. To achieve this, replication protein A (RPA) first binds to the 3'-OH single-stranded tails, which causes RAD51 filament formation to occur. This filament is a complex of RAD51, RAD52, RAD54, RAD55 and RAD57 and performs both the search for a homologous sequence and strand exchange [108;109]. The resulting D-loop is formed when DNA synthesis of the 3 '-end of the invading strand is primed by the template duplex DNA [111]. The last step of homologous recombination is resolution of the D-loop intermediate. This occurs by one of three different pathways: synthesis dependent strand annealing (SDSA), double 
Holliday junction (dHJ) or BIR (break induced replication) [109]. In SDSA, the D-loop is dissolved after DNA synthesis allowing the invading strand to anneal to the second end of the DSB [108]. In dHJ, pathway a double Holliday junction is formed when the second end of the DSB is occupied by either DNA annealing or a second strand invasion [108]. BIR occurs when only a single DSB end exists causing the D-loop to become a replication fork [109]. The breast cancer susceptibility genes, BRCA1 and BRCA2, also function in $\mathrm{HR}$. BRCA1 is an E3 ligase that promotes RAD51 recruitment and has a potential regulatory role in resection of the DSB ends [109;112]. BRCA2 is involved in RAD51 filament formation [109]. By interacting with both RAD51 and single-stranded DNA, BRCA2 mediates the binding of RAD51 to damaged DNA [113].

Nonhomologous end joining (NHEJ) ligates two DSBs without the need for extensive sequence homology between the two ends [105]. This results in NHEJ being inherently error prone with the potential result of loss of nucleotides [114]. NHEJ proceeds by detection of the DSB, protection of the DNA ends, removal of damage and DNA ligation [114]. The major proteins involved in this pathway are Ku70, Ku80, DNAdependent protein kinase (DNA-PK), Artemis, XRCC4, ligase IV and XLF/Cernunnos [114-116]. The first step in NHEJ is recognition of the DSB by the Ku protein complex, which is composed of a heterodimer of Ku70 and Ku80 (Figure 2) [103;114;115;117]. Ku70 and Ku80 make up the DNA-binding subunits of DNA-PK. After binding to the DNA ends, $\mathrm{Ku}$ translocates to internal positions of the DNA molecule making the ends accessible to the catalytic subunit of DNA-PK (DNA-PKcs) [118-120]. DNA-PKcs is a 460-kDa serine/threonine kinase that is part of the phosphotidylinositol-3-kinase family $[114 ; 117 ; 121]$. Then the two DNA ends are tethered together by a synaptic complex 


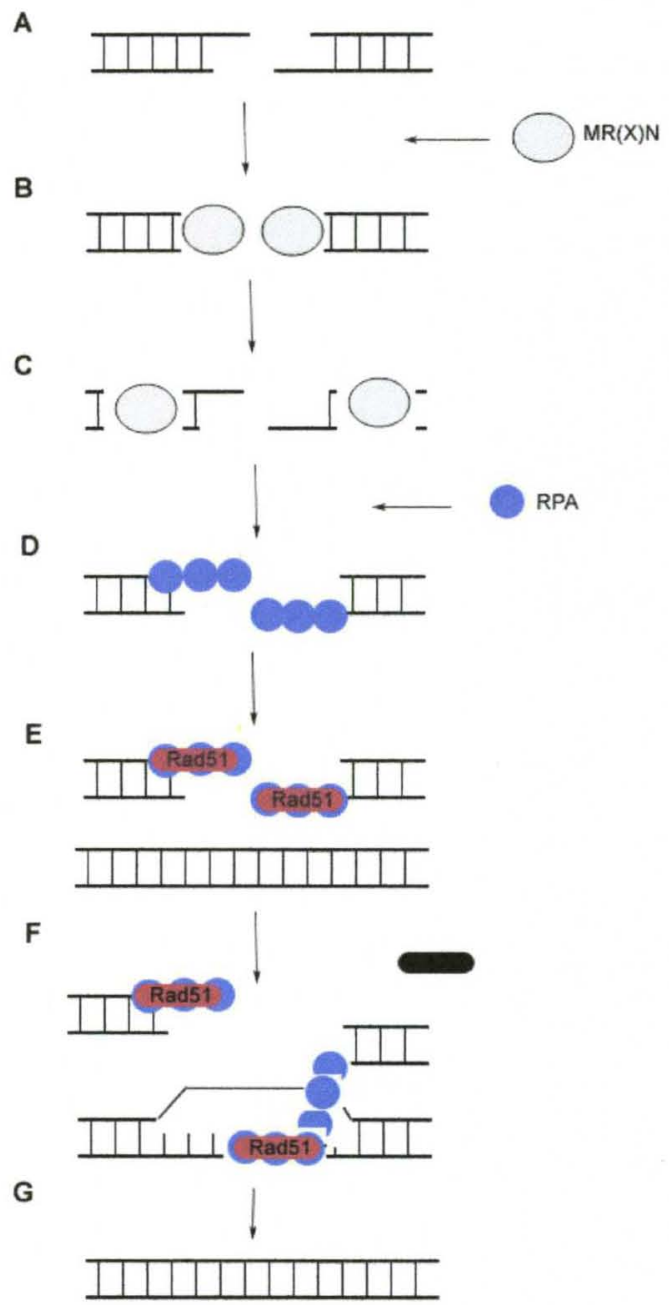

Figure 1. Steps in the homologous recombination pathway. (A) Damage in the form of a DSB occurs in the DNA. (B) The first step of homologous recombination is binding of the $\mathrm{MR}(\mathrm{X}) \mathrm{N}$ complex to the DSB. (C) Degradation of the 5'-end of the DNA strand occurs to produce 3 '-OH single-stranded tails that are able to invade a homologous DNA (d) Replication protein A (RPA) binds to the 3'-OH single-stranded tails, which causes RAD51 filament formation to occur (E). (F) The resulting D-loop is formed when DNA synthesis of the 3 '-end of the invading strand is primed by the template duplex DNA (G) The last step of homologous recombination is resolution of the D-loop intermediate and repair of the DNA. Adapted from [108]. 
formed by two DNA-PK molecules [122]. Subsequently, the kinase activity of DNAPKcs is activated causing an autophosphorylation across the DSB as well as phosphorylation of other proteins involved in NHEJ [114;123-127]. This allows other NHEJ proteins to bind to the DNA ends $[124 ; 128]$. The next step in NHEJ is processing of the DNA ends by nucleases such as Artemis. Artemis is a $5^{\prime} \rightarrow 3^{\prime}$ exonuclease that also exhibits endonuclease activity in the presence of DNA containing double-stranded DNA/single-stranded transitions $[129 ; 130]$. Artemis also possesses the ability to remove 3'-phosphoglycolate groups from DNA ends [131].

The final step in NHEJ is ligation of the DNA ends by the DNA ligase IV/XRCC4 complex. XRCC4 acts a scaffolding protein that is required for DNA ligase IV activity [132-134]. DNA ligase IV ligates the DNA ends, even if the sequences are incompatible [135]. XLF associates with $\mathrm{Ku}$ and XRCC4 and increases the ability of DNA ligase IV to achieve this [136]. The recruitment of DNA-PKcs, XRCC4 and XLF is dependent on $\mathrm{Ku}$ [137-139].

\section{Structure and function of $\mathrm{Ku}$}

$\mathrm{Ku}$ was originally identified as an autoantigen present in the sera of a patient with scleroderma polymyositis overlap syndrome [140]. It has also been identified in patients with other autoimmune diseases such as systemic lupus erythematosus, scleroderma, myositis and Sjögren's syndrome [141]. Ku is an abundant protein $(\sim 400,000$ molecules per cell) that is primarily nuclear [103;142]. Ku has also been found in the cytosols of monkey and human cells $[143 ; 144]$. The Ku protein is composed of two subunits with molecular weights of approximately 70 and $80 \mathrm{kDa}$, referred to $\mathrm{Ku} 70$ and $\mathrm{Ku} 80 . \mathrm{Ku} 70$ is 


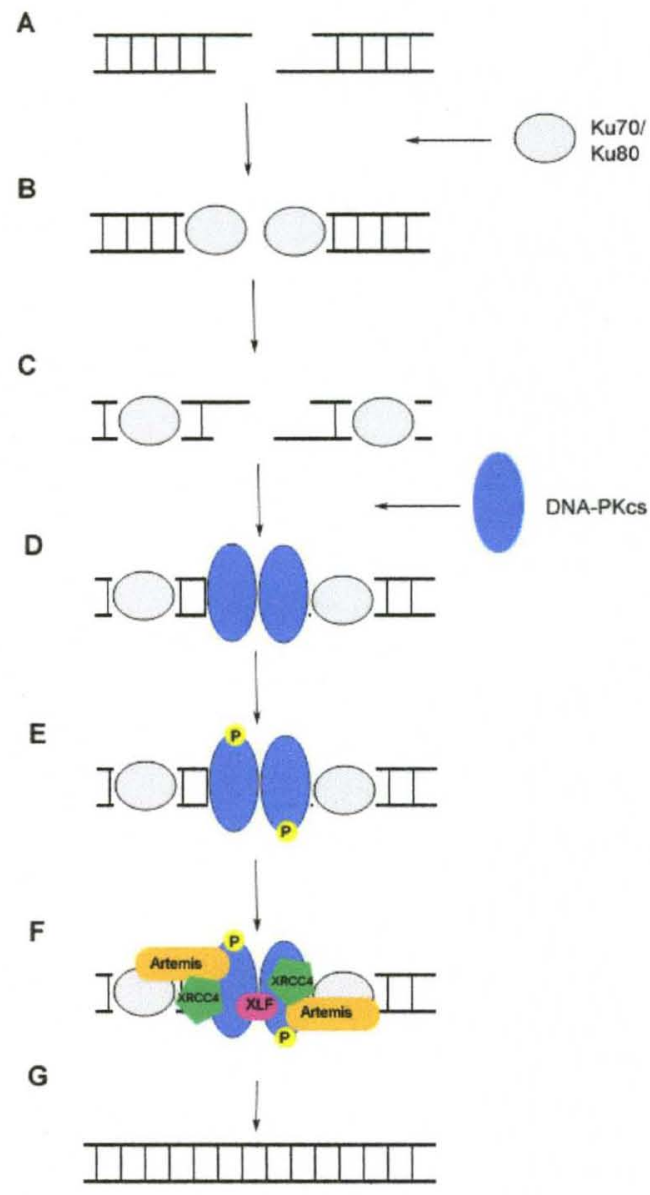

Figure 2. Steps in the nonhomologous end joining pathway. (A) Damage in the form of a DSB occurs in the DNA. (B) The first step in NHEJ is recognition of the DSB by the Ku protein complex, which is composed of a heterodimer of $\mathrm{Ku} 70$ and $\mathrm{Ku} 80$. (C) $\mathrm{Ku}$ translocates to internal positions of the DNA molecule making the ends accessible to DNA-PKcs. (D) Two DNA ends are tethered together by a synaptic complex formed by two DNA-PK molecules. (E) The kinase activity of DNA-PKcs is activated causing an autophosphorylation across the DSB. (F) This allows other NHEJ proteins to bind to the DNA ends such as Artemis, the DNA ligase IV/XRCC4 complex and XLF. (G) The final step in NHEJ is ligation of the DNA ends. Adapted from [114]. 
also known as XRCC6 and Ku80 is also known as Ku86 and XRCC5.

Ku70 and Ku80 are similar in structure but share only $14 \%$ sequence alignment [145]. Each contains a von Willebrand A domain (vWa), a central Ku core domain and a carboxy-terminal region [142] (Figure 3). The vWa domain is involved in protein-protein interactions and $\mathrm{Ku} 70$ and $\mathrm{Ku} 80$ heterodimerization. The $\mathrm{Ku}$ core domain is a $\beta$-barrel domain that binds to the sugar-phosphate backbone of DNA [146]. The N-and C-terminal regions of $\mathrm{Ku} 70$ and $\mathrm{Ku} 80$ are unique in each protein. In addition, the N-terminal region of Ku70 is an acidic domain that contains a DNA-PKcs phosphorylation site [123]. The C-terminal region of Ku70 contains a SAP (SAF-A/B, Acinus and PIAS) domain which is related to a helix-extension-helix fold and is proposed to be a DNA-binding domain $[147 ; 148]$. The C-terminal region of Ku80 is longer than Ku70 and forms a flexible arm possibly involved in protein-protein interactions $[149 ; 150]$. This region also contains a DNA-PKcs binding site and phosphorylation site [151;152]. Furthermore, Ku70 contains a nuclear localization sequence (NLS) at amino acids 539-556 and Ku80 contains a NLS at amino acids 561-569 [153;154].

The heterodimer of Ku70 and Ku80 forms an asymmetric ring that encircles dsDNA [145]. The channel formed by this ring contains positively charged residues that are responsible for the interaction between the protein and the sugar-phosphate DNA backbone. This structure allows Ku to bind DNA with high affinity and without the need for sequence specificity [142]. It is reported that this structure allows $\mathrm{Ku}$ to move inward along the DNA strand making the DNA ends accessible to DNA-PKcs [120].

The main function of $\mathrm{Ku}$ is in NHEJ as described above; however it also functions in $\mathrm{V}(\mathrm{D}) \mathrm{J}$ recombination, telomere maintenance, apoptosis and regulation of transcription 


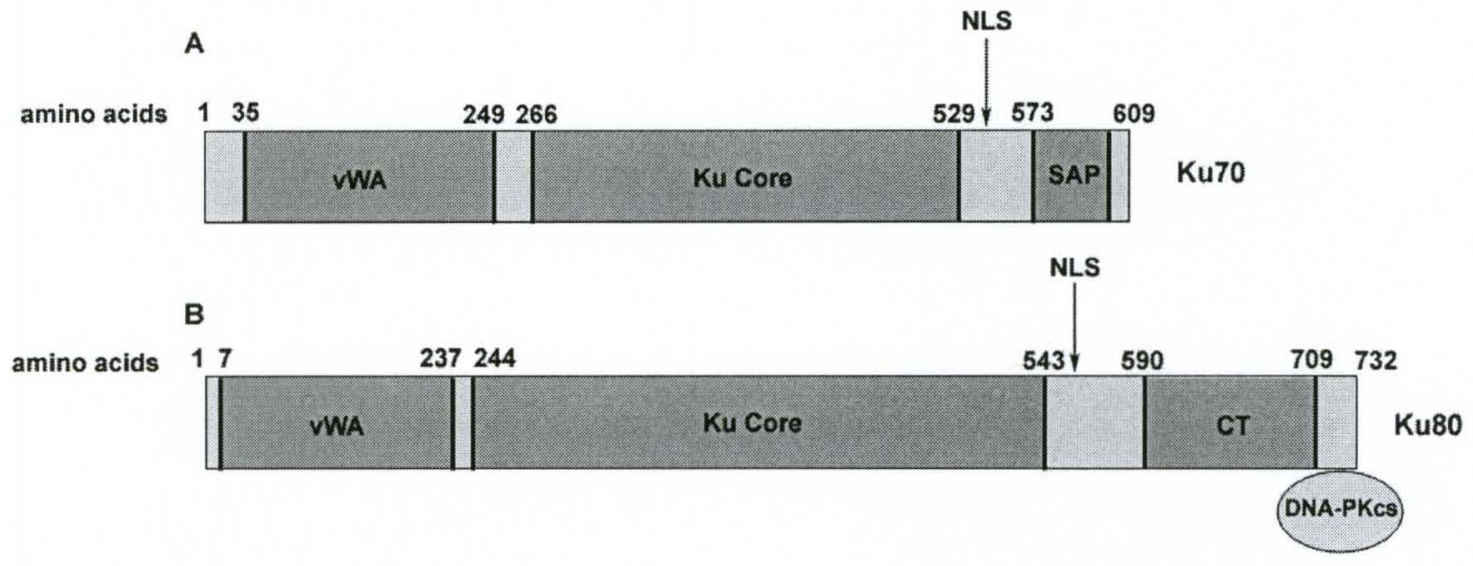

Figure 3. Structural features of Ku70 (A) and Ku80 (B). Each protein contains a von Willebrand A domain (vWa), a central Ku core domain and a carboxy-terminal region (CT). The $\mathrm{N}$-and $\mathrm{C}$-terminal regions of $\mathrm{Ku} 70$ and $\mathrm{Ku} 80$ are unique in each protein. For example, the C-terminal region of Ku70 contains a SAP (SAF-A/B, Acinus and PIAS) domain which is related to a helix-extension-helix fold and is proposed to be a DNAbinding domain. In addition, the C-terminal region of Ku80 contains a DNA-PKcs binding site. Ku70 contains a nuclear localization sequence (NLS) at amino acids 539556 and Ku80 contains a NLS at amino acids 561-569 [114;142;154]. 
[142;146;155]. In V(D)J recombination, different $\mathrm{V}, \mathrm{D}$, and $\mathrm{J}$ genes segments are joined together in various combinations generating diversity in immunoglobulins and T-cell receptors. During recombination, a hairpin structure with blunt double-stranded ends is formed. $\mathrm{Ku}$ is recruited to this structure to repair the double-stranded ends in a manner similar to NHEJ [142;156;157].

Telomeres are G-rich DNA sequences located in the ends of chromosomes of eukaryotes that function to prevent chromosome fusion and protect the chromosome from deterioration. $\mathrm{Ku}$ binds to telomeric sequences during telomere repair and helps prevent end-to-end DNA fusion through association with telomerase reverse transcriptase [158160]; however the exact mechanism for this is unclear. In S. cerevisiae, Ku localizes telomeres to the nuclear membrane and is part of the complex that is required for transcriptionally silent chromatin $[161 ; 162]$. S. cerevisiae deficient for Ku have telomeres shorter in length than wild type strains [163]. Loss of one Ku80 allele in human cells results in shorter telomere length and increased genomic instability [142].

Cytosolic Ku70 has been shown to be involved in apoptosis through its association with Bax. Bax is a member of the Bcl-2 family of pro-apoptotic proteins that regulate apoptosis through control of the integrity of mitochondria. Ku70 binds Bax preventing its localization to the mitochondria thereby inhibiting apoptosis [144]. This activity is mediated by a region in the carboxy terminus of $\mathrm{Ku} 70$ and does not require heterodimerization with Ku80. Upon apoptotic stress, Bax dissociates from Ku70, undergoing a conformational change followed by translocation to mitochondria and subsequence apoptosis [144;164]. 
$\mathrm{Ku}$ also appears to be involved in the regulation of transcription of certain genes. Some reports suggest that $\mathrm{Ku}$ binds in a sequence-specific manner to the promoters of heat shock proteins, glucose-regulated peptide 78 and glucose-regulated peptide 94 , and regulates the transcription of these genes [165-167]. However, these studies used linear DNA, raising the possibility of the DNA ends playing a role in sequence binding. Because of the ring like structure of $\mathrm{Ku}$, sequence specific binding in vivo would most likely occur through the formation of unusual DNA structures, although binding could also occur through the carboxy-terminal SAP domain of Ku70 [148;165;168]. Other reports have shown that $\mathrm{Ku}$ is involved in transcriptional regulation without sequence specific binding. For example, $\mathrm{Ku}$ associates with RNA polymerase II elongation sites through protein-protein interactions between $\mathrm{Ku} 80$ and transcription-elongation proteins. However the mechanism by which $\mathrm{Ku}$ regulates transcription is unclear [169].

\section{Preliminary Results}

Hormone Receptor Laboratory TumorMarker Database and biorepository:

The studies outlined in this dissertation utilized de-identified human tissue specimens and associated clinical data available in the IRB-approved Hormone Receptor Laboratory (HRL) Biorepository and Tumor Marker Database. Tissue specimens were collected and typically processed within an hour following surgery using stringent protocols to ensure the integrity of specimens for genomic and proteomic analyses [20;24]. Remaining tissue was stored at $-80^{\circ} \mathrm{C}$ from over 5,000 breast, ovarian, uterine and colon cancers, of which specimens were selected for these studies. The HRL Biorepository and Tumor Marker Database contain associated de-identified tumor 
marker/clinical outcome that includes up to 15 years of clinical follow-up. Available clinicopathological data include tumor-based properties (e.g., pathology, grade, stage, size and tumor marker status), patient-related characteristics (e.g., age, race, menopausal status, family history, nodal status) and clinical follow-up (e.g, treatment regimen, disease-free and overall survival). As a state and federally licensed clinical laboratory, the HRL performed biochemical assays measuring the protein levels of ER and PR for $\sim 22,000$ human tissue specimens, most of which were breast cancers. Quantitative ER and PR expression (fmol/mg cytosol protein) data were generated using two different FDA-approved clinical assays described earlier: ligand binding assay (LBA) and enzyme immunoassay (EIA, Abbott Technologies).

\section{Detection of ERE-BP in breast cancer tumor extracts}

While investigating DNA-binding properties of ER $\alpha$ in breast cancer cytosols, we discovered non-ER $\alpha$ proteins that recognized ERE sequences [170-172]. To determine the distribution of these ERE-binding proteins (ERE-BP), cytosols were prepared as previously described $[20 ; 37 ; 168]$ from various breast cancer biopsies and analyzed by electrophoretic mobility shift assay (EMSA) using a $\left[{ }^{32} \mathrm{P}\right]$ labeled Xenopus laevis vitellogenin A2 (VitA2) ERE, which contains a perfect palindrome sequence [88;173]. Four types of expression profiles of the ERE-BP were detected with band migration distances appearing lower than that of recombinant human $\mathrm{ER} \alpha(\mathrm{rhER} \alpha)$ which served as a control ERE-binding protein (Figure 4).

The most common profile (63\% of samples) consisted of a single band on an EMSA gel migrating below that of rhER $\alpha$. A few cytosols exhibited a band migrating 


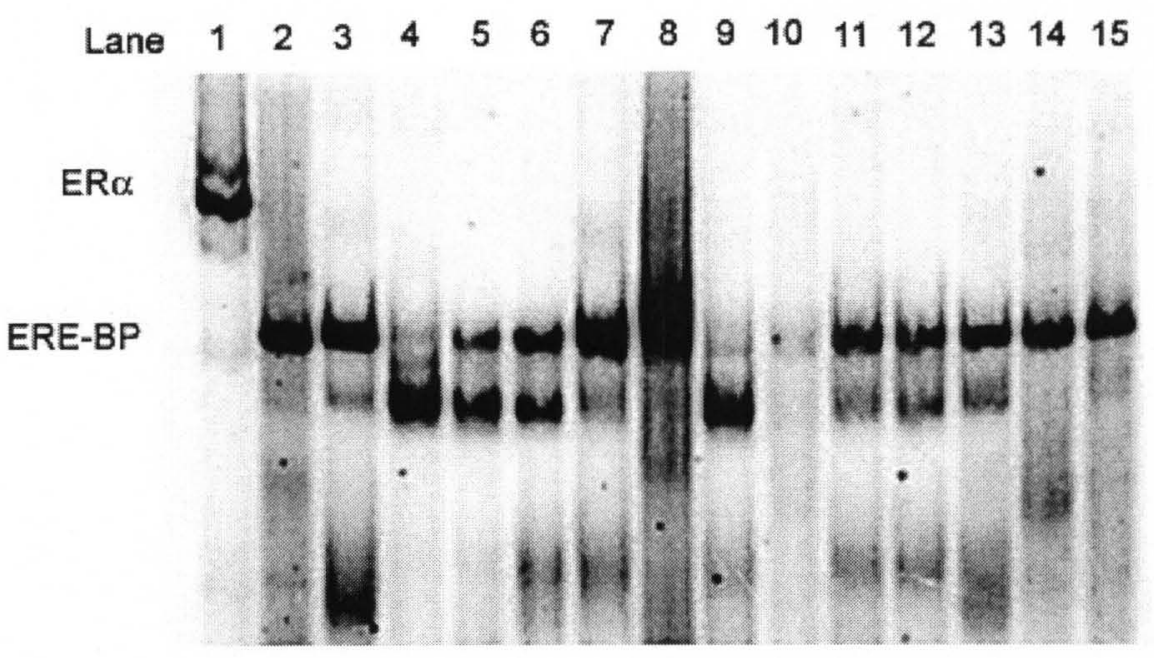

Free ERE

Figure 4. Distribution of ERE-binding proteins in breast cancer cytosols. Cytosols were prepared as previously described $[20 ; 38 ; 39 ; 174]$ from various breast cancer biopsies and analyzed by electrophoretic mobility shift assay (EMSA) using a $\left[{ }^{32} \mathrm{P}\right]$ labeled Xenopus laevis vitellogenin A2 (VitA2) ERE (Lanes 2-14). Recombinant human ER $\alpha(\operatorname{rhER} \alpha)$ served as a control ERE-binding protein (Lane 1). Equal amounts of protein $(13 \mu \mathrm{g})$ were loaded in each lane. 
lower than the major ERE-BP band ( $4 \%$ of the samples examined) while a significant number of EMSA profiles contained both bands (24\%). Nine percent of the samples were negative for ERE-BP. To determine if the presence of the ERE-BP is related to ER or PR, levels were correlated with the ER and PR status of the tumor (Figure 5). The DNAbinding levels of ERE-BP present in breast cancer cytosols were determined by scanning each lane of the EMSA gels and using Optiquant ${ }^{\mathrm{TM}}$ software for quantification. Patients were grouped according to ER and PR status and data were analyzed by box and whisker plots followed by a Kruskal-Wallis test. No correlation was found between ERE-BP level and ER/PR status suggesting these proteins are unrelated to the nuclear sex hormone receptor proteins.

To confirm that the observed complex formed is a DNA-protein complex, protein extracts were treated with pepsin, trypsin and RNaseA prior to ERE-binding reactions and analyzed by EMSA (Figure 6). Treatment with $100 \mu \mathrm{g} / \mathrm{ml}$ pepsin at $37^{\circ} \mathrm{C}$ eliminated binding of ERE-BP to the ERE. Treatment with $100 \mu \mathrm{g} / \mathrm{ml}$ pepsin at $4^{\circ} \mathrm{C}$ resulted in a smaller ERE-BP fragment. Treatment with $100 \mu \mathrm{g} / \mathrm{ml}$ trypsin at both $4^{\circ} \mathrm{C}$ and $37^{\circ} \mathrm{C}$ eliminated binding of the ERE-BP to the ERE. Treatment with $100 \mu \mathrm{g} / \mathrm{ml}$ RNase A had no effect on complex formation at either $4^{\circ} \mathrm{C}$ or $60^{\circ} \mathrm{C}$. Addition of $0.01 \%$ SDS to the reaction mixture and boiling also eliminated binding. These results confirm that the complex observed is indeed a DNA/protein complex.

To determine if these ERE-BP have prognostic significance for patients with breast carcinoma, Kaplan-Meier survival analyses were performed (Figure 7). Patients were divided into ERE-BP negative or ERE-BP positive groups and overall survival probabilities were examined [172]. At 100 months of follow-up, patients with tumors 


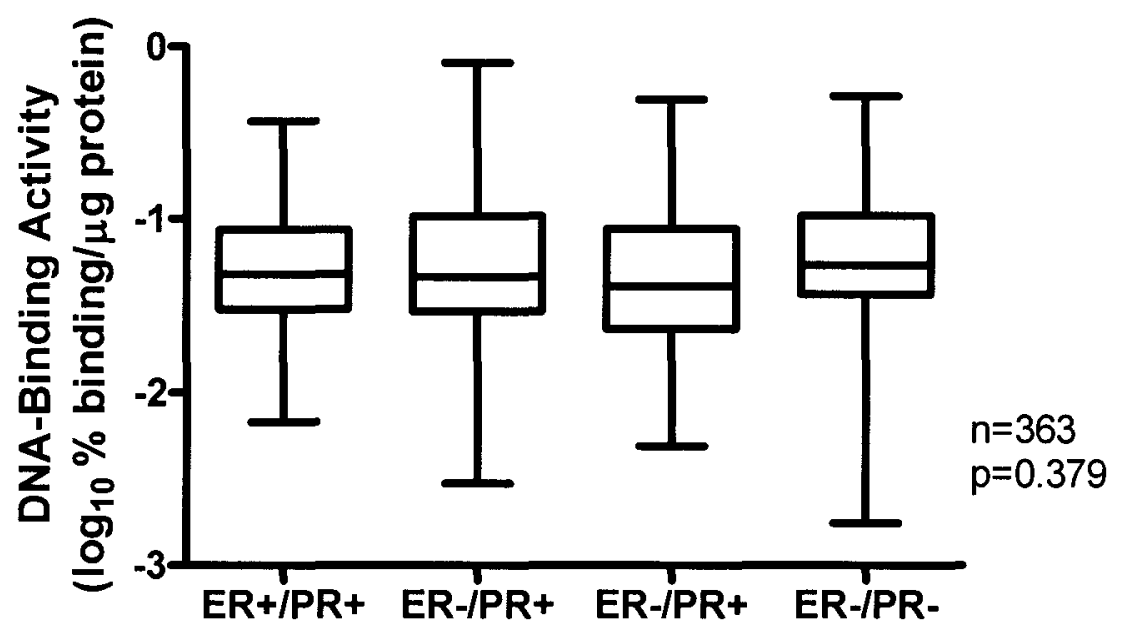

Figure 5. Correlation of ERE-BP binding activity with ER and PR status. The DNAbinding levels of ERE-BP present in breast cancer cytosols was determined by scanning each lane of the EMSA gels and using Optiquant ${ }^{\mathrm{TM}}$ software for quantification, expressed as $\log _{10} \%$ binding $/ \mu \mathrm{g}$ protein. Patients were grouped according to ER and PR status and data were analyzed by box and whisker plots followed by a Kruskal-Wallis test. 


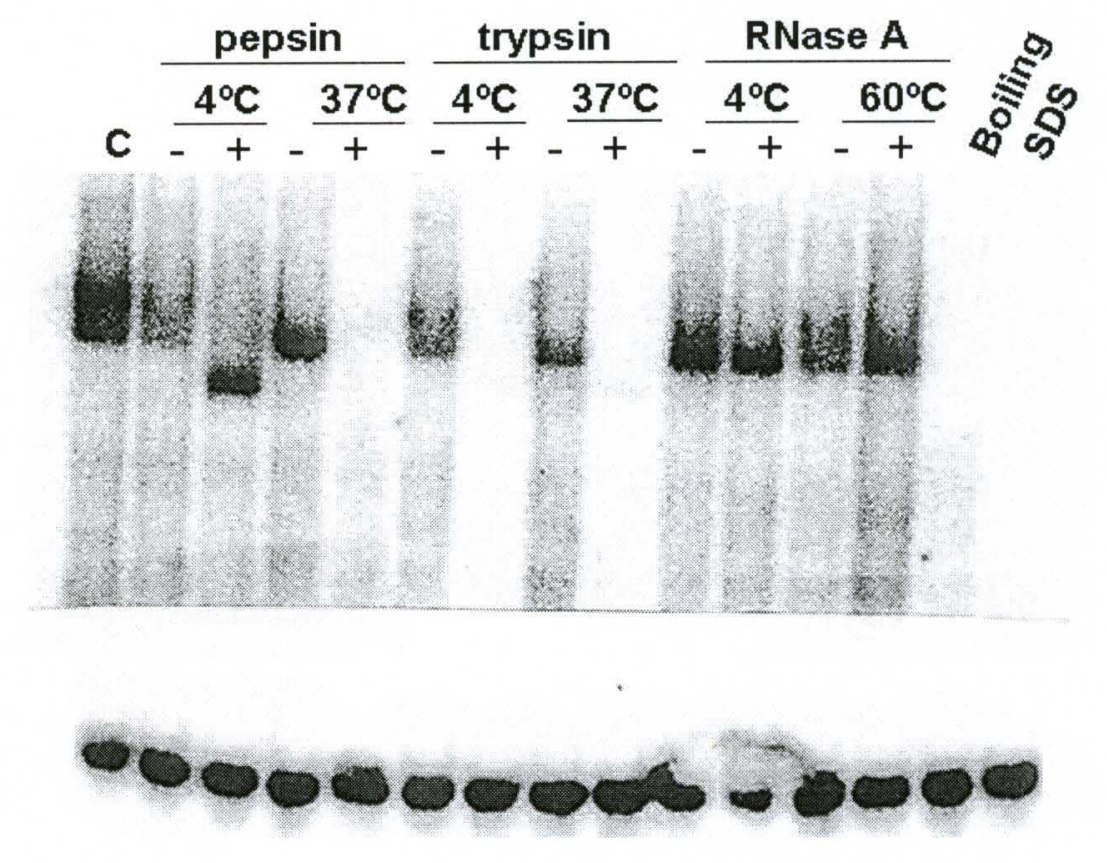

Figure 6. Effect of enzymatic digestion on ERE-BP. Cytosols containing ERE-BP were treated with either $100 \mu \mathrm{g} / \mathrm{ml}$ pepsin, $100 \mu \mathrm{g} / \mathrm{ml}$ trypsin, $100 \mu \mathrm{g} / \mathrm{ml}$ RNase A at the temperatures indicated, boiling at $95^{\circ} \mathrm{C}$ for 5 minutes or $0.01 \%$ SDS prior to the binding reaction and analyzed by EMSA. The untreated control cytosol (C) is also shown. 


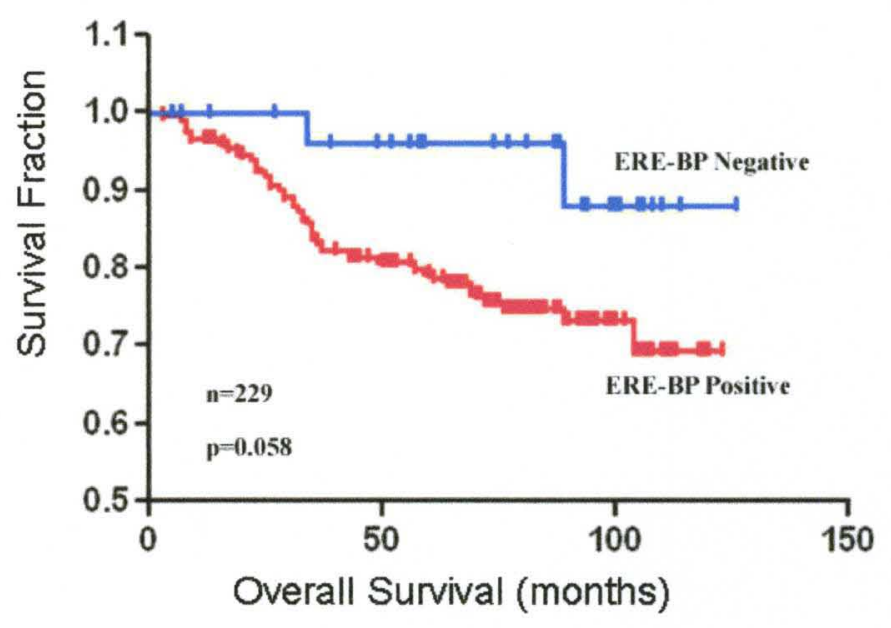

Figure 7. Overall survival probabilities of breast cancer patients as a function of ERE-BP status. Kaplan-Meier analyses were used to determine the influence of ERE-BP status (either positive or negative) on overall (OS) survival. P values were determined using a $\log -$ rank test. 
that were ERE-BP negative had survival probabilities of $90 \%$, while patients with tumors that were ERE-BP positive had survival probabilities of only $68 \%$, suggesting that these proteins may be prognostic markers for breast cancer.

\section{Hypothesis and Specific Aims}

The overall goal of these investigations is to characterize and identify these novel proteins that were first detected by their recognition of ERE sequences and confirm their clinical relevance in a larger patient population as a result of our initial detection of the proteins in human breast cancers.

The hypothesis for these investigations is that the ERE-binding protein identified in human breast cancer biopsies functions independently of estrogen receptor signaling and their DNA-binding activity correlates with breast cancer prognosis. This hypothesis will be examined in the following Specific Aims:

Specific Aim I - To determine the biological characteristics of the novel ERE-BP (e.g. sequence specificity, effect of ER ligands, tissue distribution, cellular localization).

Specific Aim II - To purify the ERE-BP using immunobased methods and identify their sequences by mass spectrometry.

Specific Aim III - To correlate ERE-BP expression and activities with properties of the breast carcinoma (e.g. pathology, stage, nodal status), patient characteristics (e.g., family 
history, age, race), and clinical outcome (disease-free and overall survival) to determine clinical relevance of ERE-BP status for prediction of a patient's prognosis and the clinical behavior of the breast carcinoma. 


\section{CHAPTER II}

\section{CHARACTERIZATION AND DISTRIBUTION OF CANDIDATE ESTROGEN RESPONSE ELEMENT BINDING PROTEINS IN HUMAN BREAST CARCINOMA}

\section{Introduction}

The focus of the studies described in this Chapter is to investigate the distribution and biochemical properties of the newly discovered ERE-binding proteins [172]. Preliminary studies in our laboratory suggested these ERE-binding proteins (ERE-BP) in cytosols were associated with breast cancer behavior and characteristics prompted this series of experiments. Our initial results revealed four types of expression profiles of ERE-BP on EMSA with band migration distances greater than that of recombinant human ER $\alpha(\operatorname{rhER} \alpha)$ and DNA-binding activities of ERE-BP were not correlated with levels of either ER or PR in extracts from breast cancer specimens, although patients with breast cancers that were ERE-BP negative exhibited decreased overall survival.

\section{Known ERE-binding proteins}

A number of proteins other than the estrogen receptor have been reported to bind to ERE sequences. Orphan receptors such as the estrogen related receptors (ERR) bind to the ERE and affects estrogen signaling either positively or negatively [175;176]. ERR $\alpha$ 
binds to the ERE sequence in the human lactoferrin gene promoter and constitutively activates transcription [177]. ERR $\alpha$ also competes with ER $\alpha$ for binding to consensus ERE sequences and either acts as a constitutive activator or as an active repressor of ERE-regulated transcription in a cell type-dependent manner [178]. These results suggest the need for evaluation methods capable of characterizing more subtle aspects of EREprotein interactions in any given tissue sample. Another orphan receptor, COUP-TF, also has been shown to bind to ERE sequences and inhibit estradiol induced gene expression [179-181].

In addition to the estrogen-related and orphan receptors, other proteins have been reported to compete with ER $\alpha$ for ERE binding [182-186]. In New World primate cells, ERE-binding proteins were discovered that compete with human estrogen receptor for binding to the consensus ERE [183]. These endogenous ERE-BP were able to block ERE-mediated transcription in marmoset B-lymphoblastoid B95-8 and owl monkey kidney cells. Chen et al. determined that the protein responsible for this activity was similar to the hnRNP C-like or hnRNP-D subfamily of heterogeneous nuclear ribonucleproteins and that its overexpression results in estrogen unresponsiveness in primates $[183 ; 184 ; 186]$. More recently, Chen et al. showed that overexpression of these ERE-binding proteins in MCF-7 cells resulted in dysregulation of normal interactions between ER $\alpha$ and the ERE [185] and that estradiol and tamoxifen could restore the normal interaction [186].

Another ERE-binding protein has been identified in cytosols of rat uteri that may influence ER binding [187]. Expression of this protein was detected in both estrogen responsive and nonresponsive tissues and injection with $17 \beta$-estradiol repressed the ERE- 
BP levels by $40-50 \%$. UV crosslinking experiments revealed that the molecular weight of the protein to be $48 \mathrm{kDa}$, however the identity of the protein was never discovered.

The purpose of this investigation was to characterize proteins observed in breast tumor extracts that bind to ERE sequences in order to determine their role in breast cancer behavior. The goal was to determine if these proteins share properties with ER $\alpha$, ER $\beta$ or with other known ERE-binding proteins discussed above.

\section{Methods and Materials}

Preparation of human recombinant estrogen receptor- $\alpha$ (rhER $\alpha)$ protein

The yeast strain BJ3505 was transformed with an $\mathrm{hER} \alpha$ expression plasmid YEpE12 and $\mathrm{hER} \alpha$ is expressed as an ubiquitin fusion under the control of CUP1 promoter [188;189]. Yeast cells were grown in complete (-Trp) medium and monitored spectrophotometrically at a wavelength of $595 \mathrm{~nm}$. When the OD595 reached $0.6, \mathrm{rhER} a$ expression was induced by addition of $\mathrm{CuSO}_{4}$ to a final concentration of $100 \mu \mathrm{M}$. After harvesting and washing with water, yeast pellets were extracted in $40 \mathrm{mM}$ Tris buffer with $1.5 \mathrm{mM}$ EDTA, $10 \%$ glycerol, $10 \mathrm{mM} \mathrm{Na}_{2} \mathrm{MoO}_{4}, 10 \mu \mathrm{M}$ monothioglycerol and 1 $\mathrm{mM}$ PMSF. Yeast cells were disintegrated with glass beads in a Vortex Genie ${ }^{\circledR}$ in 5 intervals of 30 seconds each, with 30 seconds intervals cooling on ice. Debris was removed from the preparation by centrifugation at $100,000 \mathrm{x}$ for 30 minutes at $4^{\circ} \mathrm{C}$. The supernatant containing rhER $\alpha$ was recovered for immediate assay or stored at $-80^{\circ} \mathrm{C}$ for future use as a reference representing a well characterized ERE-binding protein. 


\section{Cytosol preparation}

Cytosols were prepared from de-identified human breast cancer tissue specimens in 40 $\mathrm{mM}$ Tris- $\mathrm{HCl}$, pH 7.4, containing $1.5 \mathrm{mM}$ EDTA, $10 \%$ glycerol, $10 \mathrm{mM} \mathrm{Na}_{2} \mathrm{MoO}_{4}, 1$ $\mathrm{mM}$ PMSF and $10 \mu \mathrm{M}$ monothioglycerol, and homogenized with a Polytron PT-10-35. Homogenate was separated into pellet and cytosol by centrifugation at $105,000 \mathrm{x} g$ for 30 minutes at $4^{\circ} \mathrm{C}$, using a Beckman LE-80K ultracentrifuge [20;38;39;60;174]. Protein concentration of each cytosol was determined by the Bradford procedure [190]. Cytosols were stored at $-80^{\circ} \mathrm{C}$ for future use.

\section{Nuclear extract preparation}

Tissue sections were prepared in a nuclease and protease-free environment using a Leica cryostat/frozen microtome [191]. For preparation of nuclear extracts, ten $30 \mu \mathrm{m}$ frozen tissue sections were placed into pre-chilled $1.5 \mathrm{~mL}$ microcentrifuge tubes and immediately stored on dry ice. Sections were transferred to a chilled Duall homogenizer and homogenized in $10 \mathrm{mM}$ HEPES buffer, $\mathrm{pH} 7.9$, containing $10 \mathrm{mM} \mathrm{KCl}, 0.1 \mathrm{mM}$ EDTA, $1 \mathrm{mM}$ DTT, $0.5 \mathrm{mM}$ PMSF with aprotinin, leupeptin and pepstatin A $(0.01 \mu \mathrm{g} / \mu \mathrm{l}$ each). Lysates were centrifuged at $4^{\circ} \mathrm{C}$ at $15,000 \times \mathrm{g}$ for 3 minutes. The nuclear pellet was resuspended in $20 \mathrm{mM}$ HEPES, pH 7.9 containing $0.4 \mathrm{M} \mathrm{NaCl}, 1 \mathrm{mM}$ EDTA, $10 \%$ glycerol, $1 \mathrm{mM}$ DTT, $0.5 \mathrm{mM}$ PMSF with aprotinin, leupeptin and pepstatin A $(0.01$ $\mu \mathrm{g} / \mu \mathrm{l}$ each). The resuspended pellets were mixed at $4^{\circ} \mathrm{C}$ for 2 hours and centrifuged at $4^{\circ} \mathrm{C}, 15,000 \mathrm{x}$ g for 5 minutes [192;193]. 


\section{Labeling of ERE sequences}

For labeling with $\left[{ }^{32} \mathrm{P}\right] \mathrm{dATP}, 30 \mu \mathrm{M}$ synthetic double-stranded ERE sequences (Integrated DNA Technologies) were incubated with Klenow DNA buffer (Promega), 5\% $\beta$-mercaptoethanol (Sigma), $750 \mu \mathrm{M}$ dCTP, dGTP, and dTTP (Promega), $1.25 \mu \mathrm{M}$ $\left[\alpha^{32} \mathrm{P}\right] \mathrm{dATP}$ (Perkin Elmer) and 5 units DNA Polymerase I Large (Klenow) fragment (Promega) at $37^{\circ} \mathrm{C}$ for 30 minutes, followed by a gravity-flow separation through a NICK column (Amersham). The sample was eluted with $3 \mathrm{ml}$ TE buffer $(10 \mathrm{mM}$ Tris-HCl, $\mathrm{pH}$ 8.0 , containing $1 \mathrm{mM}$ EDTA) and collected into fractions $(\sim 100 \mu \mathrm{l}$ each). Radioactivity was measured by a scintillation counter and fractions were also run on a $4 \%$ polyacrylamide gel to confirm the presence and separation of labeled ERE from unreacted $\left[{ }^{32} \mathrm{P}\right] \mathrm{dATP}[188 ; 194]$. Representative results are shown in Figure 8.

\section{Electrophoretic mobility shift and supershift assays}

Protein extracts were incubated with 50 ng non-specific DNA, poly (dI-dC) (Amersham), $10 \mathrm{mM} \mathrm{KCl}, 1 \%$ glycerol and $\left[{ }^{32} \mathrm{P}\right]$-labeled ERE sequences in $40 \mathrm{mM}$ Tris- $\mathrm{HCl}$ buffer, pH 8.0, containing $500 \mu \mathrm{M}$ PMSF and $10 \mu \mathrm{M}$ monothioglycerol overnight at $4^{\circ} \mathrm{C}$. In ERE competition experiments, a 125-fold molar excess of unlabeled ERE was added to each reaction and incubated for 30 minutes before addition of $\left[{ }^{32}\right.$ P]ERE [195]. Sequences used are shown in Table 8 (See Appendix). For supershift assays, extracts were incubated with various antibodies for 30 minutes before addition of $\left[{ }^{32} \mathrm{P}\right] \mathrm{ERE}$. Reactions were separated by $5 \%$ polyacrylamide gel electrophoresis. The gel was pre-run for 30 minutes at $150 \mathrm{~V}$ at $4^{\circ} \mathrm{C}$ in $0.5 \mathrm{X}$ TBE buffer $(1.0 \mathrm{M}$ Tris- $\mathrm{HCl}, \mathrm{pH} 8.6$, containing $831 \mathrm{mM}$ boric acid, 10 
A

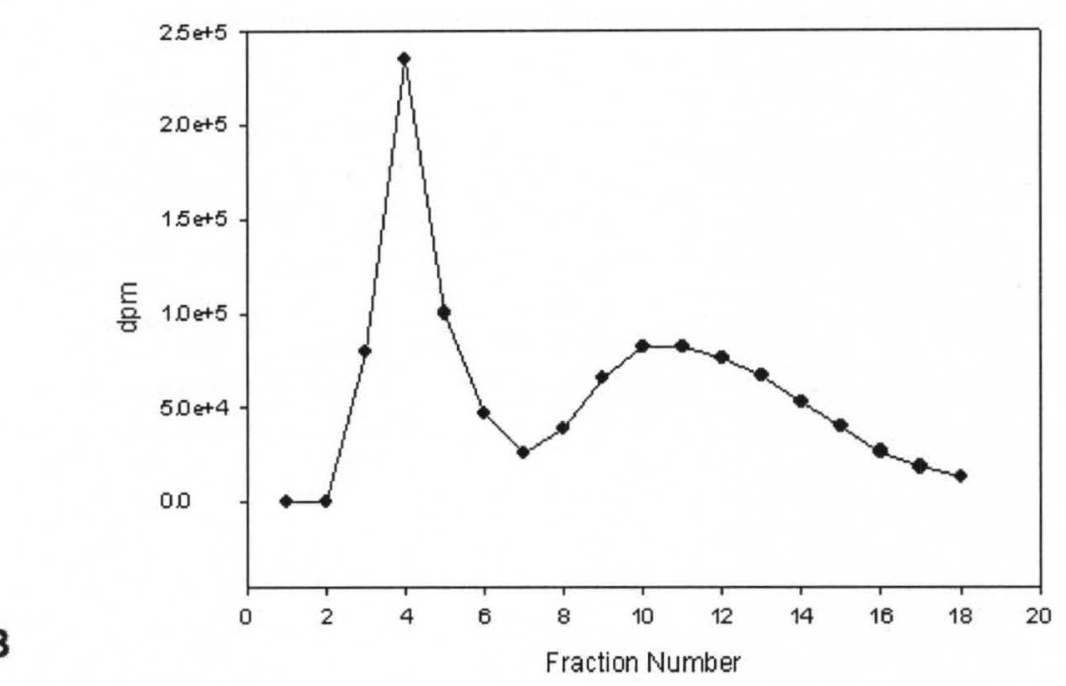

B

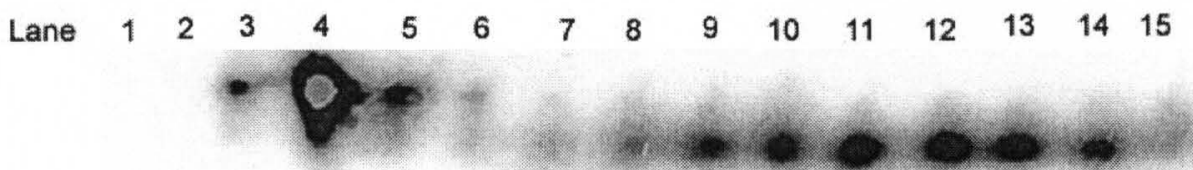

Figure 8. Labeling of ERE sequences with $\left[{ }^{32} \mathrm{P}\right] \mathrm{dATP}$. (A) Example of a profile of $\left[{ }^{32} \mathrm{P}\right]$ VitA2 ERE sequence separated from unreacted $\left[{ }^{32} \mathrm{P}\right] \mathrm{dATP}$ using a Nick column. The sharp peak at fractions 3-5 indicate the labeled ERE and the second, broad peak represents the free $\left[{ }^{32} \mathrm{P}\right] \mathrm{dATP}$. Here fraction $\# 4$ is the most active and ideal for use in EMSA experiments. (B) NICK column fractions were subjected to electrophoresis on a 4\% polyacrylamide gel. The slower moving bands (Lanes 3-5) represent labeled $\left[{ }^{32} \mathrm{P}\right]$ VitA2-ERE, while the faster migrating bands (Lanes 7-15) represent free $\left[{ }^{32} \mathrm{P}\right] \mathrm{dATP}$. 
mM EDTA). Samples were then loaded, followed by electrophoresis at $300 \mathrm{~V}$ for 5 minutes, and then $180 \mathrm{~V}$ for 4 hours. Subsequently, gels were dried and exposed to phosphor screens (Perkin Elmer) overnight. The bands representing [ $\left.{ }^{32} \mathrm{P}\right]$ ERE-protein complexes and free $\left[{ }^{32} \mathrm{P}\right] \mathrm{ERE}$ were visualized and quantified using a Cyclone Storage Phosphor System with OptiQuant ${ }^{\circledR}$ software (Perkin Elmer).

A method of estimating the DNA binding activity levels of ERE-BP in breast cancer biopsies was developed by measuring the band intensity of the ERE-BP/ERE complexes or free $\left[{ }^{32} \mathrm{P}\right]$ ERE in each lane from the EMSA using OptiQuant ${ }^{\circledR}$ software. The value of band intensities (representing the amount of $\left[{ }^{32} \mathrm{P}\right]$ Vita2-ERE ) are reported as Digital Light Units (DLU)/ $\mu$ g protein and normalized to the total DLU of the lane in order to compare between samples. A representative band quantification experiment is shown in Figure 9.

\section{ERE titrations of ERE-binding proteins}

EMSAs were performed as described above with varying amounts of $\left[{ }^{32} \mathrm{P}\right] \mathrm{VitA2}$-ERE and a constant $5 \mu \mathrm{g}$ of total protein. The reactions were incubated with either ethanol (ETOH) or $1 \mu \mathrm{M}$ diethylstilbesterol (DES), 4-hydroxytamoxifen (Tmx), 17ß-estradiol (E2) or raloxifene (Rlx) for 30 minutes before the addition of $\left[{ }^{32} \mathrm{P}\right]$ Vita2-ERE. Gels were scanned and bands quantified using OptiQuant ${ }^{(B)}$ software as previously described. A standard curve plotting fmoles of ERE versus DLU was used to determine the amount of ERE bound by protein. Data were modeled using one-site binding kinetics with GraphPad Prism ${ }^{\circledR}$ software. 

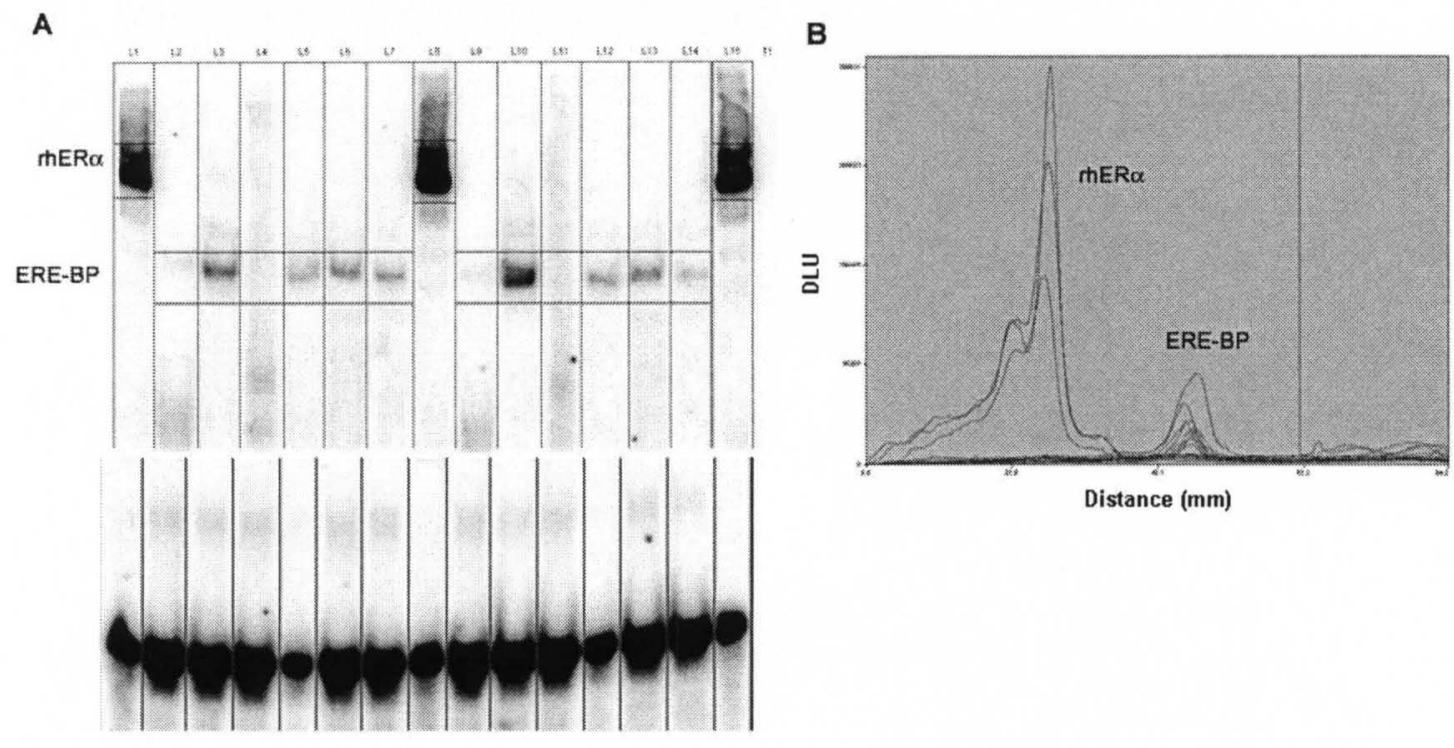

Figure 9. Method for estimating ERE-binding protein activities in breast cancer biopsies using $\left[{ }^{32} \mathrm{P}\right]$ VitA2-ERE. A representative profile of an EMSA gel is visualized using the Cyclone Phosphoimager and the total DLU representing total $\left[{ }^{32} \mathrm{P}\right]$ VitA2-ERE radioactivity in a single lane of the EMSA gel is measured in A. After outlining each lane as shown in A, the DLU for each band (ERE-BP or rhER $\alpha$ ) are determined by integrating the area under the curve using Optiquant ${ }^{\mathrm{TM}}$ software (B). 


\section{Results and Discussion}

\section{Distribution of ERE-binding proteins in various tissues}

To assess the tissue specificity of ERE-binding proteins, extracts of several human tissue reference powders prepared from breast cancer, fibroid, uterus and myometrium were analyzed by EMSA after incubation with ERE sequences for the vitellogenin gene (VitA2) and the $\mathrm{pS} 2$ gene. These reference powders were prepared previously as standards for assessment of estrogen and progestin receptor activities used in clinical trials for human breast cancer [25;26]. Cytosols from reference powders of breast cancer, uterus and fibroids exhibited prominent bands suggesting high concentrations of the ERE-binding proteins recognizing these two $\left[{ }^{32} \mathrm{P}\right] \mathrm{ERE}$ sequences (Figure 10). The myometrial cytosol only displayed a very low quantity of these proteins when the same amount of total protein was examined by EMSA. Each of the ERE-BP migrated to a position on EMSA gels lower than that of rhER $\alpha$. Cytosols prepared from frozen ovarian, colon and endometrial carcinomas as well as normal uteri were also analyzed for the presence of ERE-BP (Figure 11). Cytosols from these tissues exhibited prominent bands suggesting high concentrations of the ERE-binding proteins recognizing $\left[{ }^{32} \mathrm{P}\right]$ VitA2-ERE sequences, indicating that the ERE-BP are ubiquitous proteins present in a variety of tissues.

To examine species specificity of the ERE-binding proteins, extracts from uteri of rat, calf, and ververt monkey (Cercopithecus aethiops) also were analyzed by EMSA with the $\left[{ }^{32} \mathrm{P}\right] \mathrm{ERE}$ sequences for the VitA2 and $\mathrm{pS} 2$ genes (Figure 10). rhER $\alpha$ was used as a control on the EMSA gels to show that ERE-binding proteins migrated below the 
A

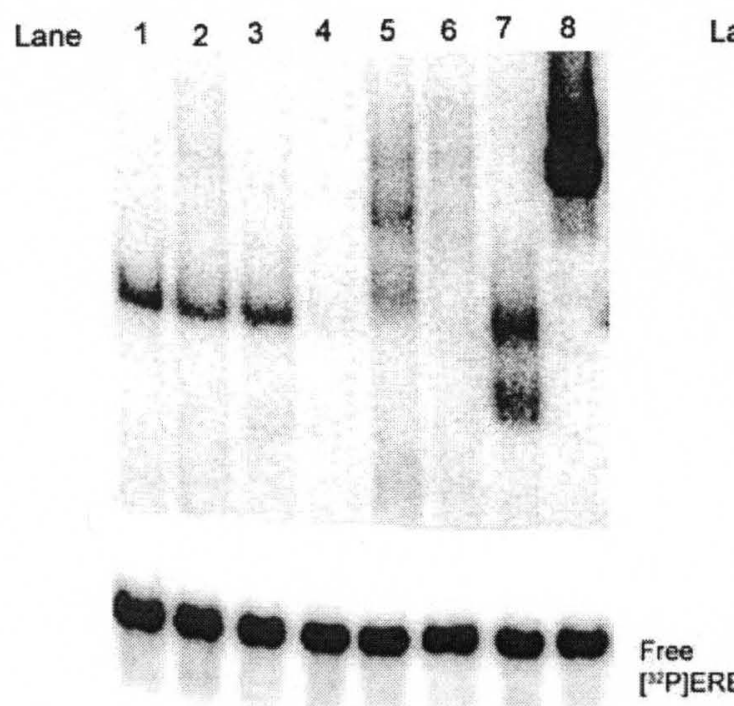

$\mathbf{B}$
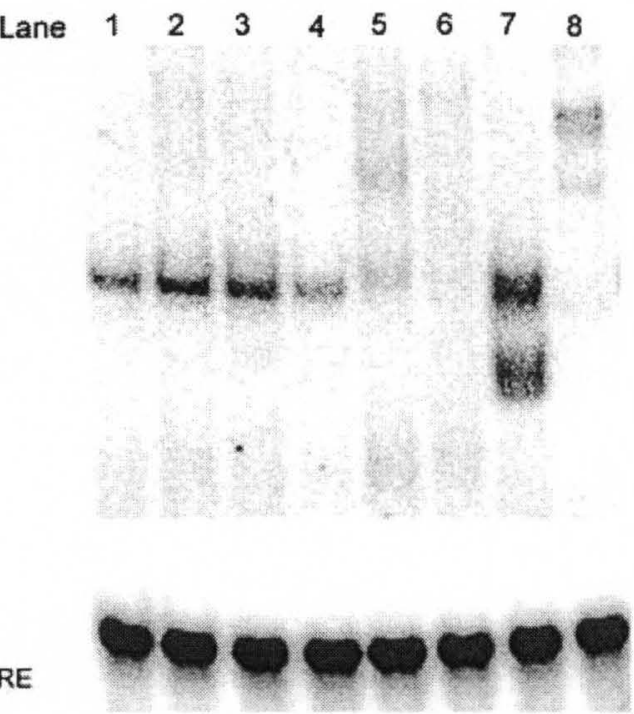

Figure 10. ERE-binding proteins from extracts of human tissue reference specimens and animal tissues associated with VitA2-ERE (A) and pS2-ERE (B). To assess tissue specificity, extracts of human tissue specimens prepared from a pooled preparation of either de-identified breast cancer (Lane 1), fibroids (Lane 2), uteri (Lane 3) and myometria (Lane 4) were analyzed by EMSA with $\left[{ }^{32} \mathrm{P}\right]$ ERE sequences for the VitA2 and pS2 genes. To evaluate species specificity of ERE-BP, uteri of rat (Lane 5), calf (Lane 6) and ververt monkey (Cercopithecus aethiops) (Lane 7) were also analyzed. rhER $\alpha$ served as a control (Lane 8). Total protein in a quantity of 17 ug was added in each lane. 


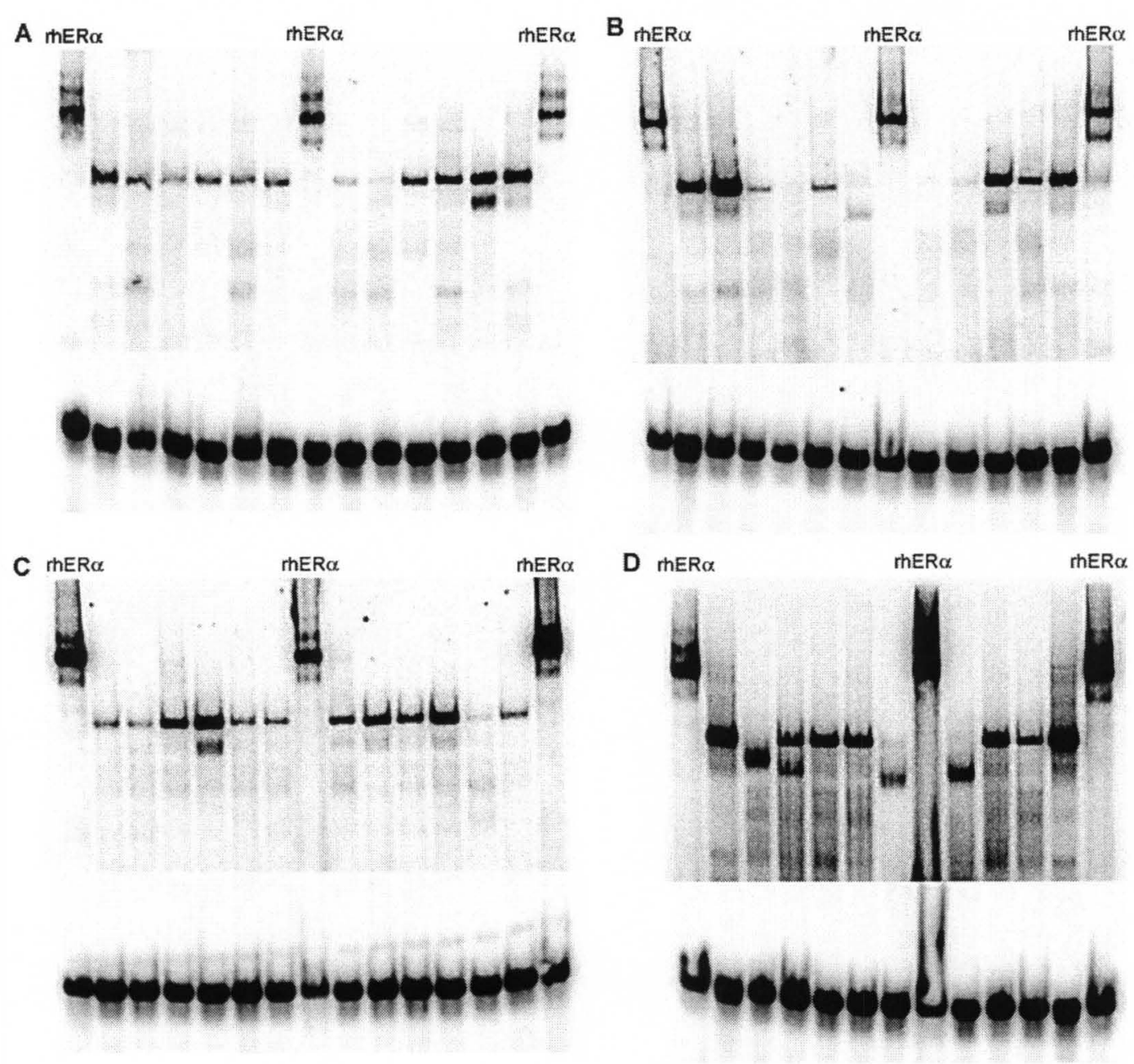

Figure 11. ERE-binding proteins from extracts of frozen human tissue specimens associated with VitA2-ERE. Cytosols of human tissue specimens prepared from either de-identified ovarian carcinoma (A), endometrial carcinoma (B), normal uteri (C) and colon carcinoma (D) were analyzed by EMSA with $\left[{ }^{32} \mathrm{P}\right] \mathrm{ERE}$ sequences for the VitA2 genes. rhER $\alpha$ served as a control as indicated. Total protein in a quantity of 25 ug was added in each lane. 
band position representative of the estrogen receptor protein. It was noted that rhER $\alpha$ recognized $\left[{ }^{32} \mathrm{P}\right]$ VitA2 ERE with a higher apparent affinity than that of $\mathrm{pS} 2 \mathrm{ERE}$. Neither cytosol from rat or calf uteri exhibited significant quantities of ERE-binding proteins, although ververt monkey uterine extracts expressed high levels of two distinct ERE-binding protein species migrating below rhERa (Figure 10).

As mentioned previously, other investigators have identified proteins recognizing the ERE sequence in New World primate B95-8 and owl monkey kidney cells [182;183]. Further characterization by these investigators revealed these proteins belong to the hnRNP family. This suggests the proteins identified in our investigations that are expressed in ververt monkey tissue may also be members of this family, which prompted our use of supershift assays using antibodies against these proteins as described below.

\section{Cellular distribution of ERE-BP}

To determine the cellular distribution of ERE-BP, levels were compared between cytosolic and nuclear extracts by EMSA. Extracts from various human tissue reference samples were prepared as described above and equal amounts of total protein were used in each of the EMSA reactions. We evaluated a variety of fresh frozen and lyophilized breast and uterine preparations that had been composed to serve as reference specimens for quality assurance surveys of ER and PR [25;26]. Results of these human tissue reference specimens are shown in Figure 12A. The DNA-binding activities of the ERE$\mathrm{BP}$ varied in both the cytosolic and nuclear extracts in each tissue sample analyzed. Generally the nuclear extracts exhibited a higher DNA-binding activity of the ERE-BP than those in cytosolic extracts. We also evaluated ERE-BP in de-identified frozen breast 
cancer biopsies. As shown in Figure 12B, the nuclear extracts of three different breast carcinomas contained significantly higher ERE-BP levels than those of cytosolic extracts of these representative specimens.

These results consistently reveal a higher abundance of these ERE-binding proteins in the cell nucleus than in the cytoplasm. Chen et al. also reported finding EREbinding proteins belonging to the hnRNP family in nuclear extracts [182] while Gray and Gorski reported finding ERE-binding proteins in cytosols [187]. Identification of the ERE-BP we have observed is necessary to determine whether these proteins are the same as those previously reported or if they represent new candidate biomarkers of breast cancer behavior.

\section{Lack of recognition of ERE-BP by antibodies against ER $\alpha$ and ERB}

Super-shift assays were performed to determine if ERE-BP contain epitopes recognized by antibodies prepared against various regions of the human ER $\alpha$ protein (e.g., AER 320/C-terminus, AER314/a.a. 125-165, 1D5/N-terminus, 5D11/a.a. 302-553) or ER $\beta$ (e.g. MAI-310/a.a. 247-261, PAI-311/a.a. 55-70, PAI-313/a.a. 467-485). The epitope for AER611 is unknown. As shown in Figure 13, $\operatorname{rhER} \alpha$ exhibited a supershift when reacted with each antibody, verifying its identity; however, ERE-BP did not supershift in the presence of anti-ER $\alpha$ antibodies recognizing different ER $\alpha$ epitopes. Reaction of rhER $\beta$ with antibodies recognizing epitopes of the various regions in the receptor protein brought about supershifts with most of the reagents. The basis for the lack of recognition of $\mathrm{Ab}-15$ is unknown; however, $\operatorname{rhER} \beta$ apparently recognized 
A

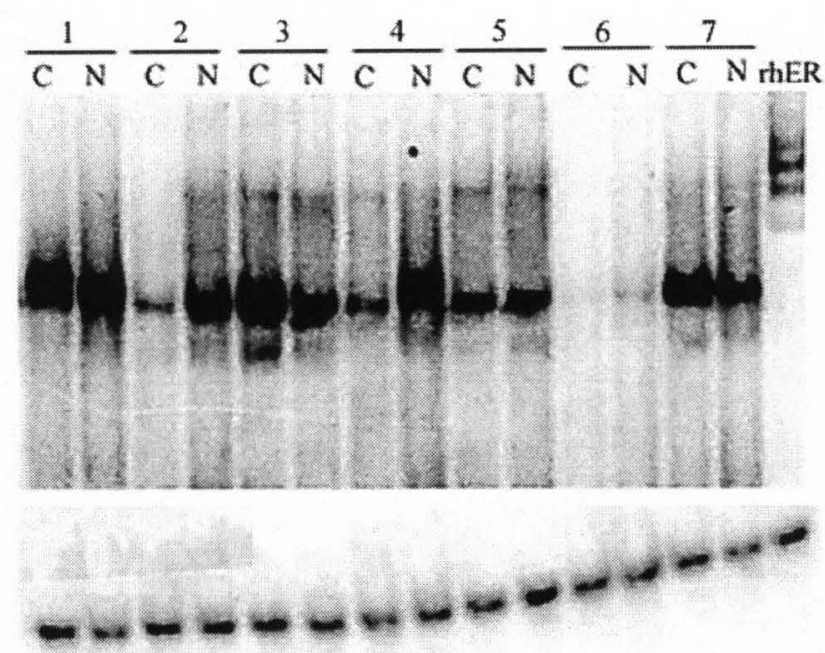

Free [32P]ERE
B

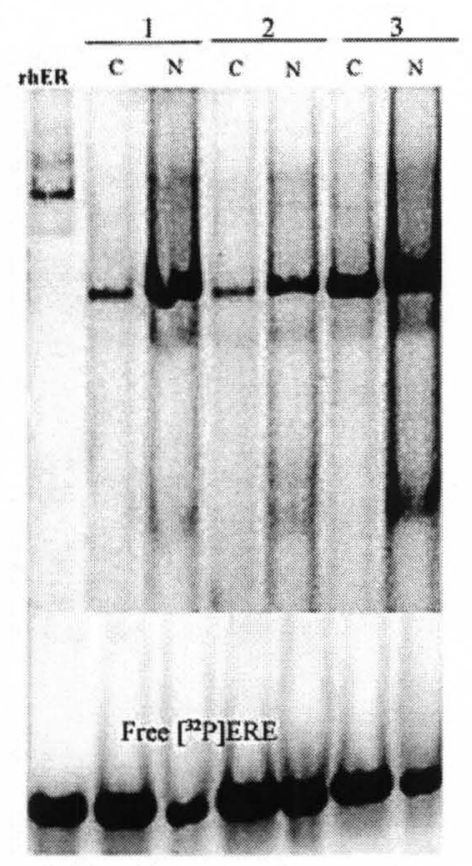

Figure 12. Comparison of ERE-BP activities in cytosolic and nuclear extracts. To determine the cellular distribution of ERE-BP, activities were compared between those of cytosolic and nuclear extracts using $\left[{ }^{32} \mathrm{P}\right]$ VitA2-ERE and EMSA. Extracts from various lyophilized human tissue reference samples were prepared as cytosol (C) and nuclear extracts $(\mathrm{N})$ as described in Materials and Methods. Equal amounts of total protein (25 $\mu \mathrm{g})$ were used in each of the EMSA reactions. The de-identified preparations examined were either breast carcinoma (pairs 1, 4 and 7) or uterine tissues (pairs 2, 3, 5 and 6) as

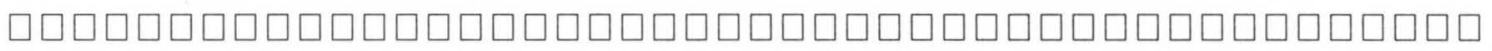

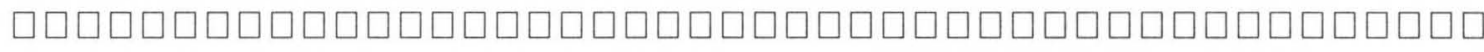



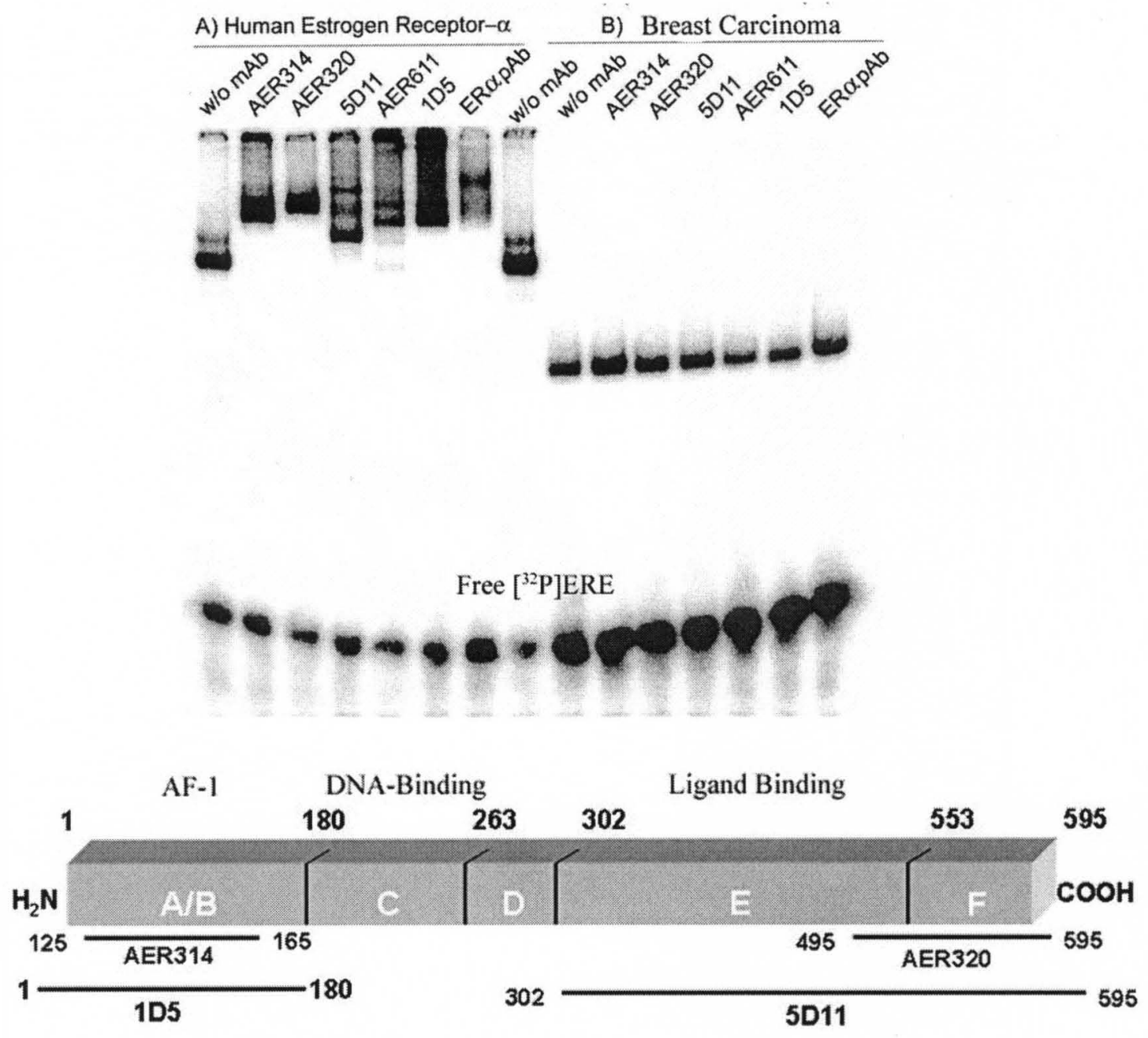

Figure 13. Influence of $h E R \alpha$ antibodies recognizing different sequence domains on the cytosolic ERE-BP assessed by super-shift assay. Recombinant hER $\alpha$ (A) and cytosol from a human breast cancer reference specimen containing ERE-BP (B) were incubated with hER $\alpha$ specific antibodies AER 314, 320, 611, 1D5 and 5D11 (NeoMarkers/Thermo Fisher) recognizing epitopes in various domains of ER $\alpha$ (e.g., AER 320/C-terminus, AER314/a.a. 125-165, 1D5/ N-terminus, 5D11/a.a. 302-553) and with ER $\alpha \mathrm{pAb}$ (PanVera/Life Technologies). 

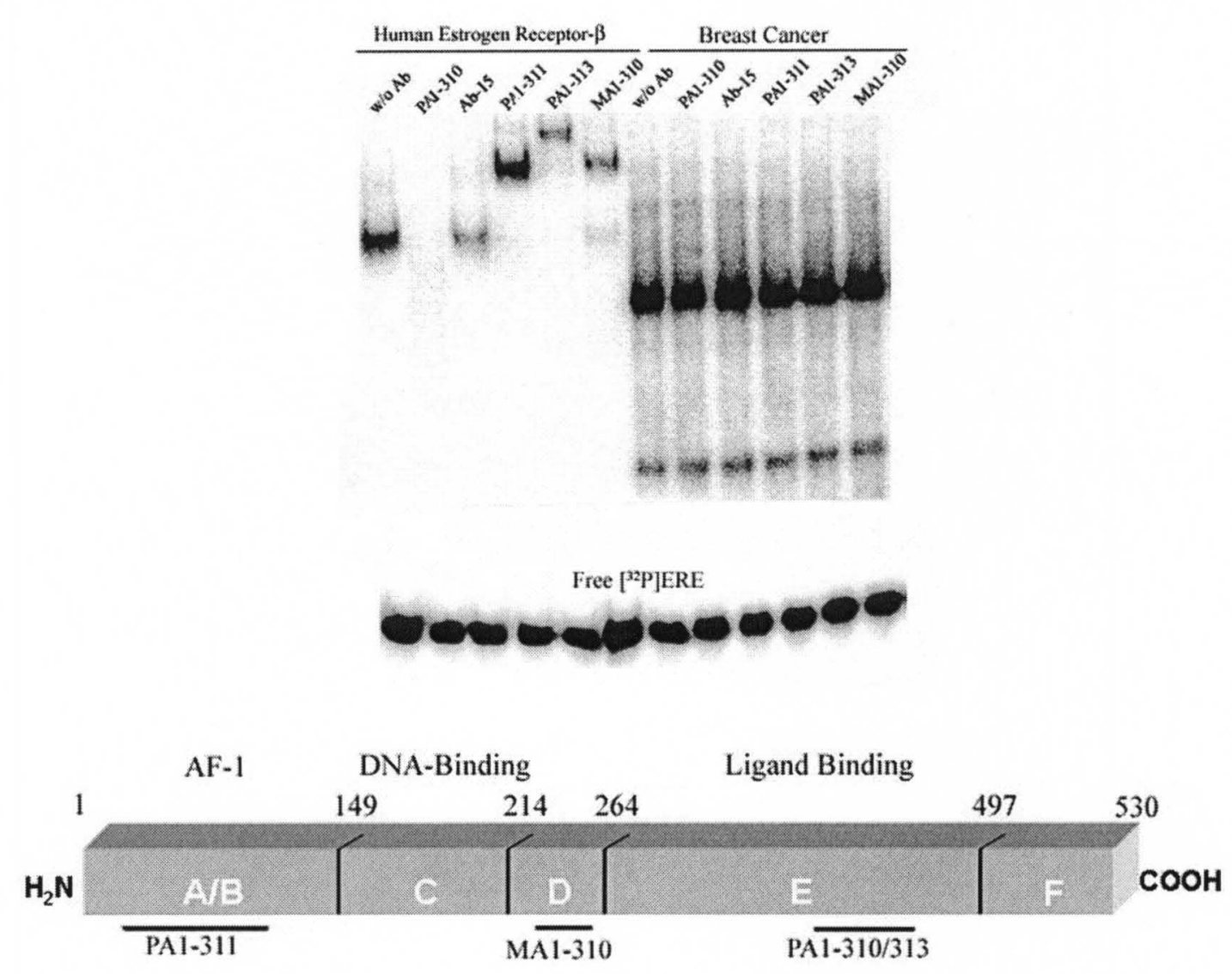

Figure 14. Influence of hER $\beta$ antibodies recognizing different sequence domains on cytosolic ERE-BP assessed by super-shift assay. Recombinant hER $\beta$ (Panvera/Life Technologies) and cytosol from a human breast cancer reference specimen were incubated with hER $\beta$ specific antibodies Ab-15 (Neomarkers/Thermo Fisher), MA1-310, PA1-310, PA1-311 and PA1-313 (Affinity Bioreagents/Thermo Fisher) recognizing epitopes in various domains of hER $\beta$ (e.g. PA1-311/a.a. 55-70, MA1-310/a.a. 247-261, PA1-310/a.a. 467-485, PA1-313/a.a. 467-485). 

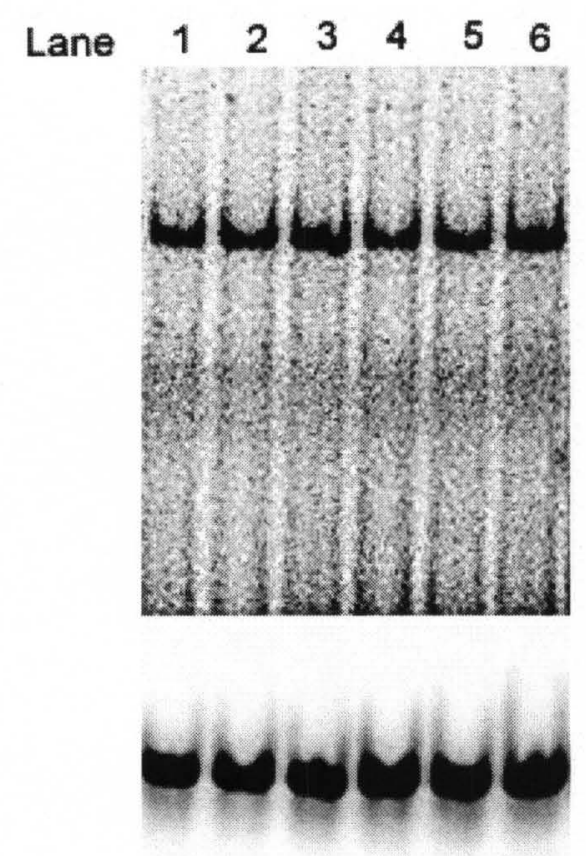

Figure 15. Supershift assay using antibodies to known ERE-binding proteins. Supershift assays were performed on cytosols from a breast cancer reference specimen with antibodies to known ERE-binding proteins. Lane 1 shows the ERE-BP control. Lane 2: hnRNP D (GenWay), Lane 3: hnRNP DL (GenWay), Lane 4: hnRNP C1/C2 (Santa Cruz), Lane 5: ERR $\alpha$ (R\&D Systems), Lane 6: COUP-TF1 (R\&D Systems). 
PAI-310 which may block binding of the receptor to $\left[{ }^{32} \mathrm{P}\right] \mathrm{ERE}$ (Figure 14). Figure 14 also shows that ERE-BP did not supershift in the presence of anti-ER $\beta$ antibodies.

Supershift assay using antibodies to known ERE-binding proteins

To evaluate whether ERE-BP were recognized by antibodies to other known ERE-BP, supershift assays were performed using antibodies prepared against hnRNP D, hnRNP DL, hnRNP C1/C2, ERR $\alpha$ and COUP-TF1 (Figure 15). No supershifts were observed when breast cancer cytosols were incubated with antibodies to either hnRNP D, hnRNP DL, hnRNP C1/C2, ERR $\alpha$ or COUP-TF1 (Figure 15), suggesting that the proteins of interest are not related to members of the hnRNP family or to COUP-TF.

These results suggest that the ERE-binding proteins we have identified are not among the more commonly known ERE-binding proteins. However, supershift assays are not definitive for protein recognition due to the nature of the non-denaturing conditions of EMSA. The native conformation of a protein may leave certain epitopes inaccessible, thereby preventing antibody recognition. Therefore, more definitive results are needed to determine and confirm the identity of these ERE-BP.

\section{ERE-BP and ER $\alpha$ compete for ERE binding}

To ascertain if ERE-BP influence ERE recognition by rhER $\alpha$, competition experiments were performed by incubating increasing quantities of cytosol from both an ERE-BP positive and an ERE-BP negative tissue, with constant concentrations of rhER $\alpha$ and VitA2-ERE (Figure 16A). Band intensities of both the ERE-BP and rhER $\alpha$ proteinDNA complexes were determined by scanning the gel lanes and integrating the areas 


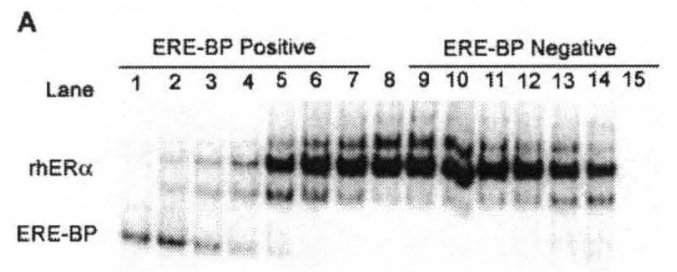

B

Free ERE
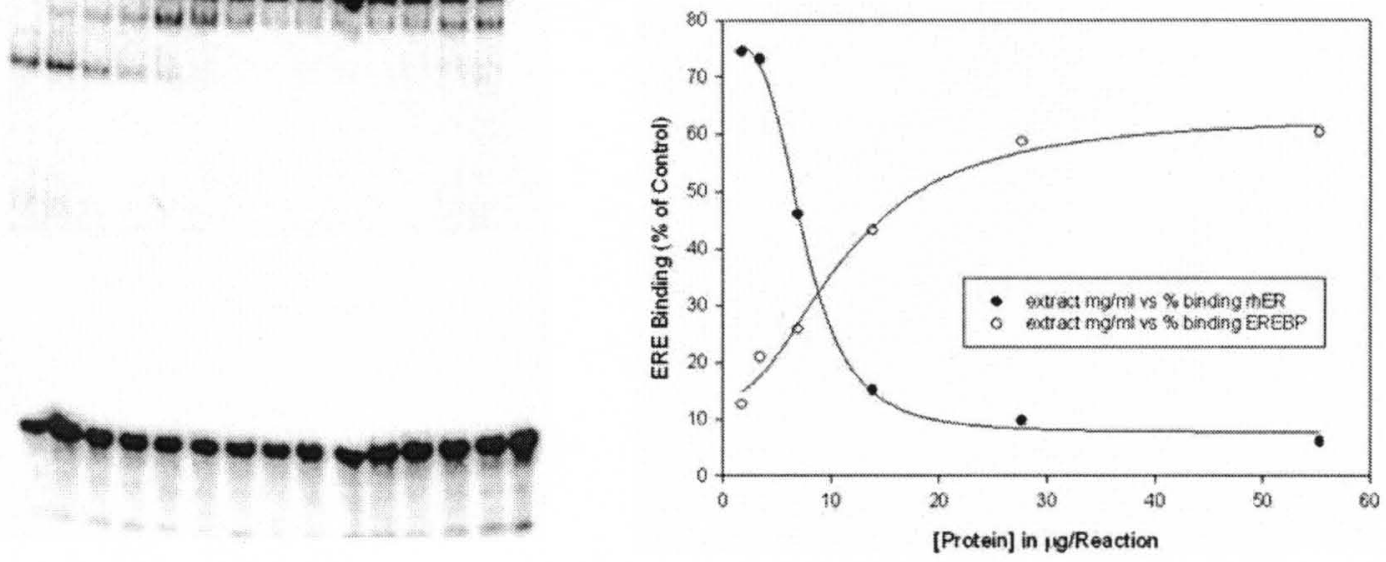

Figure 16. Competition of rhER $\alpha$ recognition of VitA2-ERE by ERE-BP in human breast cancer extracts. Competition experiments were performed by incubating increasing quantities of cytosol from either an ERE-BP positive (Lanes 1-7) or negative extract (Lanes 9-15), holding the concentrations of $\operatorname{rhER} \alpha$ and $\left[{ }^{32} \mathrm{P}\right]$ VitA2-ERE constant (A). Lanes 1 and 15 contained extract only. Lane 8 contained only $\operatorname{rhER} \alpha$. The protein concentration of rhER $\alpha$ in $\mu \mathrm{g} /$ reaction was plotted against ERE-binding expressed as a percent of the rhER $\alpha$ control $(\mathrm{B}, \bullet)$. The binding isotherm for the ERE-BP was plotted similarly $(\mathrm{B}, \mathrm{O})$. 
under the curves for each band, using Optiquant ${ }^{\circledR}$ software. Protein concentration ( $\mu \mathrm{g} /$ reaction) was plotted against ERE-binding as percent of control for either rhER $\alpha$ or ERE-BP, showing an expected sigmoidal dose-response curve (Figure 16B). An ERE-BP positive reference cytosol inhibited $\mathrm{hER} \alpha$ binding to VitA2-ERE in a concentrationdependent manner with simultaneous appearance of the novel ERE-BP. These results confirm that the observed suppression of rhER $a$ binding to ERE results from the presence of ERE-binding proteins, indicated by lack of competition by an ERE-BP negative extract (Figure 16A).

Other studies have reported that an ERE-binding protein can compete with the estrogen receptor for binding to ERE sequences. Kraus et al. reported that ERR $\alpha$ competes with ER $\alpha$ for binding to ERE sequences in MCF-7 breast cancer cells [196]. However, ERRa binding to the ERE alone was not sufficient to mediate transcription. Burbach et al. reported that COUP-TF1 competes with ER $\alpha$ for binding to the ERE and this was sufficient to repress transcription of the oxytocin gene in P19 embryonal carcinoma cells [179]. Furthermore, Chen et al. reported that the ERE-BP discovered in New World primate cells that appear to be related to hnRNPs can also compete with ER $\alpha$ for binding to the ERE and disrupt the ER/ERE interaction [182]. Competition results correlated with the amount of ERE-BP present in the extract.

Sequence binding specificity of ERE-BP

To determine if the sequence binding specificity of ERE-BP were similar to ER $\alpha$, EMSA assays were performed by incubating a human breast cancer cytosol with various 


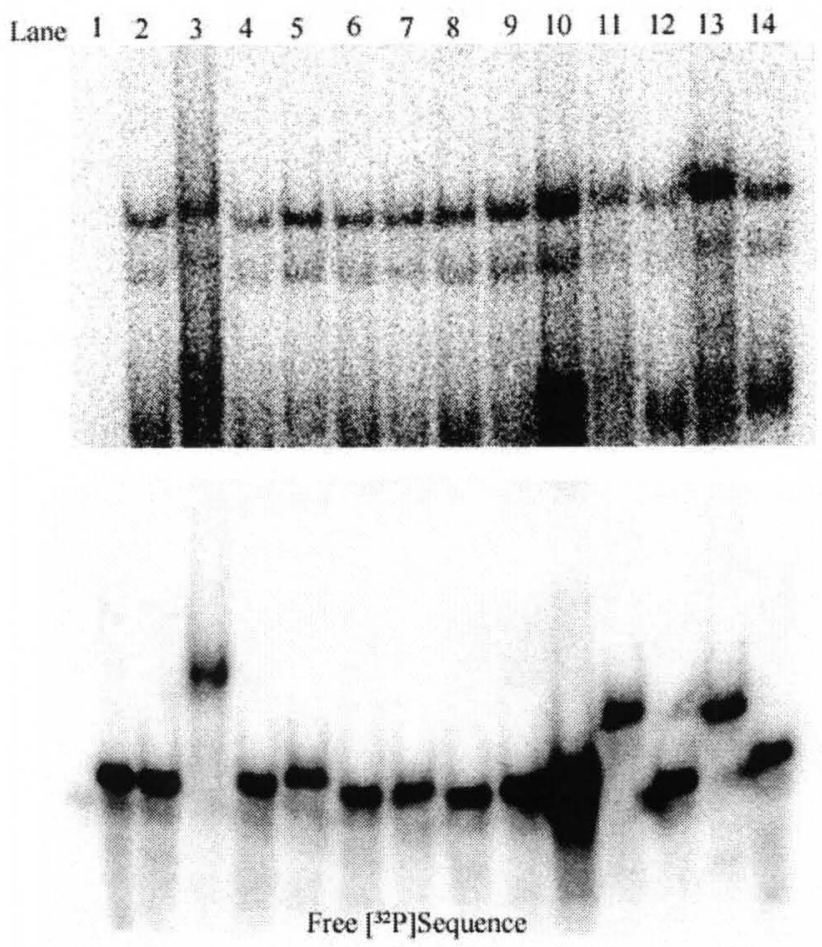

\begin{tabular}{|r|c|}
\hline Lane & Sequence \\
\hline 1 & VitA2- ERE only \\
\hline 2 & VitA2 \\
\hline 3 & Jun \\
\hline 4 & PRE \\
\hline 5 & h-fos \\
\hline 6 & pS2 \\
\hline 7 & Cathepsin D \\
\hline 8 & VitA2 \\
\hline 9 & Prolactin \\
\hline 10 & GRE \\
\hline 11 & PR form b \\
\hline 12 & Scramble 1 \\
\hline 13 & Scramble 2 \\
\hline 14 & VitA2 \\
\hline
\end{tabular}

Figure 17. ERE-BP binding to a variety of hormone response element sequences. EMSA assays were performed by incubating a breast cancer cytosol with various $\left[{ }^{32} \mathrm{P}\right]$ labeled sequences. The HRE sequences tested include those forVitA2, jun, h-fos, pS2, cathepsin D, prolactin and PR form B EREs, as well as the progesterone response element (PRE), the glucocorticoid response element (GRE) and two scrambled polynucleotide sequences. Lane 1 contains the $\left[{ }^{32} \mathrm{P}\right]$ VitA2-ERE only without extract present in the reaction. 
$\left[{ }^{32} \mathrm{P}\right]$ labeled sequences (Figure 17). Those tested include ERE sequences in the VitA2, jun, h-fos, pS2, cathepsin D, prolactin and PR form B genes, as well as the progesterone response element (PRE), the glucocorticoid response element (GRE) and two scrambled sequences. Although the ERE-BP appeared to exhibit different affinities for the wide variety of sequences, the proteins exhibited binding to each sequence tested, including the scrambled sequences. This suggests that the ERE-BP do not bind specifically to ERE sequences and thus may be general DNA binding proteins that may not recognize a specific nucleotide sequence.

To further explore the DNA binding of ERE-BP, competition experiments were performed with unlabeled response element sequences for the VitA2 and pS2 genes as well as with unlabeled thyroid hormone response element (TRE) and a mutant VitA2 (VitA2-mut) sequences (Figure 18). The TRE sequence used was a palindrome (TREpal). Presence of the ERE-BP band after addition of the unlabeled competitor indicates that the protein does not bind to that sequence as tightly as to $\left[{ }^{32} \mathrm{P}\right] \mathrm{VitA} 2$. Upon addition of $125-$ fold molar excess of unlabeled VitA2, pS2 and VitA2-mut sequences, a decrease in the amount of ERE-BP was observed. However, there was no decrease observed with the addition of TREpal, indicating that the ERE-BP did not recognize this sequence. When the same experiment was performed with the rhER $\alpha$ control, a decrease in the amount of $\mathrm{ER} \alpha$ was observed with the addition of unlabelled VitA2, pS2 and TRE, but not with VitA2-mut sequences. These data indicate that ERE-BP and ER $\alpha$ exhibit distinct DNA binding specificities.

Several additional sequences were tested by incubating $\left[{ }^{32} \mathrm{P}\right]$ VitA2-ERE and a breast cancer reference powder cytosolic extract in the presence of 125 -fold molar excess 


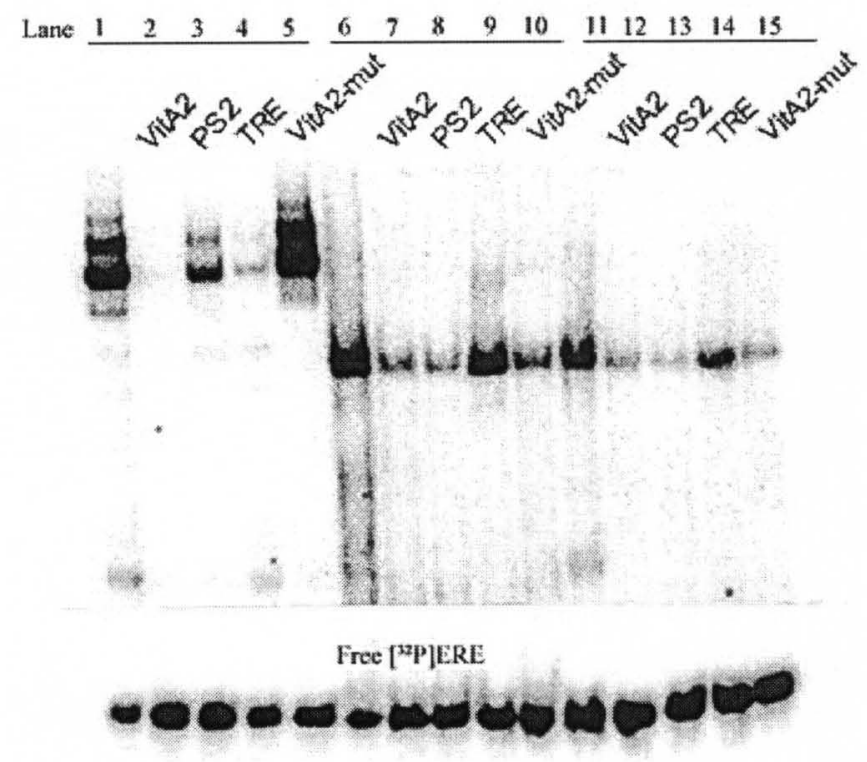

Figure 18. Competition of VitA2-ERE recognition by ERE-BP using various unlabeled response element sequences. rhER $\alpha$ (lanes 1-5), a breast carcinoma extract (lanes 6-10) and an extract of a breast cancer reference specimen (lanes 11-15) were incubated individually with $\left[{ }^{32} \mathrm{P}\right]$ VitA2-ERE and 125 -fold molar excess of unlabeled sequences VitA2, pS2, TRE and a mutant VitA2 (VitA2-mut), then analyzed by EMSA. Presence of the ERE-BP band after addition of the unlabeled competitor indicates that the protein does not bind to that sequence as tightly as to $\left[{ }^{32} \mathrm{P}\right] \mathrm{VitA} 2-\mathrm{ERE}$. 


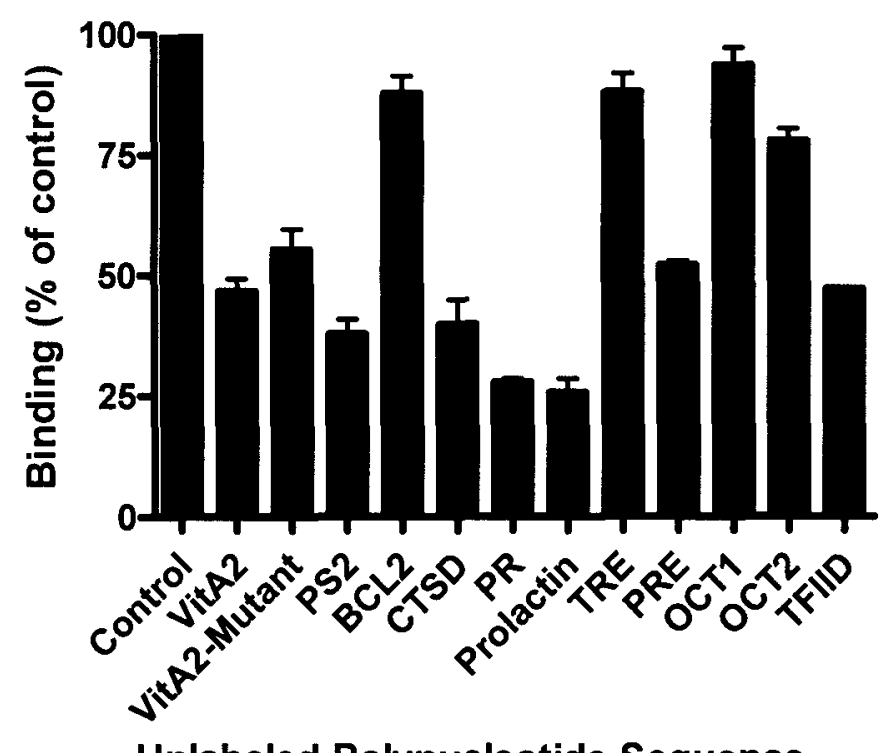

Unlabeled Polynucleotide Sequence

Figure 19. Specificity of ERE-BP binding to VitA2-ERE. Competition analyses were performed using $1 \mathrm{ng}$ of $\left[{ }^{32} \mathrm{P}\right]$ VitA2-ERE and 15 ug of cytosolic protein from a breast cancer reference specimen that was incubated in the presence of 125 -fold molar excess of unlabeled competitor (various response element sequences indicated). The extent of competition is expressed as percent of the control, which was measured is in the absence of an unlabeled polynucleotide sequence. 
of several unlabeled competitor DNA sequences (Figure 19). Results show that the pS2, PR-isoform B and rat prolactin ERE sequences competed to the greatest extent with VitA2. The VitA2 and VitA2-mut sequences only inhibited binding by $50-60 \%$. The TFIID sequence also showed only $50-60 \%$ inhibition of binding. The BCL2 ERE, TREpal and OCT-1 and 2 sequences showed little or no competition in the presence of $\left[{ }^{32} \mathrm{P}\right]$ VitA2-ERE. OCT-1 and 2 are both transcription factors that are members of the POU domain family and bind to sequences unrelated to EREs [197;198]. These results also suggest that the ERE-BP we are investigating appear to have different affinities for various sequences, but do not recognize specifically ERE sequences and as such they appear to be general DNA binding proteins with broad specificity.

Earlier, Gray and Gorski reported that the ERE-BP observed in rat uterine cytosols also were inhibited by VitA2 and mutant VitA2 ERE sequences by $50-60 \%$, which is similar to our results [187]. In their experiments OCT-1 sequences inhibited binding by approximately $10 \%$. This is similar to data observed in this study with breast cancer ERE-BP. However, they showed that the TFIID sequence inhibited binding by 80$90 \%$, while we only observed $50-60 \%$ inhibition of binding by the ERE-BP in breast cancer cytosol. Chen et al. reported that the ERE-BP they identified in New World primate cells was inhibited by $100 \%$ in the presence of a consensus ERE sequence [182]. In this experiment the TREpal sequence did not inhibit binding, which is similar to our results from this study.

There are many classes of DNA-binding proteins (e.g., transcription factors, polymerases, nucleases, DNA repair proteins and histone proteins) beyond those that recognize ERE sequences specifically. Furthermore, several classes of proteins recognize 
particular elements of DNA structure other than the nucleotide sequence (e.g., single or double-strand breaks). Novel DNA-binding proteins identified in this work may belong to one of these classes of proteins and subsequent studies described in Chapter III will address this.

\section{ERE titrations in the presence of therapeutic estrogens}

Both Chen et al. [186] and Gray and Gorski [187] reported that 17ß-estradiol represses ERE-BP binding to the ERE. Chen et al. showed that $1 \mu \mathrm{M}$ estradiol restored the association of ER $\alpha$ with the ERE sequence in MCF-7 cells. They also reported that tamoxifen was able to mimic this response at a concentration of $10 \mathrm{nM}$. Gray and Gorski showed that ERE-BP binding to the ERE decreased in rat uterine cytosols with a single $1.0 \mu \mathrm{g}$ dose of estradiol [187]. For these reasons, we performed ERE titrations in the presence of various estrogens to determine the influence on ERE-binding affinities.

ERE titrations of rhER $\alpha$ and ERE-BP were performed independently in the presence of ethanol or $1 \mu \mathrm{M}$ DES, 4-hydroxytamoxifen, $17 \beta$-estradiol or raloxifene, as shown in Figure 20. As discussed previously, tamoxifen is a SERM that is recognized by the ER ligand binding domain and enhances its DNA-binding activity and 4hydroxytamoxifen is the active metabolite of tamoxifen [60;82]. DES is a synthetic estrogen receptor agonist with extremely high affinity for the ligand binding domain that also enhances the ERE-binding activity of the estrogen receptor. Addition of DES, 4hydroxytamoxifen, $17 \beta$-estradiol or raloxifene resulted in a significant increase in EREbinding by rhER $\alpha$ compared to the ethanol control (Figure 21). The Kd of rhER $\alpha$ binding to the ERE in the presence of $17 \beta$-estradiol was $6.1 \times 10^{-10} \mathrm{M}$. This is similar to 
A
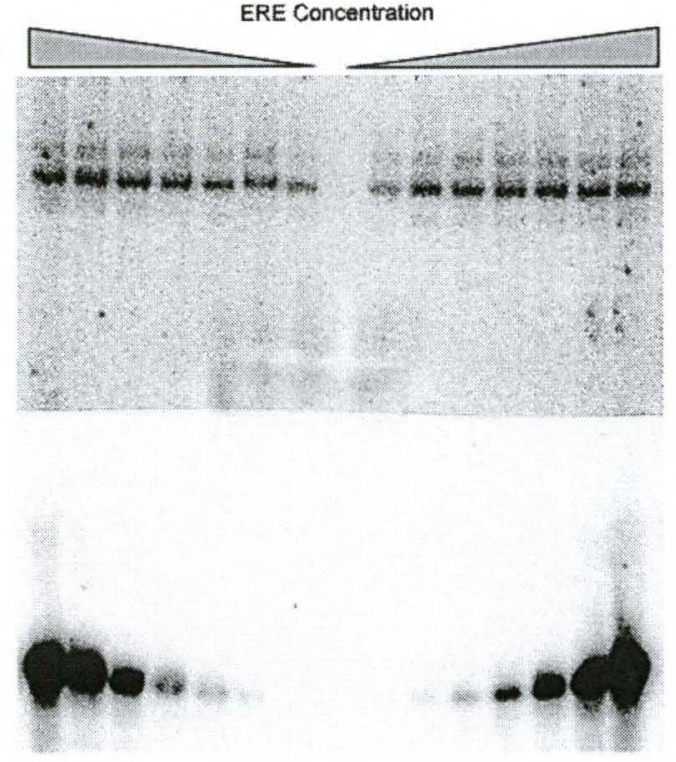

B

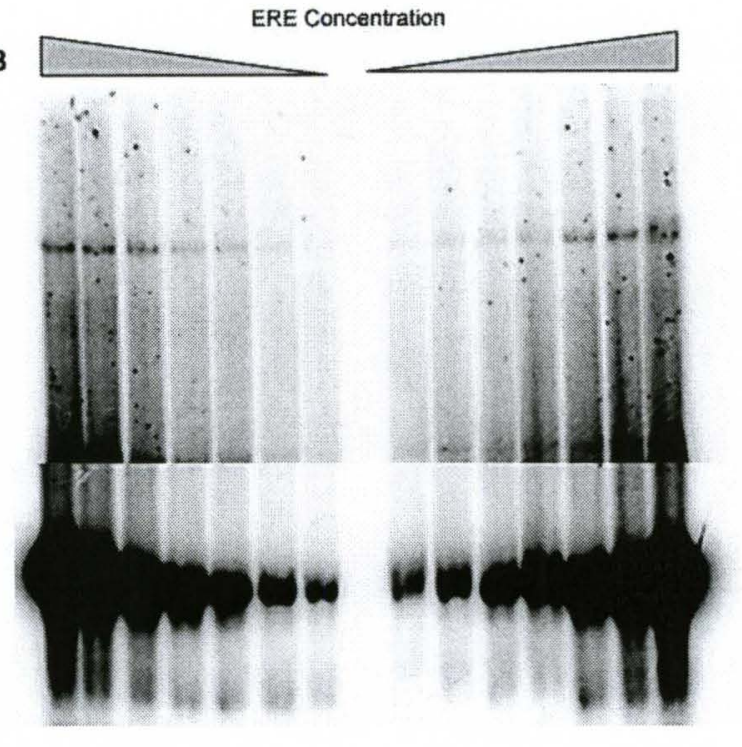

Figure 20. Representative ERE titration of rhER $\alpha$ (A) and ERE-BP (B) in the presence of $1 \mu \mathrm{M}$ diethylstilbestrol. EMSAs were performed as described in Materials and Methods with varying amounts of $\left[{ }^{32} \mathrm{P}\right]$ VitA2-ERE. rhER $\alpha$ was incubated with $1 \mu \mathrm{M}$ diethylstilbesterol (DES) for 30 minutes before the addition of 0.2-14 ng ERE. Cytosol (5 $\mu \mathrm{g}$ total protein) from a breast cancer reference specimen containing ERE-BP was incubated with $1 \mu \mathrm{M}$ diethylstilbesterol (DES) for 30 minutes before the addition of 0.5 37 ng ERE. Gels were scanned and bands quantified using OptiQuant ${ }^{\circledR}$ software as described in Materials and Methods. 


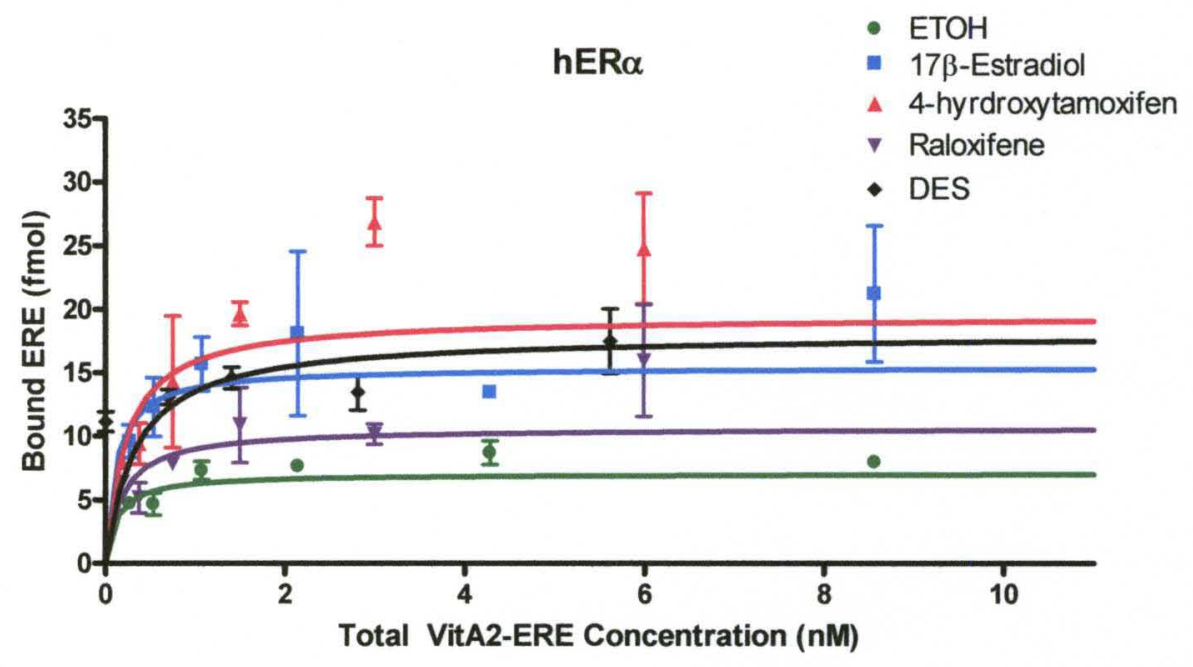

\begin{tabular}{|l|l|l|l|l|l|}
\hline $\begin{array}{l}\text { One site } \\
\text { binding }\end{array}$ & ETOH & E2 & Tmx & Rlx & DES \\
\hline BMAX (fmol) & 8.6 & 20.0 & 29.1 & 14.0 & 17.5 \\
\hline KD (M) & $5.3 \times 10^{-10}$ & $6.1 \times 10^{-10}$ & $1.3 \times 10^{-09}$ & $8.1 \times 10^{-10}$ & $4.8 \times 10^{-10}$ \\
\hline
\end{tabular}

Figure 21. Titration of rhER $\alpha$ with increasing concentrations of $\left[{ }^{32} \mathrm{P}\right]$ VitA2-ERE in the presence of various therapeutic estrogens. Data were modeled using one-site binding

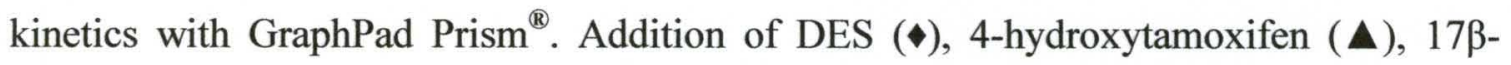
estradiol ( $\mathbf{})$ or raloxifene ( $\boldsymbol{\nabla})$ resulted in a significant increase in ERE-binding compared to that of the ethanol control $(\bullet)$. Means and SD of results from triplicate experiments are plotted. 


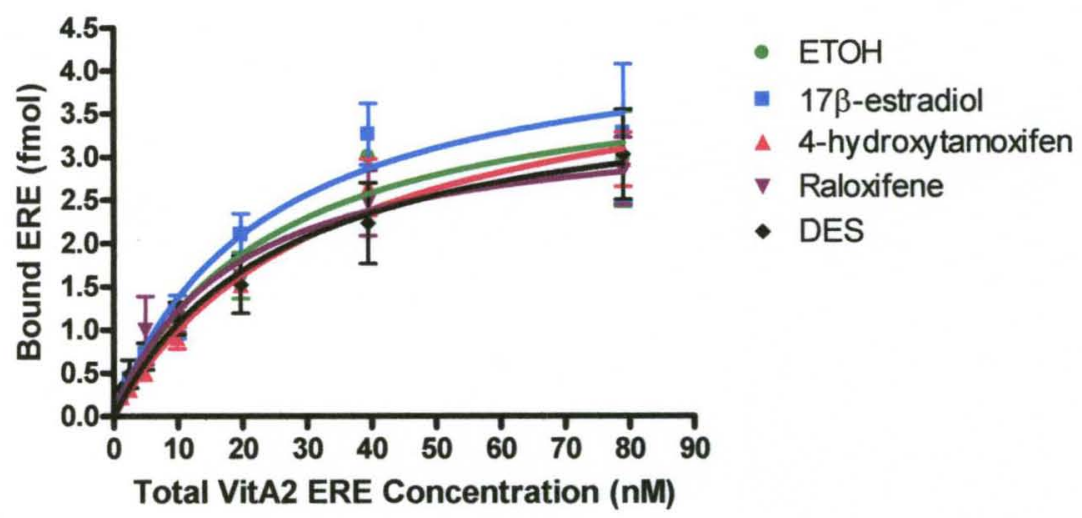

\begin{tabular}{|l|r|r|r|r|r|}
\hline One site binding & \multicolumn{1}{|c|}{ ETOH } & \multicolumn{1}{c|}{ E2 } & \multicolumn{1}{c|}{ TMX } & \multicolumn{1}{c|}{ RLX } & \multicolumn{1}{c|}{ DES } \\
\hline BMAX (fmol) & 4.1 & 4.5 & 4.4 & 3.5 & 3.9 \\
\hline KD (M) & $2.4 \times 10^{-8}$ & $2.3 \times 10^{-8}$ & $3.4 \times 10^{-8}$ & $1.9 \times 10^{-8}$ & $2.7 \times 10^{-8}$ \\
\hline
\end{tabular}

Figure 22. Titration of an ERE-BP preparation from a breast cancer reference specimen with increasing concentrations of $\left[{ }^{32} \mathrm{P}\right] \mathrm{VitA} 2-\mathrm{ERE}$ in the presence of various therapeutic estrogens. Data were modeled using one-site binding kinetics with GraphPad Prism ${ }^{\circledR}$.

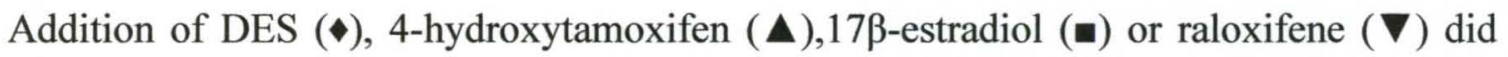
not cause a significant increase in ERE-binding compared to that of the ethanol control $(\bullet)$. Means and SD of results from triplicate experiments are plotted. 
published results of $9.2 \times 10^{-10} \mathrm{M}$ [199]. In the presence of $1 \mu \mathrm{m}$ of either DES, 4hydroxytamoxifen, 17ß-estradiol or raloxifene, the ERE binding capacity of the ERE-BP was not statistically different compared to that of the ethanol control $(\mathrm{p}=0.99)$ (Figure 22). The Kd for ERE-BP binding to the ERE in the control was $2.4 \times 10^{-8} \mathrm{M}$. In studies by Gray and Gorski, ERE-BP bound to the ERE with an apparent Kd of $1.2 \times 10^{-9} \mathrm{M}$ [187]. This is slightly lower than our results. These results suggest that the DNA binding activity of the ERE-BP is not affected by these estrogenic compounds, indicating a lack of a sex steroid ligand binding domain.

\section{Correlation of ERE-BP binding activity and estrogen responsive genes}

If ERE-BP are binding to the ERE and competing with ER $\alpha$ in vivo, it is expected that either up-regulation or down-regulation of estrogen responsive genes would occur. To determine whether ERE-BP binding activities are correlated with expression of estrogen-responsive genes, ERE-BP levels measured by EMSA in cytosols from 124 primary breast carcinoma specimens were compared to expression levels of 16 genes containing ERE sequences. Microarray data were obtained from previous studies from our laboratory in collaboration with Arcturus Applied Genomics. The data were derived from the use of populations of breast carcinoma cells procured by laser capture microdissection (LCM) from 247 primary breast cancer specimens [191;200]. Total RNA was extracted from LCM-procured cells followed by two rounds of amplification and hybridization to custom microarray chips (Agilent Technologies) containing $\sim 22,000$ genes. $\mathrm{Cy} 5 / \mathrm{Cy} 3$ ratios were determined using Universal RNA (Stratagene) as a reference. 
Table 1. Representative genes known to contain ERE sequences that were evaluated in microarray analyses of LCM-procured human breast carcinoma cells.

\begin{tabular}{|l|l|}
\hline Gene Symbol & Gene Name \\
\hline BCL2 & B-cell CLL/lymphoma 2 \\
\hline BRCA1 & Breast cancer 1, early onset \\
\hline C3 & Complement component 3 \\
\hline CTSD & Cathepsin D \\
\hline COX7RP & Cytochrome c oxidase subunit VIIa-related protein \\
\hline ESR2 & Estrogen receptor beta \\
\hline TRIM25 & Tripartite motif-containing 25/ estrogen responsive finger protein \\
\hline LTF & Lactoferrin \\
\hline PGR & Progestrone receptor \\
\hline TFF1 & Trefoil factor 1/pS2 \\
\hline CAXII & Carbonic anhydrase 12 \\
\hline RERG & RAS-like, estrogen-regulated growth inhibitor \\
\hline CD34 & CD34 antigen \\
\hline EDG1 & Endothelial differentiation sphingolipid GPCR 1 \\
\hline NQO1 & NAD(P)H dehydrogenase quinone 1 \\
\hline
\end{tabular}


A list of human genes reported to contain ERE sequences that were analyzed is shown in Table 1. Genes containing ERE sequences were selected from published reports $[88 ; 201 ; 202]$. Pearson correlations were performed to determine if an association exists between the expression level of an individual gene and the level of ERE-BP binding activity; however, no significant correlations were identified (Table 2). The population of specimens was then divided into two groups, those exhibiting low ERE-BP binding exhibited activities and those with high ERE-BP binding activities as determined by the median ERE-BP binding activity. A t-test was then used to determine if there was a significant difference in the expression levels of each gene between the two groups of carcinoma specimens. No significant differences were observed between the groups for any of the genes analyzed (Table 2). These results suggest that the expression of ERE-BP is not correlated with the transcription of these estrogen responsive genes. This confirms other results described in this Chapter indicating these unidentified DNA-binding proteins are not involved ERE-mediated transcription.

\section{Summary and Conclusions}

While investigating ERE-binding properties of ER $\alpha$ in de-identified human breast cancer extracts, proteins with different migration properties that also bind to ERE sequences were observed. In order to unravel the apparent role of these proteins in breast cancer, we initiated characterization studies. Recognition properties of ERE-BP were evaluated by electrophoretic mobility shift (EMSA) with the ERE sequence $\left[{ }^{32} \mathrm{P}\right]$ VitA2. ERE-BP were present in a variety of tissues types including breast, ovarian, uterine and colon cancers and normal tissues indicating that the proteins are ubiquitous. These 
Table 2. Correlation of cytosolic ERE-BP levels with candidate genes containing ERE sequences known to be expressed in breast carcinoma cells.

\begin{tabular}{|l|r|r|l|}
\hline GENE ID & PEARSON CORRELATION & P VALUE & t TEST P VALUE \\
\hline ESR1 & 0.03 & 0.72 & 0.43 \\
\hline BCL2 & -0.01 & 0.95 & 0.98 \\
\hline BRCA1 & 0.02 & 0.86 & 0.21 \\
\hline C3 & 0.01 & 0.91 & 0.59 \\
\hline CTSD & -0.12 & 0.17 & 0.16 \\
\hline COX7RP (COX7A2L) & -0.10 & 0.27 & 0.47 \\
\hline ESR2 & -0.04 & 0.68 & 0.16 \\
\hline TRIM25 (ZNF147) & -0.004 & 0.97 & 0.38 \\
\hline LTF & -0.12 & 0.20 & 0.20 \\
\hline PGR & -0.07 & 0.47 & 0.31 \\
\hline TFF1 (pS2) & -0.01 & 0.94 & 0.88 \\
\hline CAXII & 0.02 & 0.79 & 0.97 \\
\hline RERG & 0.08 & 0.39 & 0.22 \\
\hline CD34 & 0.01 & 0.90 & 0.97 \\
\hline EDG1 & -0.03 & 0.71 & 0.87 \\
\hline NQO1 & -0.04 & 0.65 & 0.42 \\
\hline
\end{tabular}


proteins are present in both the cytoplasm and nucleus although higher activities were detected in the nuclear extracts. Our results indicate that ERE-BP did not supershift with several anti-ER $\alpha$ or ER $\beta$ antibodies recognizing different ER epitopes suggesting that they are not fragments of ERa or ER $\beta$. Additionally, ERE-BP did not supershift with antibodies to the known ERE-binding proteins ERRa, COUP-TF1, hnRNP C1/C2, hnRNP D or the related hnRNP D-like. However, we demonstrated that the ERE-BP compete with rhER $\alpha$ for binding to the VitA2-ERE yet the ERE-BP exhibited significantly different sequence specificity compared to that of human ER $\alpha$. Collectively, our results indicate that the ERE-BP we observed in breast cancer extracts are not specific for the ERE sequences and appear to be general DNA-binding proteins. To further support this conclusion, various estrogens had no effect on the ERE-binding of these proteins in contrast to rhER $\alpha$. Furthermore, the ERE-BP activity levels did not correlate with levels of estrogen responsive genes indicating that ERE-BP do not appear to be involved directly in ER $\alpha$ - or ERE-mediated transcription. The investigations in the next chapter will focus on purification and identification of the ERE-BP we have detected. 


\section{CHAPTER III}

\section{PURIFICATION AND IDENTIFICATION OF DNA-BINDING PROTEINS USING IMMUNO-BASED METHODS AND MASS SPECTROMETRY}

\section{Introduction}

The purpose of this investigation was to purify and identify the candidate ERE-BP discovered in breast cancer biopsies. Results from Chapter II indicated that ERE-BP were present in a variety of tissues types including breast, ovarian, uterine and colon cancers indicating that the protein is ubiquitous. These proteins were also present in both the cytoplasm and nucleus although it was observed to be present at higher concentrations in the nucleus. These proteins do not share sequence homology with either estrogen receptor isoform $\alpha$ or $\beta$, or to the known ERE-binding proteins ERR $\alpha$, COUP-TF1, hnRNP C1/C2, hnRNP D or the related hnRNP D-like. Although the ERE-BP competed with rhER $\alpha$ for binding to the VitA2-ERE, these proteins exhibited significantly different sequence specificity compared to that of human ER $\alpha$. Our results suggested that the observed ERE-BP do not specifically recognize the ERE and appear to be DNA-binding proteins with broad specificity.

To further support our hypothesis, the presence of various estrogens had little effect on the ERE-binding of these proteins in contrast to the properties of rhER $\alpha$. Furthermore, the ERE-BP activity levels in breast carcinomas did not correlate with 
levels of estrogen responsive genes indicating that ERE-BP in breast carcinoma preparations are not influencing ER $\alpha$-mediated transcription. The investigations of this chapter focus on purification and identification of the observed ERE-BP using immunobased methods and mass spectrometry. Additional immuno-based methods such as western blots and supershift assays were used for confirmation of the mass spectrometry results.

\section{Methods and Materials}

Preparation of nuclear extracts

Reference powders of human breast and uterine carcinomas were homogenized using a Polytron PT 10-35 in 10 mM HEPES buffer, pH 7.9 containing $10 \mathrm{mM} \mathrm{KCl}, 0.1 \mathrm{mM}$ EDTA, $1 \mathrm{mM}$ DTT, $0.5 \mathrm{mM}$ PMSF, and $0.01 \mu \mathrm{g} / \mu \mathrm{l}$ aprotinin, leupeptin and pepstatin A. Lysates were centrifuged at $4^{\circ} \mathrm{C}$ at $15,000 \mathrm{x}$ g for 10 minutes. The nuclear pellet was resuspended in $20 \mathrm{mM}$ HEPES buffer, pH 7.9 containing $0.4 \mathrm{M} \mathrm{NaCl}, 1 \mathrm{mM}$ EDTA, $10 \%$ glycerol, $1 \mathrm{mM}$ DTT, $0.5 \mathrm{mM}$ PMSF, and $0.01 \mu \mathrm{g} / \mu \mathrm{l}$ aprotinin, leupeptin and pepstatin A. The resuspended pellets were mixed at $4^{\circ} \mathrm{C}$ for 2 hours and centrifuged $4^{\circ} \mathrm{C}, 15,000 \mathrm{x}$ g for 10 minutes. Nuclear extracts were concentrated and desalted with Amicon Ultra YM-10 columns (Millipore). To enrich the extracts for ERE-BP, the twelve most abundant plasma proteins were depleted using a Seppro ${ }^{\mathrm{TM}}$ MIXED12 Kit (GenWay Biotech) according to the manufacturer's protocol [203]. 


\section{Purification of ERE-BP}

Depleted nuclear extracts $\left(800 \mu \mathrm{g}\right.$ of total protein) were incubated overnight at $4^{\circ} \mathrm{C}$ with 300 pmol of either a biotinylated or unlabeled ERE sequence in $20 \mathrm{mM}$ HEPES buffer, pH 7.9 containing $800 \mathrm{ng}$ of poly (dI-dC) (Amersham), $10 \mathrm{mM} \mathrm{KCl}$ and $1 \%$ glycerol. Sequences used are shown in Table 8 (See Appendix). Candidate ERE-BP/ERE complexes were then incubated with $300 \mu$ of NeutrAvidin agarose beads (Pierce) for 4 hours at $4^{\circ} \mathrm{C}$ with constant rotation. These beads were chosen over streptavidin beads because they exhibit lower non-specific binding. Beads were washed three times in 20 mM HEPES pH 7.9 containing $10 \mathrm{mM} \mathrm{KCl}$ and $1 \%$ glycerol and three times in $20 \mathrm{mM}$ HEPES buffer, pH 7.9 containing $0.2 \mathrm{M} \mathrm{KCl}$. Bound proteins were eluted in $20 \mathrm{mM}$ HEPES buffer, pH 7.9 containing $1.0 \mathrm{M} \mathrm{KCl}$. Elution and wash fractions were desalted and concentrated with Amicon Ultra YM-10 columns (Millipore). Four separate experiments were performed using the same protocol and fractions were pooled to insure sufficient total protein for detection by mass spectrometery. A flow diagram showing the method of purification is shown in Figure 23.

\section{Mass spectrometry}

Fractions containing the candidate proteins eluted from the imunobeads were analyzed by tandem liquid chromatography and mass spectrometry (2D-LC-MS/MS) [204]. Spectra were obtained with an LTQ ion trap mass spectrometer (Thermo Fisher Scientific). Scaffold software (version Scaffold_3_00_08, Proteome Software) was used to analyze the results from 2D-LC-MS/MS for protein identifications. Protein identifications were 


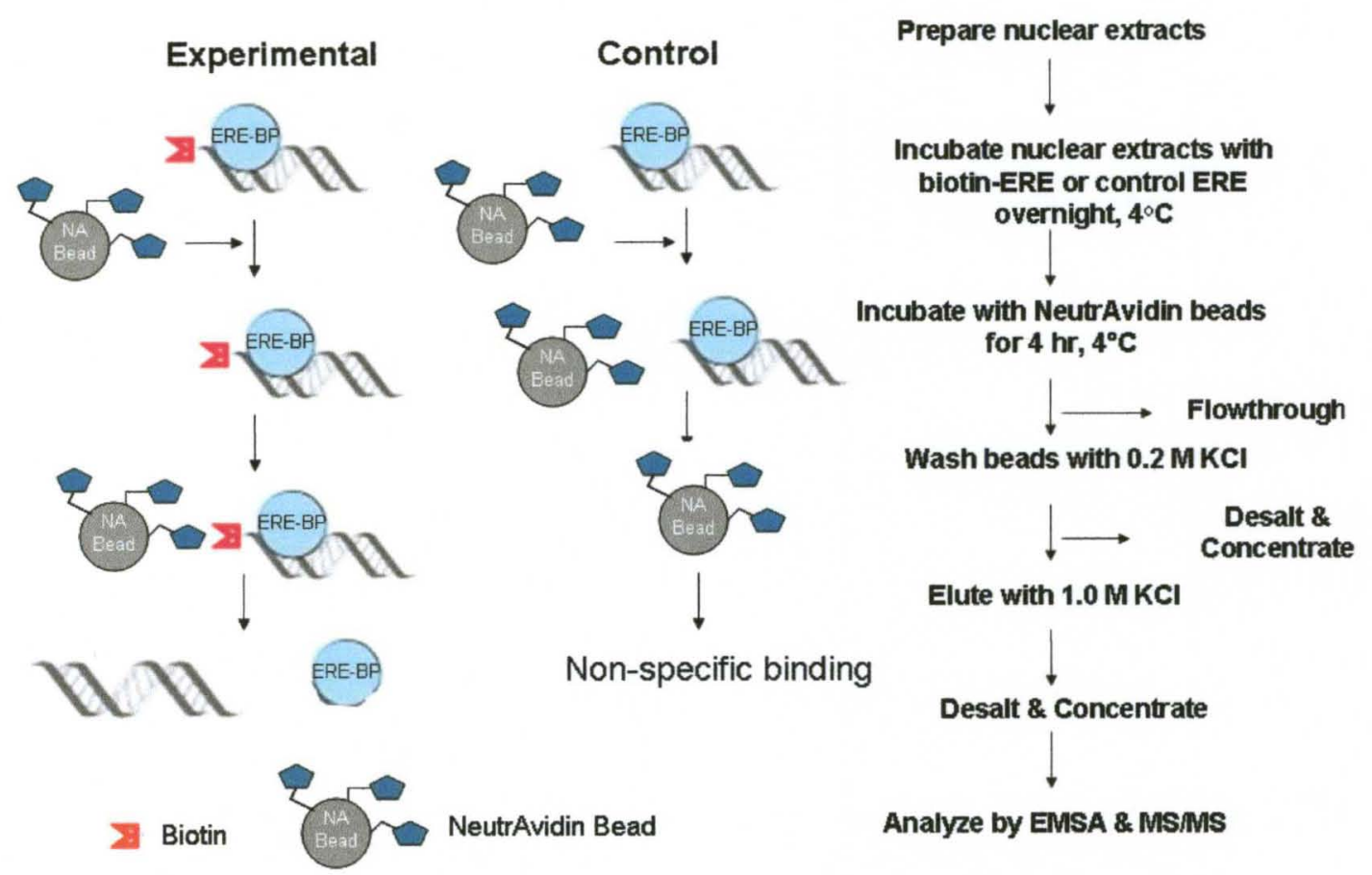

Figure 23. Method for purification of candidate ERE-BP. Nuclear extracts were concentrated and desalted with Amicon Ultra YM-10 columns. The twelve most abundant plasma proteins were depleted using a Seppro ${ }^{\mathrm{TM}}$ MIXED12 Kit (GenWay Biotech). Depleted nuclear extracts (800 $\mu$ g of total protein) were incubated overnight at $4^{\circ} \mathrm{C}$ with either 300 pmol of a biotinylated or unlabeled ERE sequence in $20 \mathrm{mM}$ HEPES buffer $\mathrm{pH} 7.9$ containing $800 \mathrm{ng}$ of poly (dI-dC) (Amersham), $10 \mathrm{mM} \mathrm{KCl}$ and $1 \%$ glycerol. Candidate ERE-BP/ERE complexes were then incubated with $300 \mu \mathrm{l}$ of NeutrAvidin agarose beads (Pierce) for 4 hours at $4^{\circ} \mathrm{C}$ with constant rotation. Beads were washed three times in $20 \mathrm{mM}$ HEPES buffer, $\mathrm{pH} 7.9$ containing $10 \mathrm{mM} \mathrm{KCl}$ and $1 \%$ glycerol and three times in $20 \mathrm{mM}$ HEPES buffer, $\mathrm{pH} 7.9$ containing $0.2 \mathrm{M} \mathrm{KCl}$. Bound proteins were eluted in $20 \mathrm{mM}$ HEPES pH 7.9 containing $1.0 \mathrm{M} \mathrm{KCl}$. Elution and wash fractions were desalted and concentrated with Amicon Ultra YM-10 columns (Millipore). All fractions were analyzed by EMSA and elutions were analyzed by mass spectrometry. 
accepted at a probability of greater than $99.9 \%$ that contained at least two identified peptides. Peptide identifications were accepted at a probability of greater than $95.0 \%$.

\section{UV crosslinking}

Reactions with protein extracts and $\left[{ }^{32} \mathrm{P}\right]$ VitA2-ERE were prepared as described above for EMSAs and UV crosslinked on ice at $1500 \mathrm{~J} / \mathrm{cm}^{2}$ for 30 minutes. Samples were separated on an $8 \%$ SDS-PAGE gel, dried, exposed to phosphor screens overnight and

analyzed with OptiQuant ${ }^{\circledR}$ software. Migration of each $\left[{ }^{32} \mathrm{P}\right]$ ERE-protein complex band was measured with OptiQuant ${ }^{\circledR}$ software and molecular weights of detected bands were extrapolated using protein molecular weight standards (EZ-RunTM Pre-Stained Rec Protein Ladder, ThermoFisher).

\section{Western blot analysis}

Proteins were separated by $10 \%$ SDS-PAGE and transferred to a nitrocellulose membrane (Bio-Rad). Membranes were blocked with 5\% nonfat dry milk overnight. The primary antibodies utilized in these experiments were Ku70 (D35, polyclonal, Cell Signaling), Ku70 (Ab-4, monoclonal, Thermo Fisher Scientific), Ku80 (Ab-2, monoclonal, Thermo Fisher Scientific), Ku80 (C48E7, monoclonal, Cell Signaling) and $\beta$-actin (polyclonal, Cell Signaling). All primary antibodies were used at a 1:2000 dilution. The secondary antibodies used were HRP-goat anti-rabbit and HRP-goat antimouse (Zymed/Life Technologies). Secondary antibodies were used at a dilution of 1:5000. Blots were visualized with Immobilon Western Chemiluminescent HRP substrate (Millipore) using the protocols supplied by the manufacturer. 


\section{Supershift assay}

Protein extracts were incubated with 50 ng non-specific DNA, poly (dI-dC) (Amersham), $10 \mathrm{mM} \mathrm{KCl}, 1 \%$ glycerol and $\left[{ }^{32} \mathrm{P}\right]$ labeled ERE sequences in $40 \mathrm{mM}$ Tris- $\mathrm{HCl}$ buffer, $\mathrm{pH}$ 8.0, containing $500 \mu \mathrm{M}$ PMSF and $10 \mu \mathrm{M}$ monothioglycerol overnight at $4^{\circ} \mathrm{C}$. Antibodies were added to the reaction and incubated for 30 minutes before addition of $\left[{ }^{32} \mathrm{P}\right] \mathrm{ERE}$. The antibodies used included hnRNP D (polyclonal, GenWay Biotech), hnRNP D (T-10, polyclonal, Santa Cruz), hnRNP DL (polyclonal, GenWay Biotech), hnRNP C1/C2 (4F4, monoclonal, Santa Cruz), ERR $\alpha$ (monoclonal, R\&D Systems), COUP-TF1 (monoclonal, R\&D Systems), Ku70/Ku80 (3F247, monoclonal Santa Cruz), Ku70/80 (Ab-3, monoclonal, Thermo Fisher Scientific), Ku80 (Ab-2, monoclonal, Thermo Fisher Scientific), Ku80 (C48E7, monoclonal, Cell Signaling), phospho-ATM (D6H9, monoclonal, Cell Signaling), phospho-BRCA1 (Ser 1524, polyclonal, Cell Signaling), DNA-PK (polyclonal, Cell Signaling), Mre11 (31H4, monoclonal, Cell Signaling), phospho-p95/NBS1 (Ser343, polyclonal, Cell Signaling), Rad50 (polyclonal, Cell Signaling), Rad52 (polyclonal, Cell Signaling), XLF (polyclonal, Cell Signaling). Normal mouse and rabbit IgG (Santa Cruz) were used as controls.

Reactions were separated by $5 \%$ polyacrylamide gel electrophoresis. The gel was pre-run for 30 minutes at $150 \mathrm{~V}$ at $4^{\circ} \mathrm{C}$ in $0.5 \times$ TBE buffer $(1 \mathrm{M}$ Tris- $\mathrm{HCl}, \mathrm{pH} 8.6$, containing $831 \mathrm{mM}$ boric acid, $10 \mathrm{mM}$ EDTA). Samples were then loaded, followed by electrophoresis at $300 \mathrm{~V}$ for 5 minutes, and then $180 \mathrm{~V}$ for 4 hours. Subsequently, gels were dried and exposed to phosphor screens (Perkin Elmer) overnight. The bands recognizing $\left[{ }^{32} \mathrm{P}\right]$ ERE-protein complexes and free $\left[{ }^{32} \mathrm{P}\right] \mathrm{ERE}$ were visualized and 
quantified using a Cyclone Storage Phosphor System $^{\mathrm{TM}}$ with OptiQuant ${ }^{(\mathbb{B}}$ software (Perkin Elmer) as described in Chapter II.

\section{Results and Discussion}

\section{Removal of high abundant proteins from nuclear extracts}

To determine the identity of the ERE-BP present in breast cancer extracts, a method of purification was established. In order to enrich the extracts for candidate ERE$\mathrm{BP}$, the twelve most abundant plasma proteins were depleted from the samples. These include serum albumin, IgG, fibrinogen, transferring, IgA, IgM, HDL, haptoglobin, $\alpha 1$ antitrypsin, $\alpha 1$-acid glycoprotein and $\alpha 2$-macroglobulin. Removing these proteins has been shown to increase yield for protein detection assays [203;205]. Nuclear extracts made from a uterine cancer reference powder $(\mathrm{NE})$ and a separate preparation of the same NE that was depleted of the high abundant proteins (NE-HAP) as described in Materials and Methods were analyzed by EMSA, which showed that the ERE-BP were present in a higher concentration in the plasma protein depleted samples (Figure 24A). The untreated $\mathrm{NE}$, the NE depleted of high abundant proteins (NE-HAP) and the fractions eluted from the immunobead that contained the high abundant proteins (HAP) were analyzed by $10 \%$ SDS-PAGE. The proteins on the gel were stained with SYPRO $^{\mathrm{TM}}$ Ruby protein stain (Figure 24B). Results demonstrate that the majority of the high abundant proteins were removed from the nuclear extract and there was enrichment for the ERE-BP in the resulting preparation. 


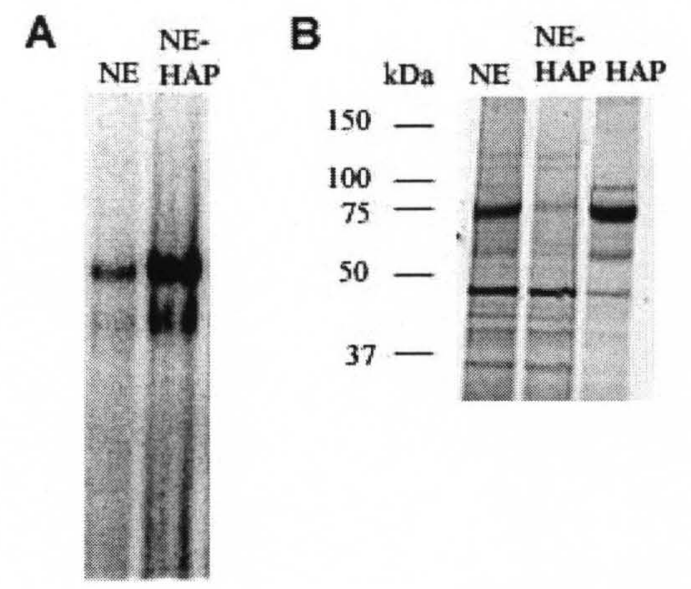

Figure 24. Removal of high abundant proteins from nuclear extracts of a uterine cancer reference powder. (A) A representative nuclear extract made from a uterine cancer reference powder (NE) and a separate preparation of the same NE that was depleted of the high abundant proteins (NE-HAP) as described in Materials and Methods were analyzed by EMSA. Equal amounts of protein were added in each lane. (B) The untreated $\mathrm{NE}$, the NE depleted of high abundant proteins (NE-HAP) and the fractions eluted from the immunobead that contained the high abundant proteins (HAP) were analyzed by $10 \%$ SDS-PAGE. The proteins on the gel were stained with SYPRO ${ }^{\mathrm{TM}}$ Ruby protein stain and EZ-Run ${ }^{\mathrm{TM}}$ pre-stained Rec protein ladder (Thermo-Fisher) was used as molecular weight markers. 
Influence of various biotinylated DNA sequences on the "pull-down" of candidate EREBP from nuclear extracts

To determine the optimal DNA sequences that could be used for purification of ERE-BP and which could be used as negative controls, candidate ERE-BP were purified from nuclear extracts using NeutrAvidin beads and various biotinylated DNA sequences. VitA2, a hairpin VitA2, pS2 and PR form b ERE sequences were tested. After the pulldown reaction, the proteins eluted from these sequences were analyzed by EMSA (Figure 3). Each of these sequences was able to pull-down ERE-BP from nuclear extracts. Our previous results showed that a palindromic TRE sequence showed the least amount of competition in the presence of VitA2-ERE (Figure 19, Chapter II), therefore both a palindromic and direct repeat TRE oligonucleotide were tested as negative controls. EMSA analysis shows that both of these sequences were also able to pull down ERE-BP from nuclear extracts, therefore are unsuitable as negative controls (Figure 25). Using EMSA we previously illustrated that the ERE-BP also bound to multiple DNA oligonucleotides that did not contain ERE sequences (Figure 17, Chapter II). The results shown in Figure 25 confirm our previous data suggesting the ERE-BP may be general DNA-binding proteins and are not specifically recognizing the ERE sequences.

\section{Purification of ERE-BP for analysis by mass spectrometry}

In order to determine the identity of these proteins by mass spectrometry, candidate ERE-BP were purified from nuclear extracts prepared from a uterine cancer reference powder using the VitA2-ERE as described above. A uterine cancer reference powder was chosen over breast in order to ensure the highest concentration of ERE-BP 


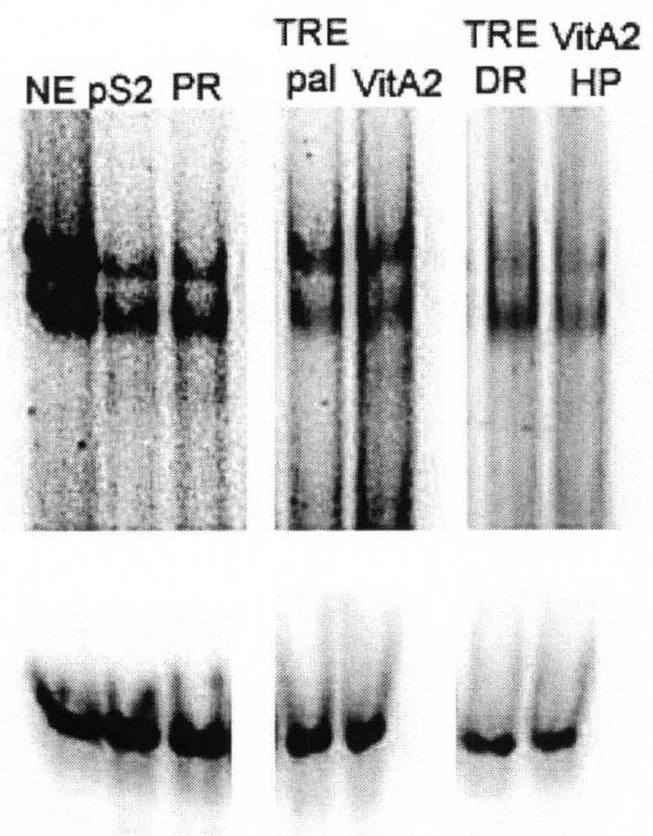

Figure 25. Influence of various biotinylated DNA sequences on the "pull-down" of candidate ERE-BP from nuclear extracts. ERE-BP were purified from nuclear extracts using NeutrAvidin beads and biotinylated DNA sequences as described in Materials and Methods. Sequences were evaluated for ERE-BP recognition and analyzed by EMSA to determine which may be useful for purification. VitA2, a hairpin VitA2 (VitA2 HP), pS2, PR form b (PR) ERE sequences were tested, as well as both a palindromic (TREpal) and direct repeat TRE (TRE DR) sequence. A nuclear extract prepared from a uterine cancer reference specimen is shown as a control (NE). 
possible in the starting material, as illustrated by comparing EMSA profiles from different extracts. High abundant proteins were depleted from these nuclear extracts which were then incubated with either a biotinylated or unlabeled VitA2-ERE, followed by incubation with NeutrAvidin agarose beads. Without DNA biotinylation, the NeutrAvidin agarose beads do not exhibit specific binding to the protein-DNA complex, allowing only proteins non-specifically bound to the beads to be pulled down. Therefore, unbiotinylated VitA2-ERE was used as a negative control. Fractions from each purification step were analyzed by EMSA and results are shown in Figure 26A.

Nuclear extracts exhibiting the presence of ERE-BP in the starting material is shown in Lane 1. Lane 2 showed the increased amounts of ERE-BP in nuclear extracts after removal of the high abundant proteins. These results confirm previous results that removal of the high abundant proteins enriches for the ERE-BP. Proteins which were not bound to the ERE-NeutrAvidin bead complex (flow-through) are shown in Lanes 3 (control) and 4 (biotinylated VitA2). The fractions resulting from the wash steps are shown in Lanes 5 (control) and 6 (biotinylated VitA2). Proteins that were eluted from the ERE-NeutrAvidin bead complex are shown in Lanes 7 (control) and 8 (biotinylated VitA2). ERE-BP were eluted from the biotinylated VitA2-ERE but not the control unlabeled ERE. The control and experimental elution fractions were separated by SDSPAGE electrophoresis and the gels were stained with SYPRO ${ }^{\mathrm{TM}}$ Ruby protein stain to determine the number and relative amount of protein bands present (Figure 26B). The control elution did not contain as many proteins as the labeled VitA2 elution and there 

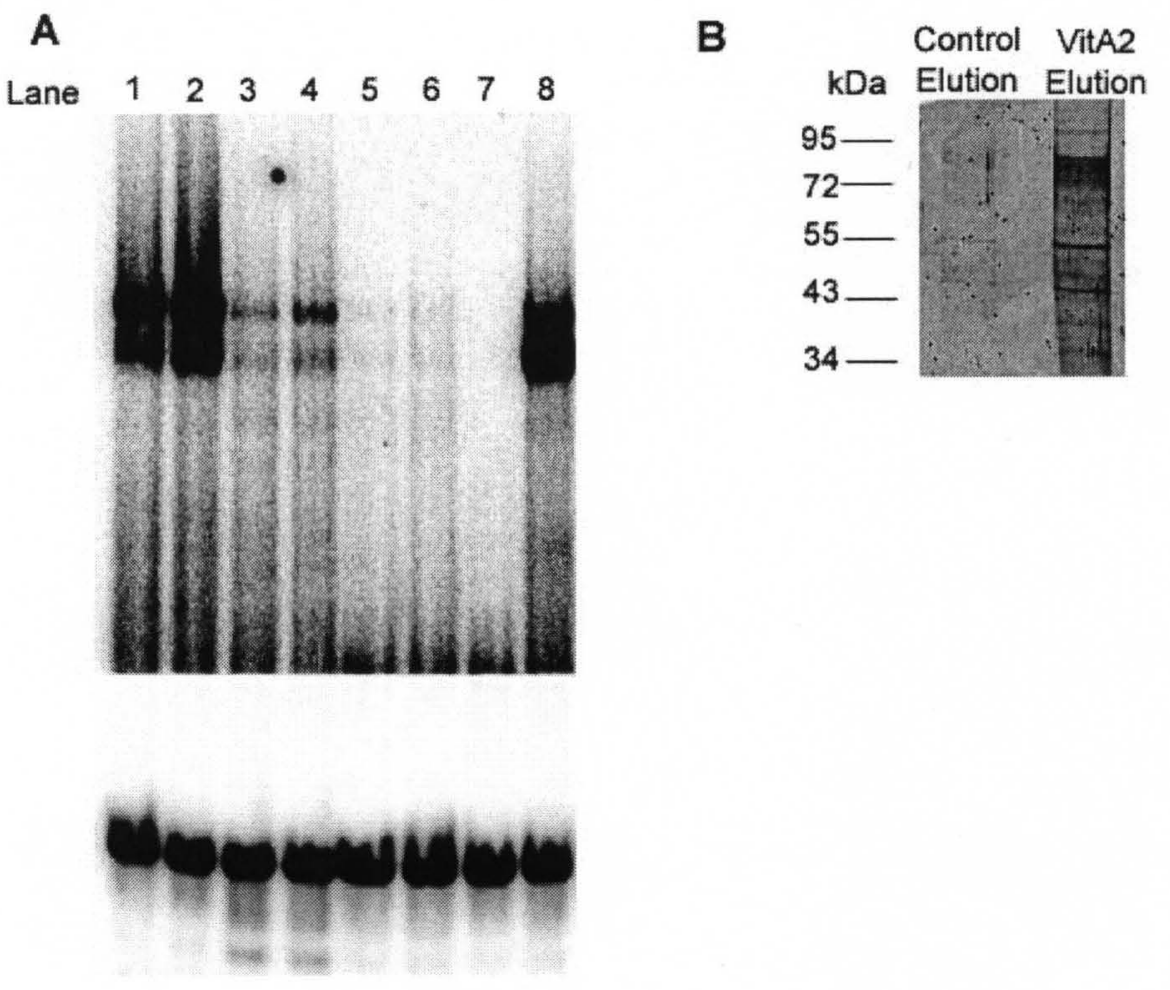

Figure 26. Purification of ERE-BP for analysis by mass spectrometry. (A) Fractions from each step of the purification process were analyzed by EMSA. Nuclear extract from a uterine cancer reference powder showing the presence of ERE-BP in the starting material is shown in Lane 1. Lane 2 shows the increased amounts of ERE-BP in nuclear extracts after removal of the high abundant proteins. Proteins which were not bound to the ERENeutrAvidin bead complex (flow-through) are shown in Lanes 3 (control) and 4 (VitA2ERE). The fractions resulting from the wash steps are shown in Lanes 5 (control) and 6 (VitA2-ERE). Proteins identified as ERE-BP that were eluted from the ERE-NeutrAvidin bead complex are shown in Lanes 7 (control) and 8 (VitA2-ERE). (B) A SYPRO ${ }^{\mathrm{TM}}$ Ruby protein stain was reacted with proteins in the control and experimental elutions to determine the number and amount of proteins present. 
appeared to be a sufficient amount of the purified proteins to be analyzed by mass spectrometry.

\section{Identification of candidate ERE-BP by mass spectrometry}

Proteins eluted from the control VitA2-ERE and the biotinylated VitA2, the hairpin VitA2 and the BCL2 ERE were analyzed by mass spectrometry in three separate experiments as described in Methods and Materials. Table 3 shows a list of the proteins identified. Scaffold software was used to analyze the protein identifications and the spectral count for each protein is shown. The spectral count is the count given to an identified peptide spectra. Scaffold normalizes these counts across samples by taking the average and then multiplying by the average divided by the individual sample's sum.

Although twenty seven proteins were identified using this approach [204], only 8 were identified that were present in at least one labeled ERE elution and not the control: pyruvate kinase isozymes M1/M2 isoform M2 (PKM2), X-ray repair crosscomplementing protein $5(\mathrm{XRCC} 5 / \mathrm{Ku} 80)$, X-ray repair cross-complementing protein 6 (XRCC6/Ku70), heterogeneous nuclear ribonucleoprotein D-like (HNRPDL), $\alpha$-actinin 4 (ACTN4), high mobility group protein B1 (HMGB1), periostin isoform 1 (POSTN) and protein disulfide isomerase $\mathrm{A} 3$ (PDIA3).

PKM2 is a pyruvate kinase that catalyzes the transfer of a phosphoryl group from phosphoenolpyruvate to ADP during glycolysis, generating ATP and pyruvate [206]. PKM2 also interacts with the DNA-binding domain of the transcription factor Oct-4 to regulate transcription [207]. Ku70 and Ku80 form a heterodimer and make up the DNAbinding subunits of DNA-dependent protein kinase (DNA-PK), which is involved DNA 
Table 3. List of proteins in the final purified sample that were identified by mass spectrometry.

\begin{tabular}{|l|l|l|l|l|l|l|l|}
\hline \multicolumn{1}{|c|}{ Identified Proteins } & $\begin{array}{c}\text { MW } \\
(\mathbf{k D a})\end{array}$ & BCL2 & Cont. 1 & $\begin{array}{c}\text { HP } \\
\text { VitA2 }\end{array}$ & Cont. 2 & VitA2 & Cont. 3 \\
\hline pescadillo homolog & 68 & 2 & 2 & 12 & 11 & 0 & 0 \\
\hline $\begin{array}{l}\text { chromodomain-helicase- } \\
\text { DNA-binding protein 3 } \\
\text { isoform 2 }\end{array}$ & 223 & 1 & 2 & 2 & 4 & 0 & 0 \\
\hline titin isoform N2-A & 3713 & 1 & 1 & 2 & 0 & 0 & 0 \\
\hline $\begin{array}{l}\text { chromodomain-helicase- } \\
\text { DNA-binding protein 5 }\end{array}$ & 223 & 1 & 2 & 2 & 4 & 0 & 0 \\
\hline $\begin{array}{l}\text { glycine-,glutamate-, } \\
\text { thienylcyclohexylpiperidine- } \\
\text { binding protein }\end{array}$ & 104 & 1 & 1 & 0 & 0 & 0 & 0 \\
\hline $\begin{array}{l}\text { lactotransferrin isoform 2 } \\
\text { pyruvate kinase isozymes } \\
\text { M1/M2 isoform M2 }\end{array}$ & 73 & 3 & 2 & 0 & 0 & 0 & 0 \\
\hline $\begin{array}{l}\text { dentin sialophosphoprotein } \\
\text { preproprotein }\end{array}$ & 131 & 0 & 2 & 0 & 4 & 0 & 0 \\
\hline $\begin{array}{l}\text { X-ray repair cross- } \\
\text { complementing protein 5 }\end{array}$ & 83 & 3 & 0 & 2 & 0 & 0 & 0 \\
\hline $\begin{array}{l}\text { zinc finger protein 37 } \\
\text { homolog }\end{array}$ & 71 & 0 & 0 & 2 & 7 & 0 & 0 \\
\hline histone H1.2 & 21 & 1 & 2 & 0 & 0 & 0 & 0 \\
\hline $\begin{array}{l}\text { Heterogeneous nuclear } \\
\text { ribonucleoproteins C1/C2 } \\
\text { isoform a }\end{array}$ & 34 & 1 & 1 & 0 & 0 & 0 & 0 \\
\hline tropomyosin alpha-1 chain \\
isoform 5
\end{tabular}




\begin{tabular}{|l|l|l|l|l|l|l|l|}
\hline \multicolumn{1}{|c|}{ Identified Proteins } & $\begin{array}{c}\text { MW } \\
(\mathbf{k D a})\end{array}$ & BCL2 & Cont. 1 & $\begin{array}{c}\text { HP } \\
\text { VitA2 }\end{array}$ & Cont. 2 & VitA2 & Cont. 3 \\
\hline $\begin{array}{l}\text { erythroid differentiation- } \\
\text { related factor 1 isoform 1 }\end{array}$ & 139 & 0 & 2 & 0 & 0 & 0 & 0 \\
\hline $\begin{array}{l}\text { splicing factor 3A subunit 1 } \\
\text { isoform 2 }\end{array}$ & 82 & 0 & 2 & 0 & 0 & 0 & 0 \\
\hline $\begin{array}{l}\text { high mobility group protein } \\
\text { B1 }\end{array}$ & 25 & 1 & 0 & 0 & 0 & 0 & 0 \\
\hline periostin isoform 1 & 93 & 1 & 0 & 0 & 0 & 0 & 0 \\
\hline $\begin{array}{l}\text { protein disulfide-isomerase } \\
\text { A3 precursor }\end{array}$ & 57 & 1 & 0 & 0 & 0 & 0 & 0 \\
\hline $\begin{array}{l}\text { heat shock 70 kDa protein } \\
\text { 1A/1B }\end{array}$ & 70 & 0 & 0 & 0 & 0 & 4 & 4 \\
\hline
\end{tabular}

Proteins eluted from the control VitA2-ERE sequence and the biotinylated VitA2, the hairpin VitA2 and BCL2 ERE were analyzed by mass spectrometry in three different experiments as described in Methods and Materials. Sequences of the various EREs are described in the Appendix. Scaffold software was used to analyze the protein identifications and the spectral count for each protein is shown. The spectral count is the count given to an identified peptide spectra. Scaffold normalizes these counts across samples by averaging them and then multiplying by the average divided by the individual sample's sum. 
double strand break repair via non-homologous end-joining [114]. Polymorphisms in these genes are associated with increased breast cancer susceptibility [208-210]. HNRPDL belongs to the subfamily of heterogeneous nuclear ribonucleoproteins and is an RNA and DNA binding protein involved in pre-mRNA processing [211]. ACTN4 is an actin filament cytoskeletal protein that has recently been shown to be involved in tumor development and progression [212]. ACTN4 has also recently been shown to be a nuclear receptor coactivator that regulates ER $\alpha$-mediated transcription in breast cancer cells [213]. In addition, HMGB1 is a ubiquitous nuclear DNA-binding protein that induces structural changes in the DNA to facilitate in transcription [214;215] while POSTN is an extra-cellular matrix protein that plays a role in bone, tooth and cardiac development [216;217]. Increased levels of this protein are associated with breast cancer [217], however there is currently no evidence that periostin functions as a DNA-binding protein. PDIA3 is a member of the family of protein disulfide isomerases which catalyze formation, reduction and isomerization of disulfide bonds in proteins in the endoplasmic reticulum [218]. PDIA3 has also been shown to bind DNA in the nucleus and is associated with the nuclear matrix [219].

Since most of these candidate proteins have DNA-binding activity, further analysis was necessary to confirm which of these were components of the ERE-BP/ERE complex. Of these eight proteins that were not present in the control elutions, only three appeared in ERE elutions in more than one of the mass spectrometry experiments: Ku70, Ku80, and $\alpha$-actinin, making these proteins the most likely potential candidates. The molecular weights of $\mathrm{Ku} 70, \mathrm{Ku} 80$, and $\alpha$-actinin are 70, 83 and 105 kilodaltons $(\mathrm{kDa})$, 
respectively. Determination of the molecular weight of the ERE-BP will further narrow down which protein candidate to pursue.

Determination of molecular weight of ERE-BP

To determine the molecular weight of the ERE-BP and narrow down the potential protein candidates, UV crosslinking experiments were performed. Nuclear extracts from breast and uterine cancer reference powders as well as proteins eluted from the pS2-ERE described above were UV crosslinked to VitA2-ERE and separated by SDS-PAGE (Figure 27). Nuclear extracts contained three complexes at approximately 47,74 and 82 $\mathrm{kDa}$ (Figure 27A). The $74 \mathrm{kDa}$ band was present at significantly higher concentrations compared to the $47 \mathrm{kDa}$ and $82 \mathrm{kDa}$ bands. These molecular weights correlate with the weights of Ku70 and Ku80, but not with $\alpha$-actinin. The $47 \mathrm{kDa}$ band correlates with the molecular weight of hnRNP D-like. The ERE-BP/ERE complex eluted from the NeutrAvidin beads contained a major protein complex at approximately $72 \mathrm{kDa}$ (Figure 27B). This molecular weight appears to correlate with the weight of Ku70 (XRCC6). Based on these results and the fact that $\mathrm{Ku} 70$ and $\mathrm{Ku} 80$ form heterodimers during DNAbinding, we concluded that these proteins were the most likely candidates for the identity of the ERE-BP.

Western blot analyses of proteins eluted during the purification of ERE-BP with NeutrAvidin beads

The presence of $\mathrm{Ku} 70$ and $\mathrm{Ku} 80$ in the fractions collected during purification of ERE-BP was ascertained by Western blot analyses using antibodies to Ku70 (D35, Cell 

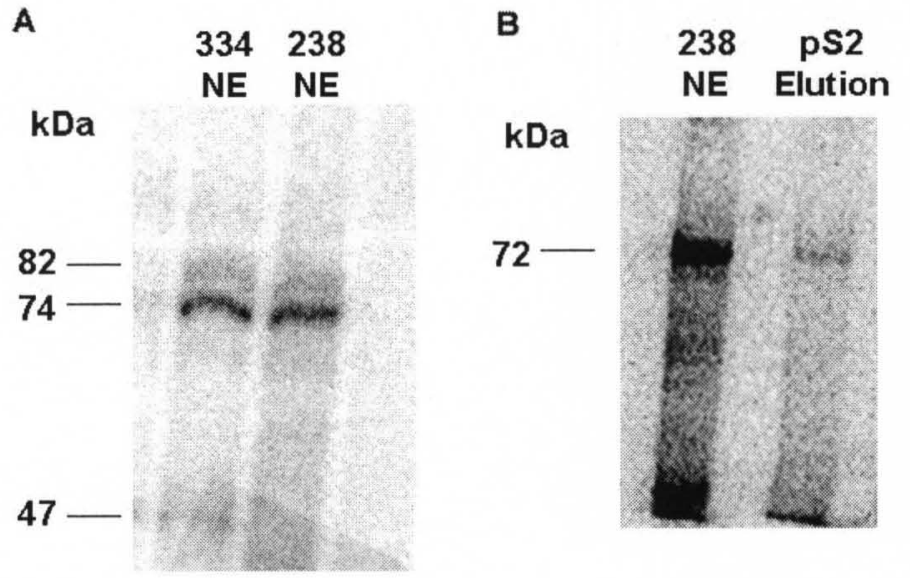

Figure 27. Determination of molecular weight of ERE-BP in reference specimens of human breast and uterine carcinomas. UV crosslinking was performed to determine the molecular weight of the ERE-BP as described in Materials and Methods. Nuclear extracts were subjected to UV light to promote crosslinking to VitA2-ERE sequences and separated by SDS-PAGE (A). Proteins eluted from a pS2-ERE sequence were also subjected to UV crosslinking to VitA2-ERE sequences and separated by SDS-PAGE (B). 


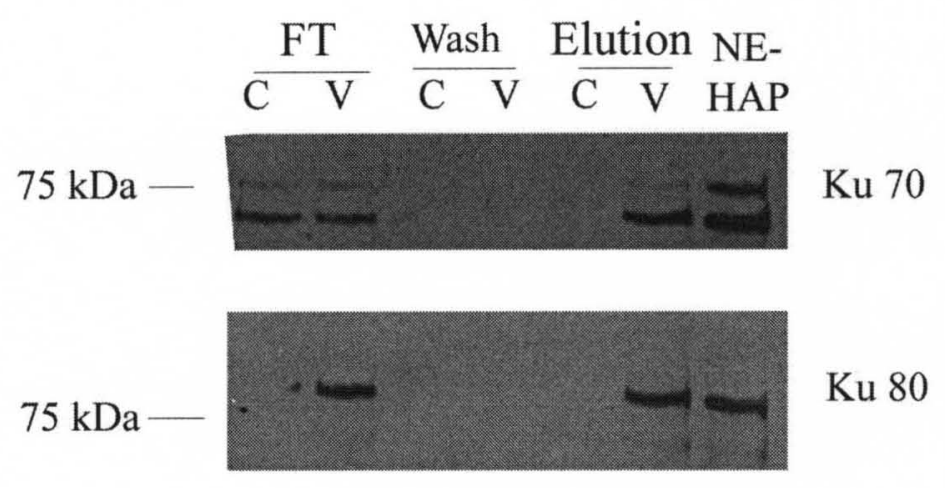

Figure 28. Western blot analyses of proteins eluted during the purification of ERE-BP with NeutrAvidin beads. The presence of Ku70 and Ku80 in the fractions collected during purification of ERE-BP were ascertained by Western blot analyses using antibodies to Ku70 (D35, Cell Signaling) and Ku80 (C48E7, Cell Signaling). Flowthrough (FT), wash and elution fractions from both a control purification (C) and a purification using biotinylated VitA2-ERE (V) are shown. A NE from a uterine cancer reference powder with the high abundant proteins (NE-HAP) removed is also shown. 
Signaling) and Ku80 (C48E7, Cell Signaling) (Figure 28). Flow-through (FT), wash and elution fractions from both a control purification $(\mathrm{C})$ and a purification using biotinylated VitA2-ERE (V) are shown. A NE from a uterine cancer reference powder with the high abundant proteins (NE-HAP) is also shown. Both $\mathrm{Ku} 70$ and $\mathrm{Ku} 80$ were present in the control nuclear extract and in the flow-through fractions, but not in the wash fractions. Both proteins are present in the labeled ERE elution but not from the control elution. These results confirm those from the mass spectrometry experiments that show $\mathrm{Ku} 70$ and Ku80 were present in the fractions eluted from the immunobeads and support further that these proteins are the most likely candidates for the identification of ERE-BP.

\section{Recognition of ERE-BP by an antibody detecting heterodimers of Ku70/Ku80}

To test the hypothesis that $\mathrm{Ku} 70$ and $\mathrm{Ku} 80$ are present in the ERE-BP/ERE complex, supershift assays were performed on nuclear extracts of reference powders, nuclear extracts from which the high abundant proteins were removed and rhER $\alpha$ with an antibody that recognizes the Ku70/80 heterodimer. A supershift of the ERE-BP was observed with an antibody to Ku70/80 in both of the nuclear extract samples but not with the control mouse IgG (Figure 29A). No supershift of $\operatorname{rhER} \alpha$ was observed with this antibody or with the control IgG.

These results indicate that this Ku70/80 antibody specifically recognizes and binds to the ERE-BP. To further validate that the observed ERE-BP are a Ku70/80 heterodimer, supershift assays were performed with additional antibodies against the Ku70/80 heterodimer or Ku70 and Ku80 individually (Figure 29B). Nuclear extracts 


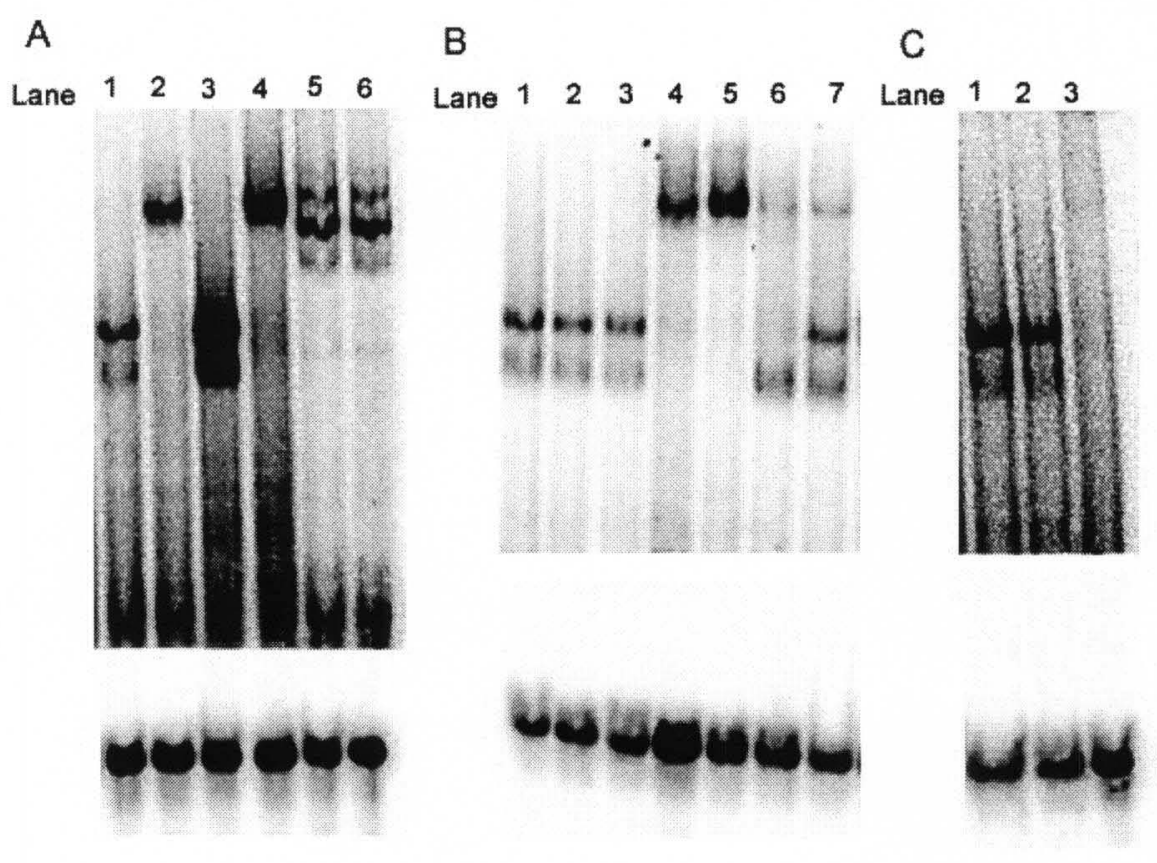

Figure 29. Recognition of ERE-BP by an antibody detecting heterodimers of Ku70/Ku80.

(A) Supershift assays were performed on uterine cancer reference powder nuclear extracts, uterine cancer reference powder nuclear extracts (Lanes 1 and 2) after removal of high abundant proteins (Lanes 3 and 4) and rhER $\alpha$ (Lanes 5 and 6) with an antibody that recognizes the Ku70/80 heterodimer (Lanes 2, 4, 6) (Santa Cruz). Normal mouse IgG was used as a negative control (Lanes 1, 3, 5). (B) Uterine cancer reference powder nuclear extracts were incubated with either normal mouse $\operatorname{IgG}$ (Lane 2), normal rabbit IgG (Lane 3), antibody to Ku70/80 (Santa Cruz) (Lane 4), antibody to Ku70/80 (Ab-3, Thermo Fisher) (Lane 5), antibody to Ku80 (ab-2, Thermo Fisher) (Lane 6) or antibody to Ku80 (C48E7, Cell Signaling) (Lane 7). (C) Untreated nuclear extracts (NE) were separated by EMSA (Lane 1) and compared with the EMSA profile of a nuclear extract that was treated with either an antibody recognizing heterodimers of Ku70/80 (Santa Cruz) (Lane 3) or with a control normal mouse IgG (Lane 2) followed by incubation with Protein A/G agarose beads (Santa Cruz). 
from a uterine cancer reference powder nuclear extracts were incubated with either normal mouse IgG, normal rabbit IgG, an antibody to Ku70/80 (Santa Cruz), an antibody to Ku70/80 (Ab-3, Thermo Fisher), an antibody to Ku80 (ab-2, Thermo Fisher) or with an antibody to Ku80 (C48E7, Cell Signaling). A supershift of the ERE-BP was observed with each of these antibodies to Ku70/80 but not with the control mouse or rabbit IgG. Immunodepletion experiments were also performed to determine whether $\mathrm{Ku} 70 / 80$ antibody recognizes ERE-BP. Nuclear extracts (NE) were incubated with either a control normal mouse IgG or with an antibody that recognizes the heterodimers of Ku70/80 (Santa Cruz) followed by incubation with Protein $A / G$ agarose beads (Santa Cruz). Nuclear extracts and immunodepleted samples were analyzed by EMSA (Figure 29C). ERE-BP were depleted in the samples incubated with a Ku70/80 antibody but not with the control IgG, supporting the hypothesis that the ERE-BP is a heterodimer of Ku70/Ku80.

\section{Influence of antibodies to double strand breaks repair proteins}

In order to verify that the ERE-BP are not related to other DNA repair proteins, supershift assays were performed with antibodies to various double strand break repair proteins including Ku70 and Ku80 separately (Figure 30). The antibodies used were Ku80 (C48E7), Ku70 (D35), DNA-PK, phosphor-ATM, Mre11, NBS1, Rad50, Rad52, $\mathrm{XLF}$ and phospho-BRCA1. Normal rabbit IgG was used as a negative control. In both breast cancer cytosols (Figure 30A) and nuclear extracts (Figure 30B) only the antibody to Ku80 (C48E7) showed a supershift. Although the Ku70 antibody did not cause a supershift, these results suggest that the observed ERE-BP are a Ku70/80 heterodimer 
A

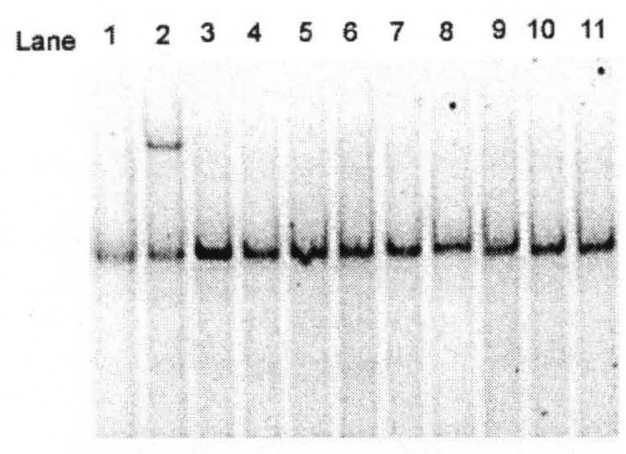

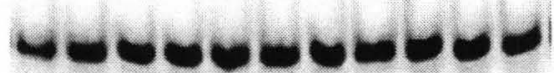

B

Lane $\quad \begin{array}{llllllllllll}1 & 2 & 3 & 4 & 5 & 6 & 7 & 8 & 9 & 10 & 11\end{array}$
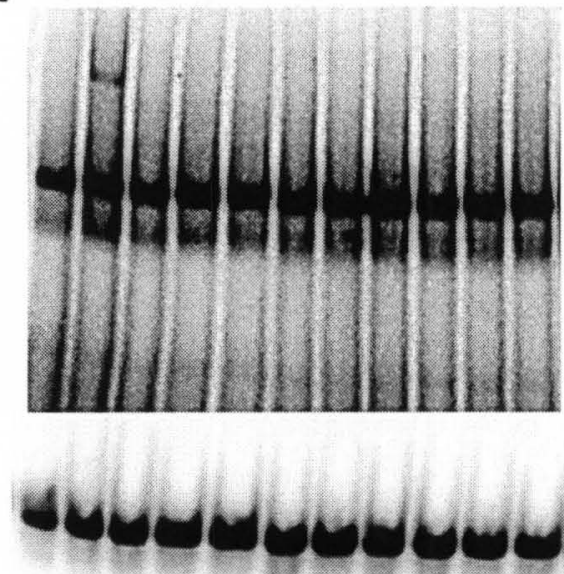

Figure 30. Influence of antibodies to double strand breaks repair proteins on candidate ERE-binding proteins. Cytosols (A) and nuclear extracts (B) from a representative reference powder of breast carcinoma were incubated independently with antibodies to various double strand breaks repair proteins and analyzed by supershift assays. Lane 1: normal rabbit IgG, Lane 2: Ku80 (C48E7), Lane 3: Ku70 (D35), Lane 4: DNA-PK, Lane 5: phosphor-ATM, Lane 6: Mre11, Lane 7: NBS1, Lane 8: Rad50, Lane 9: Rad52, Lane 10: XLF and Lane 11: phospho-BRCA1. Note that both cytosol and nuclear extracts contained Ku80. 
and are not related to other double strand break repair proteins. A possible explanation for the Ku70 antibody not causing a supershift is that the epitope is not accessible under the non-denaturing conditions of the EMSA and is buried in the tertiary structure of the protein. For example, the $\mathrm{Ku} 70$ antibody used in these experiments recognizes the $\mathrm{N}$ terminus of the protein which forms a $\beta$-barrel structure and is involved in $\mathrm{Ku} 80$ dimerization and DNA-binding [145;220]. The Ku80 antibody used in these experiments recognizes the C-terminus of the protein, which is flexible and known to be involved in protein-protein interactions but not DNA-binding [145;150].

Influence of various antibodies to $\mathrm{Ku} 70 / \mathrm{Ku} 80$ on $E R E-B P$ in frozen cytosols from breast cancer

The previous supershift assays were performed on freshly prepared extracts from various human tissue reference specimens. In order to confirm these results in breast cancer, supershift assays with various $\mathrm{Ku} 70 / 80$ antibodies were performed on previously frozen and stored breast cancer cytosols prepared for the clinical measurement of ER and PR [20] (Figure 31). Two breast cancer cytosols were analyzed, one showing only the lower band and one with both bands. Extracts were incubated with either normal mouse $\mathrm{IgG}$, normal rabbit $\mathrm{IgG}$, an antibody to $\mathrm{Ku} 70 / 80$ (Santa Cruz), an antibody to $\mathrm{Ku} 70 / 80$ (Ab-3, Thermo Fisher), an antibody to Ku80 (ab-2, Thermo Fisher) or an antibody to Ku80 (C48E7, Cell Signaling). For the sample containing the lower band only, a supershift was observed with each antibody to the $\mathrm{Ku} 70 / 80$ heterodimer and to $\mathrm{Ku} 80$ alone, but not with the control mouse or rabbit $\operatorname{IgG}$ or the $\mathrm{Ku} 80$ antibodies alone. These results suggest that the Ku80 antibody doesn't recognize the lower band. It is unlikely 

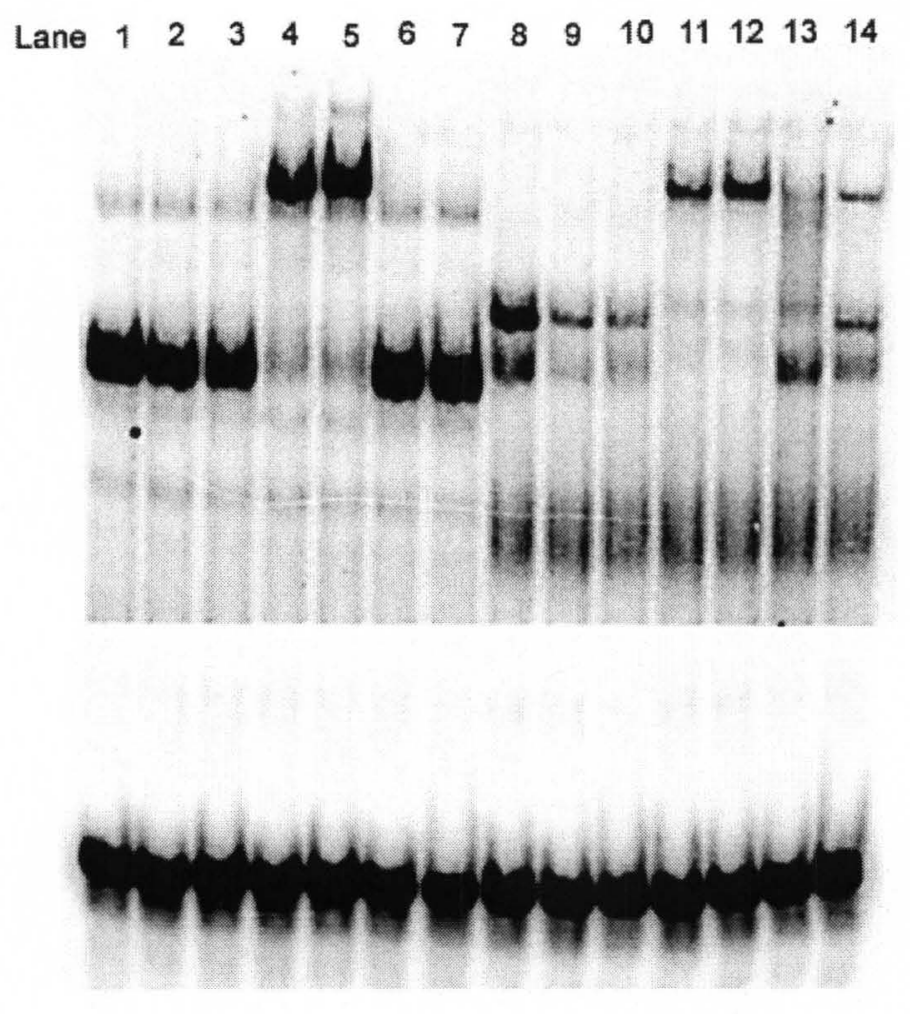

Figure 31. Influence of various antibodies to Ku70/Ku80 on ERE-BP in frozen cytosols from breast cancer. Supershift assays of frozen breast cancer cytosols with various Ku70/80 antibodies were performed. Two breast cancer cytosols were analyzed, one showing only the lower band (Lanes 1-7) and one with both bands (Lanes 8-14). Extracts were incubated as described in Materials and Methods with either normal mouse $\operatorname{IgG}$ (Lanes 2, 9), normal rabbit IgG (Lanes 3, 10), antibodies to Ku70/80 (Santa Cruz) (Lanes 4, 11), antibodies to Ku70/80 (Ab-3, Thermo Fisher) (Lanes 5, 12), Ku80 (ab-2, Thermo Fisher) (Lanes 6, 13) or antibodies to Ku80 (C48E7, Cell Signaling) (Lanes 7, 14) and separated by supershift assays. 
that this is due to the lower band being Ku70 alone because heterodimer formation is necessary for DNA binding in EMSA [221;222]. The C-terminal regions of both proteins and the N-terminal region of $\mathrm{Ku} 70$ are required for DNA end binding [220;222]. Heterodimer formation is required for DNA-binding of N-terminal region of Ku70; however the DNA-binding activity of the C-terminal is independent of heterodimer formation [220]. A possible explanation is that the heterodimer contains a $69-\mathrm{kDa} \mathrm{Ku} 80$ variant rather than the full length protein. This variant has a truncated C-terminal domain but retains the ability to form a heterodimer with Ku70 and bind DNA [223-226]. Both Ku80 antibodies used in these experiments recognize the C-terminal domain of the protein. In contrast, for the sample containing both bands, a supershift was observed with each antibody to the Ku70/80 heterodimer and the Ku80 antibodies but not with the control mouse or rabbit IgG. Both bands of the ERE-BP complex observed in breast cancer cytosols are recognized by a Ku70/Ku80 antibody consistent with our previous results.

Comparison of Ku protein levels and DNA-binding activities measured by EMSA

To determine if the levels of DNA-binding observed in previously frozen breast cancer cytosols correspond with $\mathrm{Ku} 70$ and Ku80 protein levels, 50 samples were analyzed concurrently by EMSA and Western blot. Cytosols were analyzed by EMSA using VitA2-ERE as described previously. Western blot analyses were performed using primary antibodies for Ku70 (Ab-4, Thermo Fisher Scientific), Ku80 (Ab-2, Thermo Fisher Scientific) and $\beta$-actin (Cell Signaling). Representative EMSA and Western blot 
A
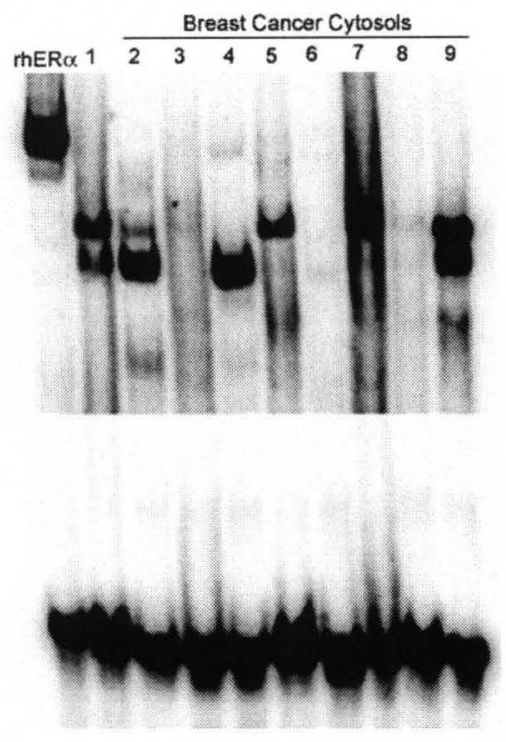

B

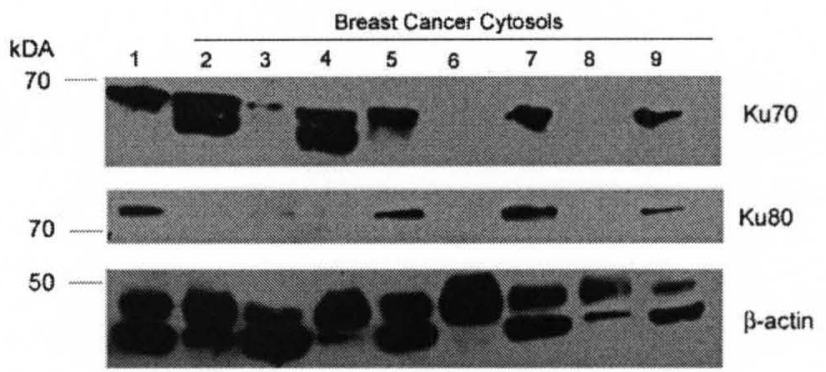

Figure 32. Comparison of Ku DNA-binding activities and protein levels. To determine if the levels of DNA-binding observed in previously frozen breast cancer cytosols correspond with $\mathrm{Ku} 70$ and $\mathrm{Ku} 80$ protein levels, breast cancer cytosols were analyzed concurrently by EMSA (A) and Western blot (B). Cytosols were analyzed by EMSA using VitA2-ERE as described previously. $\operatorname{rhER} \alpha$ was used as a control. Western blot analyses were performed using primary antibodies for Ku70 (Ab-4, Thermo Fisher Scientific), Ku80 (Ab-2, Thermo Fisher Scientific) and $\beta$-actin (Cell Signaling). Lane 2 contains a nuclear extract prepared from a uterine cancer reference specimen. Lanes 3-9 contain cytosols prepared from breast cancer biopsies. 
results are shown in Figure 32. Samples with various DNA-binding activities were analyzed by EMSA and compared to Ku70 and Ku80 protein levels. Ku70 protein levels appear to correlate with EMSA results more consistently than Ku80 protein levels. To quantify the bands obtained from Western blot analysis, all samples were normalized to the $\beta$-actin loading control and then a nuclear extract standard. ImageJ software (NIH) was used to calculate the relative densities for each band. Ku70 and Ku80 protein levels were compared to EMSA activities by two-tailed Spearman correlations (Figure 33). A significant correlation was observed between DNA-binding activities and both Ku70 $(\mathrm{r}=0.67, \mathrm{p}<0.0001)$ and $\mathrm{Ku} 80(\mathrm{r}=0.47, \mathrm{p}=0.0003)$ protein levels, the correlation with Ku80 is not as strong. This is most likely due to the presence of the variant $69-\mathrm{kDa}$ form of Ku80 which would not be recognized by the antibody used for Western blotting. Because the DNA-binding activity is a measurement of both $\mathrm{Ku} 70$ and $\mathrm{Ku} 80$, the levels of these proteins measured by Western blot were added together and correlated with the EMSA data, which showed a higher $r$ value than either protein alone $(r=0.73, p<0.0001)$. The protein levels of Ku70 and Ku80 also correlate with each other $(\mathrm{r}=0.58, \mathrm{p}<0.0001)$, which is consistent with the crystal structure of the $\mathrm{Ku}$ heterodimer showing that $\mathrm{Ku} 70$ and Ku80 bind to DNA in a 1:1 ratio [145].

\section{Summary \& Conclusions}

The goals of this investigation were to purify and identify the candidate ERE-BP from tisssue extracts. A method for purifying and identifying proteins present in tissue extracts that bind to the ERE was established. This method used a combination of biotin labeled ERE sequences, NeutrAvidin beads and mass spectrometry. These techniques 
A

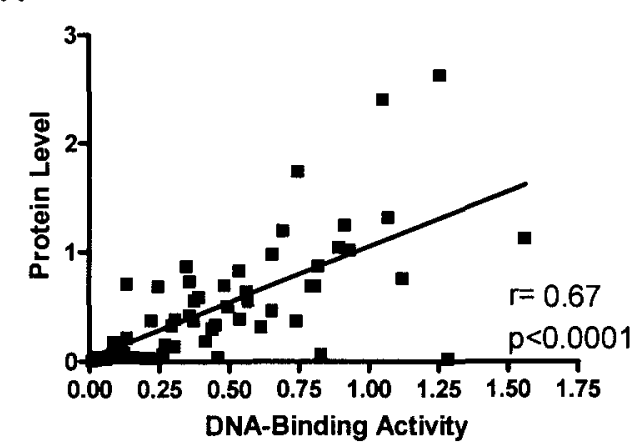

C

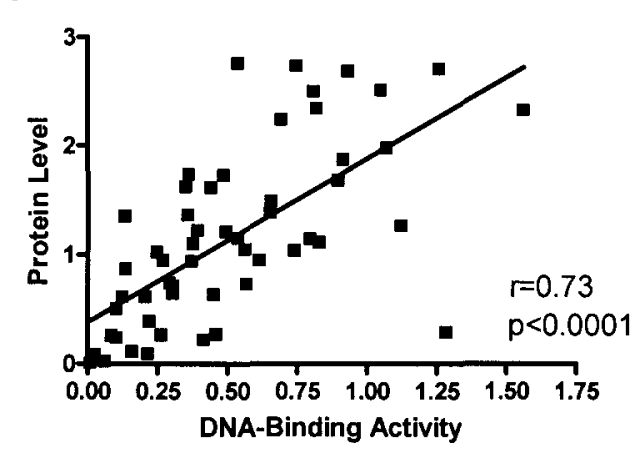

B

Ku80

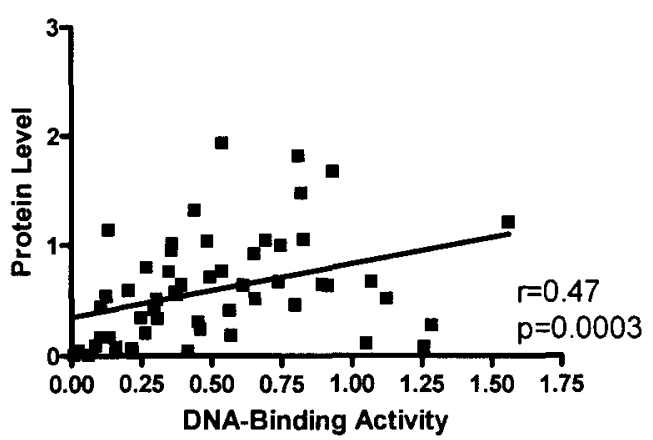

D

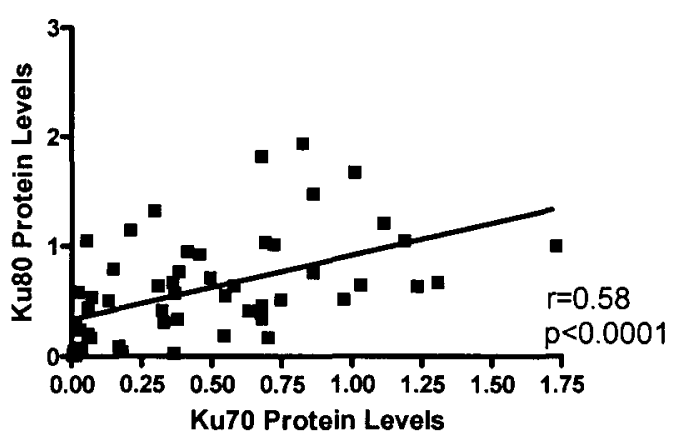

Figure 33. Correlation of $\mathrm{Ku}$ DNA-binding activities and protein levels. A two-tailed Spearman correlation was used to determine if $\mathrm{Ku}$ DNA-binding activities measured by EMSA are related to $\mathrm{Ku} 70$ and $\mathrm{Ku} 80$ protein levels measured by Western blot. $\mathrm{Ku} 70$ alone (A), Ku80 alone (B), the addition of Ku70 and Ku80 DNA-binding activities (C) and $\mathrm{Ku} 70$ protein levels versus $\mathrm{Ku} 80$ protein levels (D) are shown. 
generated a list of candidate proteins that could be tested by antibody-based methods. UV crosslinking experiments were performed to determine the molecular weight of these proteins. Based on these data, Ku70 and Ku80 were determined to be the most likely candidates. Western blot and supershift assays confirmed the presence of these proteins in breast and uterine cancers. Supershift assays also confirmed that ERE-BP/ERE complex observed by EMSA was specifically recognized by antibodies to the Ku70/Ku80 heterodimer.

These results are consistent with the data in Chapter II that suggest these proteins are non-specific DNA-binding proteins that are present in both the cytoplasm and the nucleus. After the initiation of DSBs, Ku70 and Ku80 form a heterodimer that bind to the free ends of DNA independent of sequence and structure [118;227-230]. The Ku heterodimer forms a ring around the DNA but does not make contact with the bases themselves [145]. Instead, $\mathrm{Ku}$ fits sterically to the minor and major groove [145]. Fluorescence anisotropy studies revealed that electrostatic interactions play a large role in DNA-binding and are possibly the primary mechanism for DNA recognition [231]. Ku70 and Ku80 localize in both the cytoplasm and nucleus [143;154;232-234]. It has also been shown that $\mathrm{Ku} 70$ and $\mathrm{Ku} 80$ localize to the nucleus in response to cell cycle status. Ku70 and Ku80 are localized in the cytoplasm and nucleus during late telophase and early G1, but are mainly associated with metaphase chromosomes during the G2/M phase [154]. Additionally, they have been shown to translocate in response to stimuli such as irradiation and serum starvation $[143 ; 235 ; 236]$.

In conclusion, we have identified that the ERE-BP present in breast cancer extracts are complexes containing the DNA repair proteins $\mathrm{Ku} 70$ and $\mathrm{Ku} 80$. Our 
preliminary data suggested that presence of these proteins observed by EMSA was associated with decreased survival in breast cancer patients (Fig 7, Chapter I). Given that these proteins are involved in the prevention of cell death by apoptosis and are associated with tumorigenesis and cancer progression, it would be expected that increased DNAbinding activity would be associated with decreased survival. The focus of the investigations Chapter IV will be to confirm our preliminary results in a larger population of breast cancer patients. 


\section{CHAPTER IV}

\section{CLINICAL UTILITY OF THE DNA-BINDING PROTEIN KU AS A BIOMARKER OF BREAST CARCINOMA BEHAVIOR}

\section{Introduction}

The studies reported in Chapter III illustrated that the identity of the ERE-binding proteins that we observed previously in breast cancer biopsies is the protein Ku. Our preliminary data suggested that breast cancer patients with tissue biopsies negative for $\mathrm{Ku}$ DNA-binding activity have higher overall survival probabilities than patients positive for Ku DNA-binding activity. Ku has been implicated in DNA repair, telomere maintenance and apoptosis and plays an important role in chromosomal integrity and cell survival [146]. A correlation has been shown between $\mathrm{Ku}$ and the development of several cancers. Over-expression of $\mathrm{Ku}$ apparently leads to tumorigenesis through hyperproliferation and resistance to apoptosis, while under-expression of $\mathrm{Ku}$ may lead to genomic instability [146;237].

$\mathrm{Ku}$ protein and mRNA levels have been associated with patient survival and proliferation in various cancers. For example, Saviozzi et al. measured XRCC5 mRNA levels in both normal lung and non-small cell lung tumors [238]. Their results showed a significant correlation between over-expression of XRCC5 and shorter patient survival probabilities as well as a correlation with increased tumor grade. XRCC5 expression was 
higher in poorly differentiated tumors and over-expression correlated with more aggressive cancers. Ghezzi et al. also demonstrates that Ku70 gene expression correlated with poorly differentiated colorectal tumors [239]. In addition, Hu et al. reported that expression of $\mathrm{Ku} 70$ protein measured by IHC was significantly higher in gastric cancers compared to normal gastric mucosa and precancerous lesions and that over-expression of Ku70 was associated with shortened telomeres [240].

Parella et al. demonstrated that non-melanoma skin cancers exhibited a significant increase in both $\mathrm{Ku} 70$ and $\mathrm{Ku} 80$ protein levels measured by IHC compared to those in normal skin [241]. This study also measured the DNA-binding activities of $\mathrm{Ku}$ in basal cell carcinomas, squamous cell carcinomas and normal skin tissue. An increase in DNAbinding activity was observed in both the basal and squamous cell carcinomas compared to the normal skin. Furthermore, over-expression of both proteins was also associated with an increased rate of tumor cell proliferation. Expression of $\mathrm{Ku} 70$ has also been associated with survival in cervical carcinoma. For example, Wilson et al. reported that patients whose tumors had low Ku70 protein expression as measured by IHC exhibited significantly higher survival times [242]. This correlation with overall survival was also seen for Ku80 although it did not reach statistical significance.

Both Ku70 and Ku80 have been associated with breast cancer progression. Pucci et al. reported that DNA-binding activities of cytoplasmic Ku measured by EMSA were increased 2 to 10 -fold in tumors compared to normal tissue [243]. They also examined $\mathrm{Ku}$ protein levels by Western blot and found a 4-18-fold increase in expression in tumor extracts compared to normal tissue extracts. Lagadec et al. using breast cancer cells in culture, showed that Ku80 associated with the TrkA tyrosine kinase receptor [244]. 
Breast tumors expressed higher levels of TrkA compared to normal breast tissue, which increased cell growth and invasion [245]. Although this study did not evaluate the clinical significance of Ku80 itself, it was found that Ku80 was upregulated in TrkA overexpressing cells and involved in cell invasion, indicating that Ku80 may have an important role in breast cancer metastasis. They also showed that $\mathrm{Ku} 70$ associated with TrkA and enhances survival of cancer cells over-expressing this protein [246].

The purpose of the investigations described in this Chapter was to examine the prognostic significance of $\mathrm{Ku}$ DNA-binding activity with regard to breast cancer recurrence and patient survival. Better understanding of the relationship between $\mathrm{Ku}$ DNA-binding activity in breast cancer biopsies and breast cancer survival will aid in defining the role of $\mathrm{Ku}$ as a potential prognostic biomarker.

\section{Methods and Materials}

\section{Patient population}

This study utilized de-identified breast carcinoma specimens from 363 patients collected between 1989-1997 and selected from the IRB-approved Hormone Receptor Laboratory (HRL) Biorepository and Tumor Marker Database. De-identified human tissue specimens were collected from patients with primary carcinomas of the breast. Tissue specimens were typically processed within an hour following surgery using stringent protocols to

ensure the integrity of specimens for genomic and proteomic analyses [20;191]. Available clinicopathological data include tumor-based properties (e.g., pathology, grade, stage, size and tumor marker status), patient-related characteristics (e.g., age, race, 
menopausal status, family history, nodal status) and clinical follow-up (e.g, treatment regimen, disease-free and overall survival).

As a clinical laboratory, the HRL performed biochemical assays measuring the protein levels of ER and PR in cytosols for $\sim 22,000$ human tissue specimens with both ligand binding and EIA methods for quantification [20]. Breast cancer cytosols previously prepared and stored at $-80^{\circ} \mathrm{C}$ were used for these investigations. A diagram describing the flow of breast cancer specimens and associated patients through the study according to the reporting recommendations for tumor marker prognostic studies (REMARK) is shown in Figure 34 [247]. Table 4 describes the characteristics of the patient population used in this investigation. The median patient age was 63 years with a range of 21 to 89.5 years. The median observation time was 70 months and ranged from 1 to142 months. No evidence of bias was detected in the population of patients and associated breast cancer specimens selected for this study.

\section{Cytosol preparation}

Cytosols were prepared from de-identified human breast cancer tissue specimens in 40 mM Tris- $\mathrm{HCl}, \mathrm{pH} 7.4$, containing $1.5 \mathrm{mM}$ EDTA, $10 \%$ glycerol, $10 \mathrm{mM} \mathrm{Na} \mathrm{MoO}_{4}, 1$ $\mathrm{mM}$ PMSF and $10 \mu \mathrm{M}$ monothioglycerol, and homogenized with a Polytron PT-10-35. Homogenate was separated into pellet and cytosol by centrifugation, using a Beckman LE-80K ultracentrifuge at $105,000 \times \mathrm{g}$ for 30 minutes at $4^{\circ} \mathrm{C}[20 ; 38 ; 39 ; 174]$. Protein concentration of each cytosol was determined by the Bradford procedure [190]. Cytosols were stored at $-80^{\circ} \mathrm{C}$ for future use. 


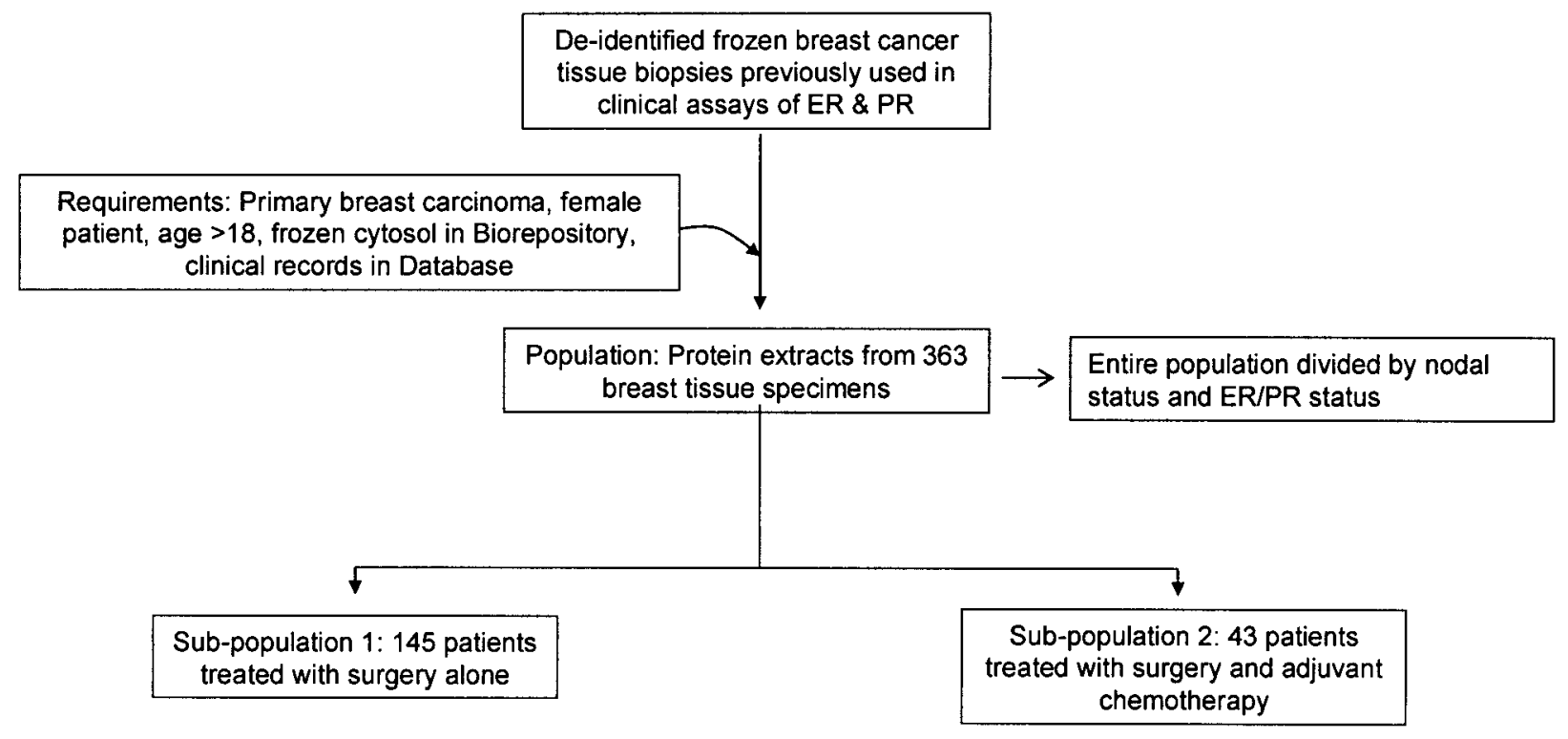

Figure 34. REMARK diagram describing the patient population used to investigate the clinical relevance of $\mathrm{Ku}$. The flow of patients and associated breast cancer specimens through the study is shown according to the reporting recommendations for tumor marker prognostic studies (REMARK). 
Table 4. Characteristics of the overall patient population with associated clinical data.

\begin{tabular}{|c|c|c|}
\hline \multicolumn{3}{|c|}{ Patient Parameters } \\
\hline Median Age (range) & 63 years $(21-89.5)$ & 363 \\
\hline Median Observation $\mathrm{t}$ & $\begin{array}{l}7 \text { e (range) } \\
70 \text { months }(1-142)\end{array}$ & \\
\hline Race & $\begin{array}{l}\text { white } \\
\text { black } \\
\text { asian } \\
\text { hispanic }\end{array}$ & $\begin{array}{r}292 \\
52 \\
2 \\
1\end{array}$ \\
\hline Histology & $\begin{array}{l}\text { Invasive ductal carcinoma } \\
\text { Invasive lobular carcinoma } \\
\text { Other }\end{array}$ & $\begin{array}{r}136 \\
30 \\
45 \\
\end{array}$ \\
\hline Median Tumor Size ( & $\begin{array}{l}\text { ange) } \\
60 \mathrm{~mm}(1-120)\end{array}$ & 324 \\
\hline Stage & $\begin{array}{l}0 \\
1 \\
2 \\
3 \\
4\end{array}$ & $\begin{array}{r}9 \\
92 \\
178 \\
43 \\
17\end{array}$ \\
\hline Grade & $\begin{array}{l}1 \\
2 \\
3\end{array}$ & $\begin{array}{r}35 \\
114 \\
113 \\
\end{array}$ \\
\hline Lymph Node Status & $\begin{array}{l}\text { negative } \\
\text { positive }\end{array}$ & $\begin{array}{l}171 \\
137\end{array}$ \\
\hline Hormone Receptor S & $\begin{array}{l}\text { tus } \\
\text { ER+/PR+ } \\
\text { ER+/PR- } \\
\text { ER-/PR+ } \\
\text { ER-/PR- }\end{array}$ & $\begin{array}{r}200 \\
39 \\
36 \\
88\end{array}$ \\
\hline Recurrence Status & $\begin{array}{l}\text { yes } \\
\text { no } \\
\text { never disease free }\end{array}$ & $\begin{array}{r}75 \\
235 \\
53\end{array}$ \\
\hline
\end{tabular}


Determination of DNA-binding activities

Protein extracts were incubated with 50 ng non-specific DNA, poly (dI-dC) (Amersham), $10 \mathrm{mM} \mathrm{KCl}, 1 \%$ glycerol and $\left[{ }^{32} \mathrm{P}\right]$ labeled VitA2-ERE sequences in $40 \mathrm{mM}$ Tris- $\mathrm{HCl}$ buffer, pH 8.0, containing $500 \mu \mathrm{M}$ PMSF and $10 \mu \mathrm{M}$ monothioglycerol overnight at $4^{\circ} \mathrm{C}$. The gel was pre-run for 30 minutes at $150 \mathrm{~V}$ at $4^{\circ} \mathrm{C}$ in $0.5 \mathrm{X}$ TBE buffer $(1.0 \mathrm{M}$ Tris- $\mathrm{HCl}$, $\mathrm{pH}$ 8.6, containing $831 \mathrm{mM}$ boric acid, $10 \mathrm{mM}$ EDTA). Samples were then loaded, followed by electrophoresis at $300 \mathrm{~V}$ for 5 minutes, and then $180 \mathrm{~V}$ for 4 hours. Subsequently, gels were dried and exposed to phosphor screens (Perkin Elmer) overnight. The bands representing $\left[{ }^{32} \mathrm{P}\right] \mathrm{ERE}$-protein complexes and free $\left[{ }^{32} \mathrm{P}\right] \mathrm{ERE}$ sequences were visualized and quantified using a Cyclone Storage Phosphor System ${ }^{\mathrm{TM}}$ with OptiQuant ${ }^{\circledR}$ software (Perkin Elmer). A method of estimating the relative DNA-binding activity levels of ERE-BP in breast cancer biopsies was developed by measuring the band intensity of the $\mathrm{Ku} / \mathrm{ERE}$ complexes or free $\left[{ }^{32} \mathrm{P}\right] \mathrm{ERE}$ sequences in each lane from the EMSA in OptiQuant $^{\circledR}$ software (See Chapter II). The $\mathrm{Ku}$ DNA-binding activity is reported as Digital Light Units (DLU)/ $\mu \mathrm{g}$ protein and normalized to the total DLU of the lane in order to compare between samples.

\section{Statisical analyses}

Graphical analyses, e.g. scatter plots, box and whisker plots, Kaplan-Meier analyses and linear regression were employed to evaluate various realtionships. For Kaplan-Meier survival curves, $\mathrm{p}$ values were determined with a log-rank test. Chi-square analyses and statistical analyses (e.g. Kruskal-Wallis, Mann-Whitney tests) were performed with Prism 4 (GraphPad, Inc.). Cox regression analyses were performed using SPSS Statistics 18.0 
(SPSS, Inc.). Kaplan-Meier and Cox regression analyses were performed using relative Ku70/80 DNA-binding activity levels as determined by EMSA. Kaplan-Meier analyses were also performed using Ku70 and $\mathrm{Ku} 80$ protein levels measured by Western blot and gene expression levels measured by microarray.

\section{Results and Discussion}

\section{Reproducibility of EMSA measurement of Ku DNA-binding activities}

To assess the intra-assay variation, $\mathrm{Ku}$ DNA-binding activities in cytosols from ten representative breast carcinomas were measured in three experiments by EMSA using band intensities from two lanes on the same gel and averaged (Figure 35A). For the estimate of inter-assay variation, $\mathrm{Ku}$ DNA-binding activities of the same ten breast cancer specimens were measured by EMSA in three separate experiments (Figure 35B). Results are expressed as mean \pm SEM. In general, the reproducibility of the method developed was satisfactory for performing investigations of the clinical utility of $\mathrm{Ku}$ in assessing breast cancer prognosis.

Relationships of cytosolic Ku DNA-binding activities in breast cancers and various patient characteristics

$\mathrm{Ku}$ DNA-binding activities were measured in cytosols as described using 363 breast cancer biopsies and correlated with various clinical characteristics, including stage, grade, nodal status, age and race (Figure 36). Box and whisker plots of the data are 

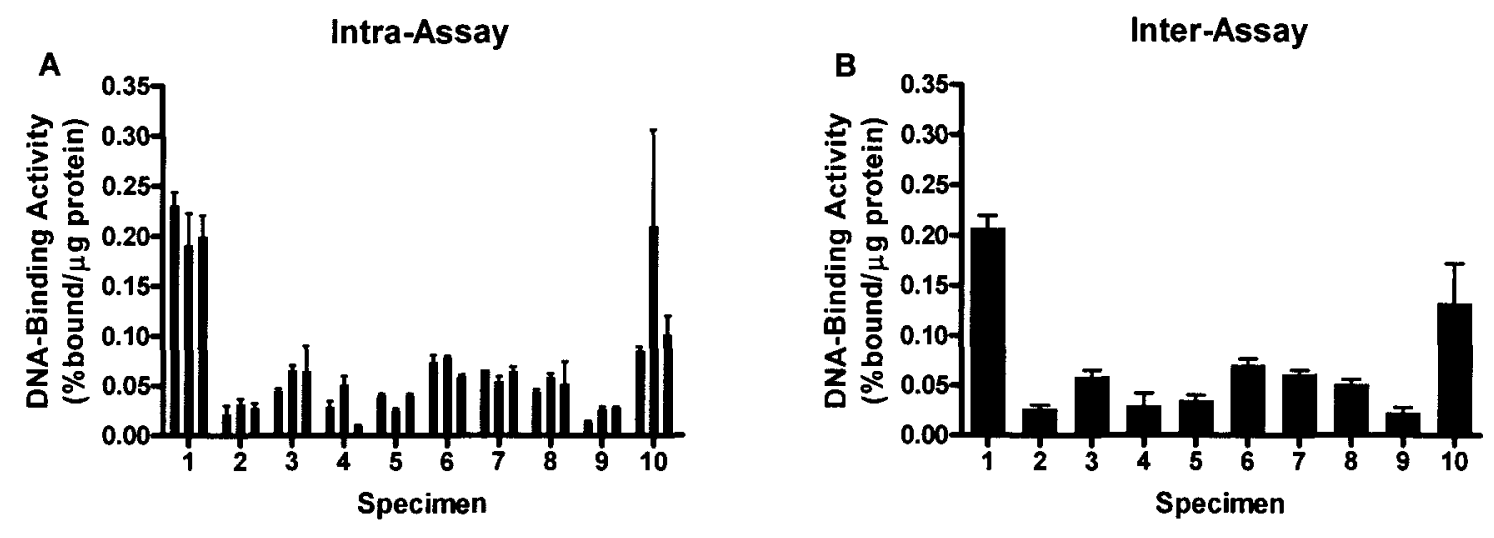

Figure 35. Reproducibility of EMSA measurement of Ku DNA-binding activities. To assess the intra-assay variation (A), Ku DNA-binding activities in cytosols from ten representative breast carcinomas were measured by EMSA using band intensities from two lanes on the same gel and averaged. For the estimate of inter-assay variation (B), Ku DNA-binding activities of the same ten breast cancer specimens were measured by EMSA in three separate experiments. Results are expressed as mean $\pm \mathrm{SEM}$. 

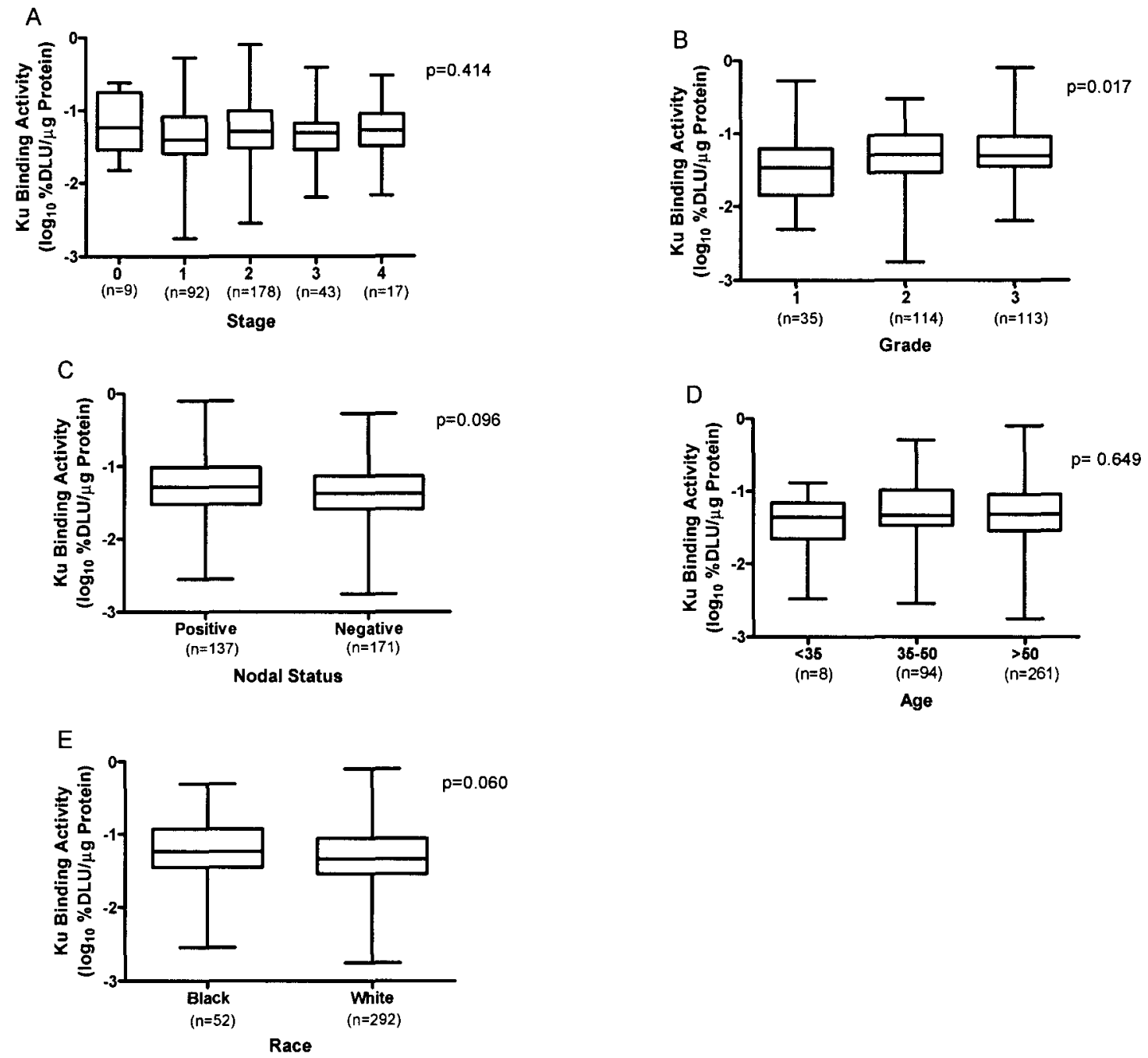

Figure 36. Inter-relationships of cytosolic Ku DNA-binding activities in breast cancers and various patient characteristics. Cytosolic Ku DNA-binding activities measured by EMSA were correlated with stage (A), grade (B), nodal status (C), age (D) and race (E). Box and whisker plots of the data are shown. The boxes represent the lower quartile, median and upper quartile, while the whiskers indicate the sample maximum and minimum. For stage, grade and age, a Kruskal-Wallis test was used to determine if a significant difference existed between the groups. For nodal status and race, a MannWhitney test was used. 
shown. The boxes represent the first quartile, median (line within the box) and third quartile, while the whiskers indicate the sample maximum and minimum. For stage, grade and age, a Kruskal-Wallis test was used to determine if a significant difference exists between the groups. A Mann-Whitney test was used to examine statistical significance for nodal status and race.

No significant correlation was observed between Ku DNA-binding activities and either patient age, race, nodal status, or stage. However a significant correlation was observed with cancer grade. Patients with higher grade cancers appear to exhibit higher $\mathrm{Ku}$ DNA-binding activities. These observations are consistent with the lung cancer study by Saviozzi et al. and the Ghezzi et al. colorectal cancer study that correlated higher $\mathrm{Ku}$ levels with poorly differentiated tumors [238;239].

To further examine the relationship of cytsolic Ku DNA-binding activities with patient characteristics, the population was divided into two groups: those with primary breast cancers exhibiting below median Ku activity levels and those with above median $\mathrm{Ku}$ activity levels. Chi-square analysis was performed for each parameter to determine if there was a difference between the two patient groups (Table 5). Results showed that the increased Ku DNA-binding activity was correlated with node positive cancer $(\mathrm{p}=0.029)$ as well as development of metastases $(\mathrm{p}=0.008)$. These results are also consistent with the Saviozzi et al. lung cancer study that found an association with Ku70 over-expression and more aggressive tumors [238]. 
Table 5. Association of cytsolic $\mathrm{Ku}$ DNA-binding activities with various patient characteristics. The population was divided into two groups: those with primary breast cancers exhibiting below median $\mathrm{Ku}$ activity levels and those with above median $\mathrm{Ku}$ activity levels. Chi-square analysis was performed to determine if a difference existed between the two patient groups.

\begin{tabular}{|c|c|c|c|}
\hline & $\begin{array}{l}\text { Below Median } \\
(n=182) \text { No. }(\%)\end{array}$ & $\begin{array}{l}\text { Above Median } \\
(n=181) \text { No. }(\%)\end{array}$ & P value \\
\hline Age & & & 0.978 \\
\hline$<35$ & $4(2)$ & $4(2)$ & \\
\hline $35-50$ & $48(26)$ & $46(25)$ & \\
\hline$>50$ & $130(71)$ & $131(72)$ & \\
\hline Tumor Size & & & 0.057 \\
\hline$\leq 20 \mathrm{~mm}$ & $83(46)$ & $63(35)$ & \\
\hline$>20 \mathrm{~mm}$ & $81(44)$ & $96(53)$ & \\
\hline missing & $18(10)$ & $22(12)$ & \\
\hline Nodal Status & & & 0.029 \\
\hline Positive & $62(34)$ & $75(41)$ & \\
\hline Negative & $100(55)$ & $72(40)$ & \\
\hline missing & $20(11)$ & $34(19)$ & \\
\hline Grade & & & 0.061 \\
\hline $\mathbb{1}$ & $24(13)$ & $11(6)$ & \\
\hline III & $53(29)$ & $61(34)$ & \\
\hline IIII & $54(30)$ & $59(16)$ & \\
\hline missing & $51(28)$ & $50(28)$ & \\
\hline Stage & & & 0.252 \\
\hline 0 & $4(2)$ & $5(3)$ & \\
\hline II & $55(30)$ & $36(20)$ & \\
\hline III & $84(46)$ & $94(52)$ & \\
\hline IIII & $20(11)$ & $23(13)$ & \\
\hline IV & $7(4)$ & $10(5)$ & \\
\hline missing & $12(7)$ & $13(7)$ & \\
\hline Histology & & & 0.875 \\
\hline Infiltrating Ductal & $136(75)$ & $135(75)$ & \\
\hline Invasive Lobular & $14(8)$ & $16(9)$ & \\
\hline Other & $29(16)$ & $26(14)$ & \\
\hline missing & $3(2)$ & $4(2)$ & \\
\hline \multicolumn{4}{|l|}{ Hormone Receptor Status } \\
\hline$E R+/ P R+$ & $100(55)$ & $100(55)$ & 0.37 \\
\hline ER+/PR- & $21(12)$ & $18(10)$ & \\
\hline ER-/PR+ & $22(12)$ & $14(8)$ & \\
\hline ER-IPR- & $39(21)$ & $49(27)$ & \\
\hline Treatments & & & 0.433 \\
\hline Surgery Only & $75(41)$ & $70(39)$ & \\
\hline Chemotherapy & $28(15)$ & $37(20)$ & \\
\hline Hormonal therapy & $30(16)$ & $21(12)$ & \\
\hline Radiation therapy & $8(4)$ & $12(7)$ & \\
\hline Combined therapies & $41(23)$ & $41(23)$ & \\
\hline Development of metastasis & & & 0.008 \\
\hline Yes & $29(16)$ & $46(25)$ & \\
\hline $\mathrm{No}$ & $132(36)$ & $103(28)$ & \\
\hline Never disease free & $22(6)$ & $31(8)$ & \\
\hline
\end{tabular}


Significance of known prognostic indicators

To ensure that the population of patients used in this study is representative of the general population of breast cancer patients, survival analysis was performed with known prognostic factors. Kaplan-Meier analyses were used to determine the relationship between survival and stage, nodal status and grade in the study population (Figure 37). As anticipated, higher stage, higher grade and positive nodal status were associated with decreased disease-free (DFS) and overall (OS) survival probabilities [3;12]. KaplanMeier analyses were also used to determine the relationship between survival and ER/PR status of the breast carcinoma in the study population (Figure 38). Patients with either ER or PR negative breast carcinomas were associated decreased disease-free and overall survival probabilities compared to those patients with ER or PR positive cancers. As described previously, breast cancer patients with tumors that are ER and/or PR positive generally exhibit increased disease-free and overall survival [3]. These results suggest that this population is representative of the general population of patients with primary breast cancers.

Correlation of cytosolic Ku DNA-binding activities with survival of breast cancer patients

Our preliminary data described in Chapter I suggested that presence of $\mathrm{Ku}$ (then called ERE-BP) in breast cancer cytosols correlated with patient survival. To further evaluate this finding, Ku DNA-binding activities were measured by EMSA using cytosols prepared and analyzed as described previously. Kaplan-Meier analyses were 
A

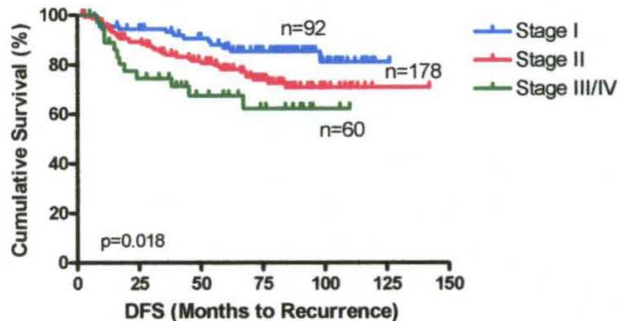

C

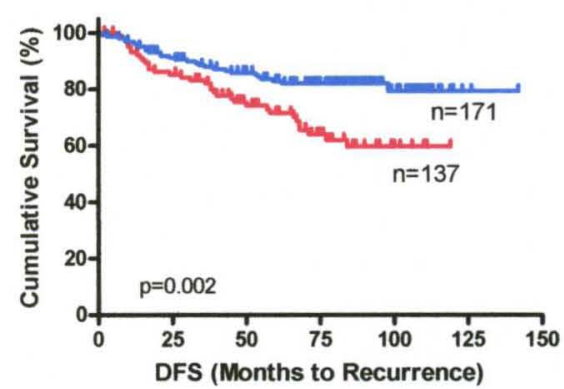

$\mathrm{E}$

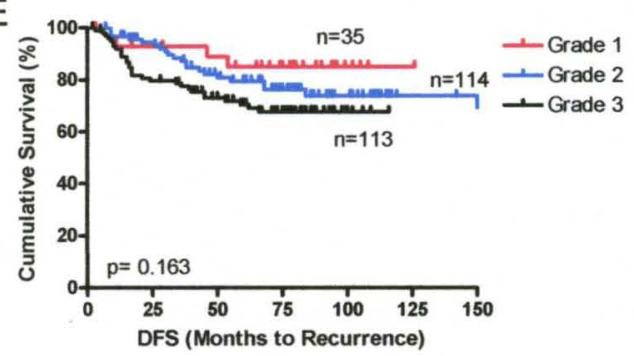

B

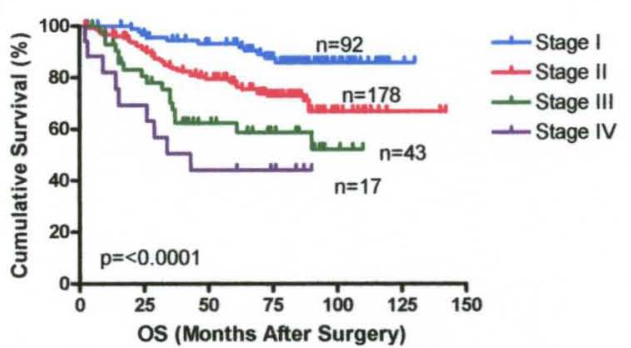

D

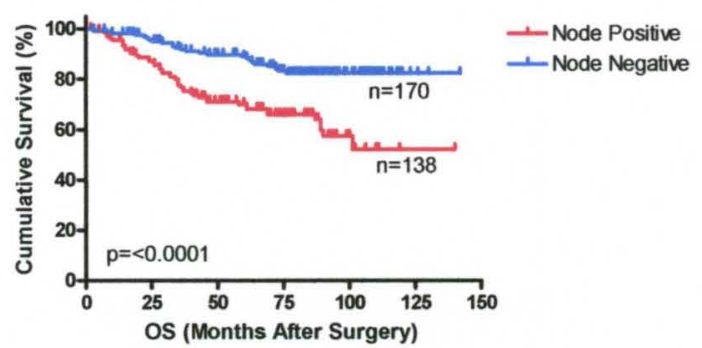

$\mathrm{F}$

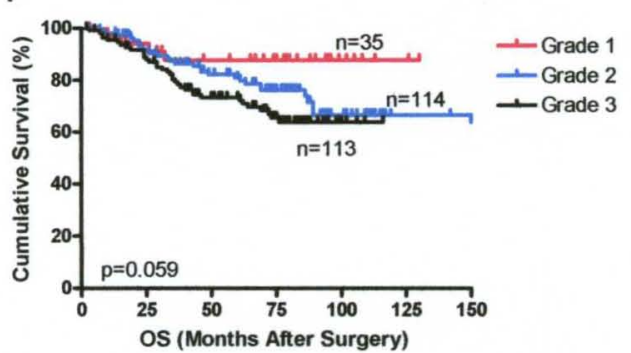

Figure 37. Disease-free and overall survival probabilities of the study population as a function of known prognostic indicators. Kaplan-Meier analyses were used to determine the influence of stage (A \& B), nodal status (C \& D) and grade (E \& F) on disease-free (DFS) and overall (OS) survival. P values were determined using a log-rank test. 
A
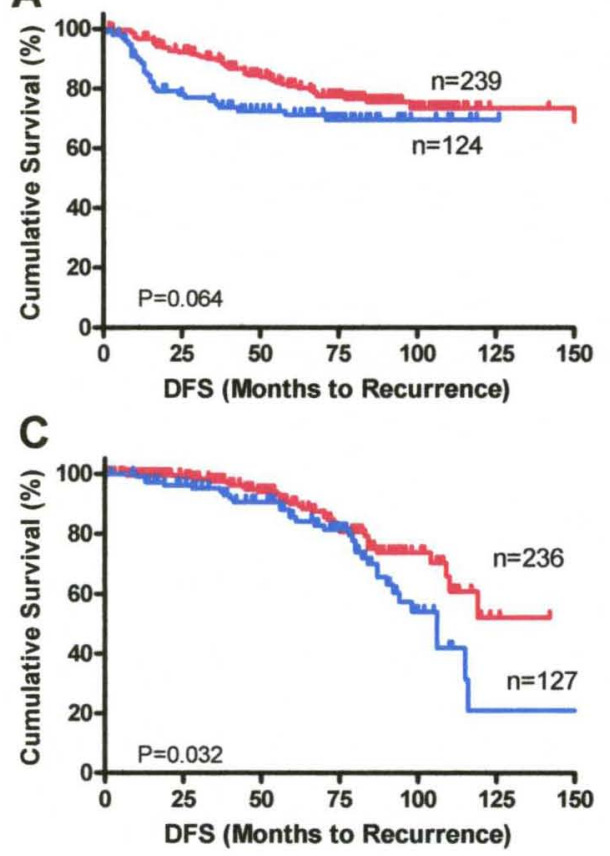

B
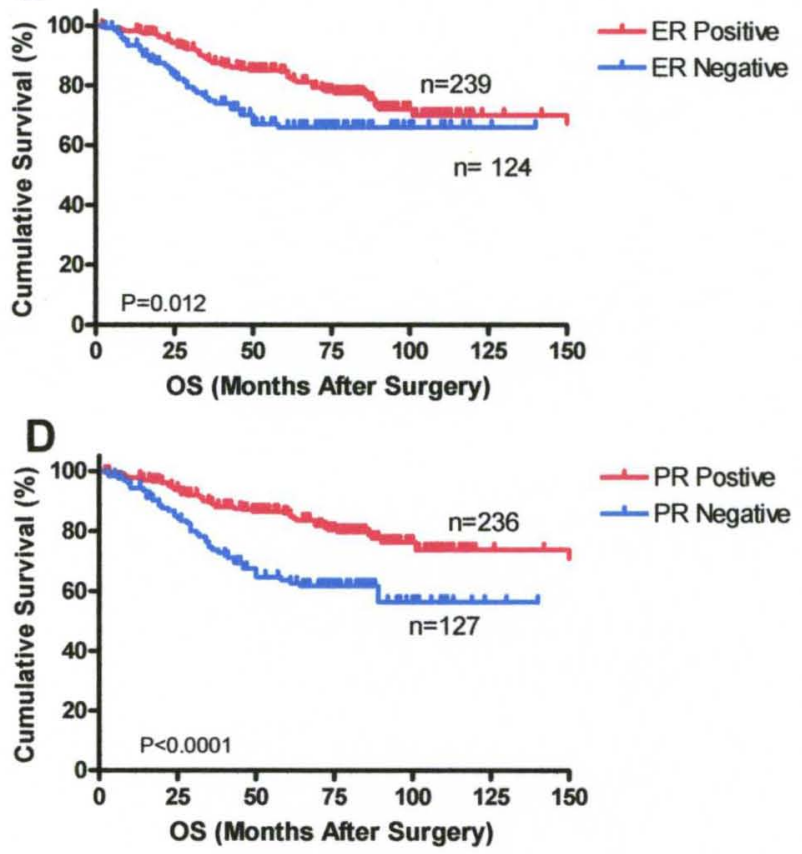

Figure 38. Disease-free and overall survival probabilities of the study population as a function of ER and PR status of the breast carcinomas. Kaplan-Meier analyses were used to determine the influence of ER status (A \& B) and PR status (C \& D) on disease-free (DFS) and overall (OS) survival. Using established criteria, a level greater than 10 fmol/mg protein by ligand binding and $15 \mathrm{fmol} / \mathrm{mg}$ protein by enzyme immunoassay were used to distinguish between ER/PR positive and negative samples [35]. P values were determined using a log-rank test. 

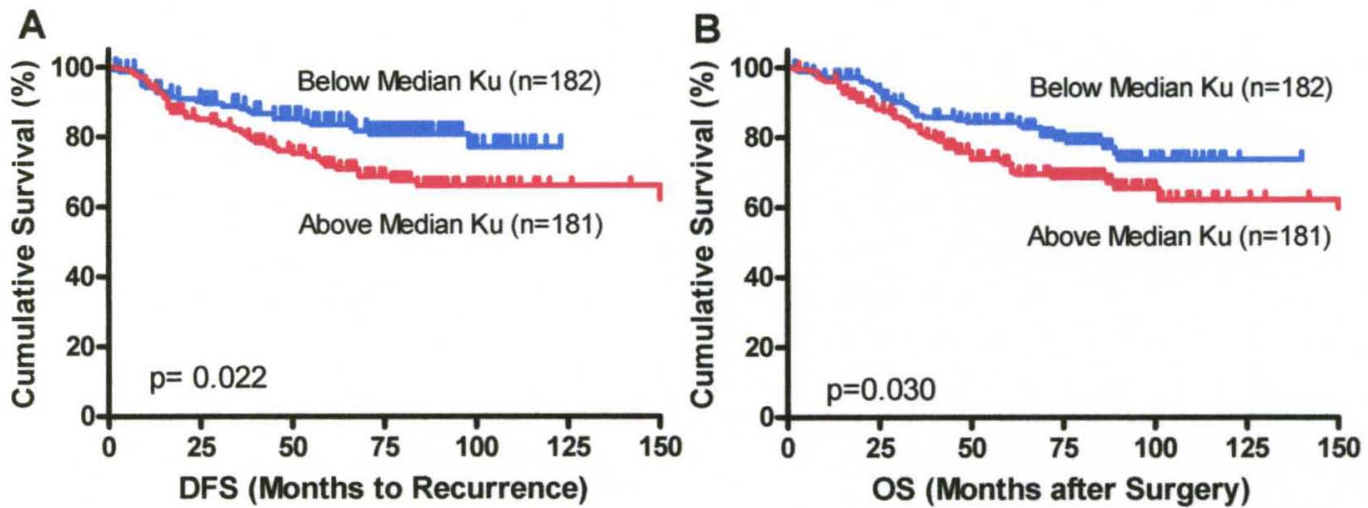

Figure 39. Disease-free and overall survival probabilities as a function of Ku DNAbinding activity in breast carcinomas. Ku DNA-binding activities were measured by EMSA using cytosols prepared and analyzed as described previously. Kaplan-Meier analyses were used to determine the relationship of Ku DNA-binding activities with disease-free (DFS) (A) and overall (OS) (B). The patient population was divided into two groups with either $\mathrm{Ku}$ DNA-binding activities above or below the median value, regardless of ER/PR status. P values were determined using a log-rank test. 
used to determine the relationship of Ku DNA-binding activities with DFS and OS (Figure 39). The patient population was divided into two groups with either Ku DNAbinding activities above or below the median value. Patients with increased Ku DNAbinding activities had decreased disease-free $(\mathrm{p}=0.022)$ and overall survival $(\mathrm{p}=0.030)$ probabilities. DFS percentages for patients with tumors with increased $\mathrm{Ku}$ binding activities were $67 \%$ compared to $79 \%$ for patients with decreased activities $(\mathrm{p}=0.022)$. For OS percentages, patients with tumors with increased $\mathrm{Ku}$ binding activities were $62 \%$ compared to $74 \%$ for patients with decreased $\mathrm{Ku}$ binding activities $(\mathrm{p}=0.030)$.

To analyze the relationship between survival and Ku DNA-binding activity as a continuous variable, univariate Cox regression analysis was performed for both DFS and OS (Table 6). The hazard ratio for DFS was $4.88(\mathrm{p}=0.002)$ while the hazard ratio for OS was $2.14(\mathrm{p}=0.192)$. The hazard ratio is a means of relating the Ku DNA-binding activity value to survival. A hazard ratio of 1 indicates that $\mathrm{Ku}$ DNA-binding activity has no effect on survival, while a value of $<1$ indicates that higher Ku DNA-binding activity is correlated with increased survival. A hazard ratio of $>1$ indicates that higher Ku DNAbinding activity is correlated with decreased survival. Thus the hazard ratios of 4.88 and 2.14 indicate that higher Ku DNA-binding activities in tissue biopsies are associated with decreased survival in breast cancer patients.

In Chapter III, we documented a correlation between Ku DNA-binding activities and protein levels measured by Western blot. To determine if $\mathrm{Ku} 70$ and $\mathrm{Ku} 80$ protein levels also correlated with survival, Kaplan-Meier analyses were used to determine the relationship of Ku protein levels with DFS and OS (Figure 40). Ku70 and Ku80 were measured by Western blot as described previously in a population of 50 patients. The 
Table 6. Influence of Ku DNA-binding activity in frozen breast cytosols from breast carcinomas for predicting the disease-free and overall survival of patients. Univariate Cox regression analyses were performed as a function of $\mathrm{Ku}$ DNA-binding activities determined by EMSA as described previously.

\begin{tabular}{|l|l|l|}
\hline & Hazard Ratio (95\% CI) & P value \\
\hline DFS & $4.88(1.78-13.36)$ & 0.002 \\
\hline OS & $2.14(0.681-6.75)$ & 0.192 \\
\hline
\end{tabular}



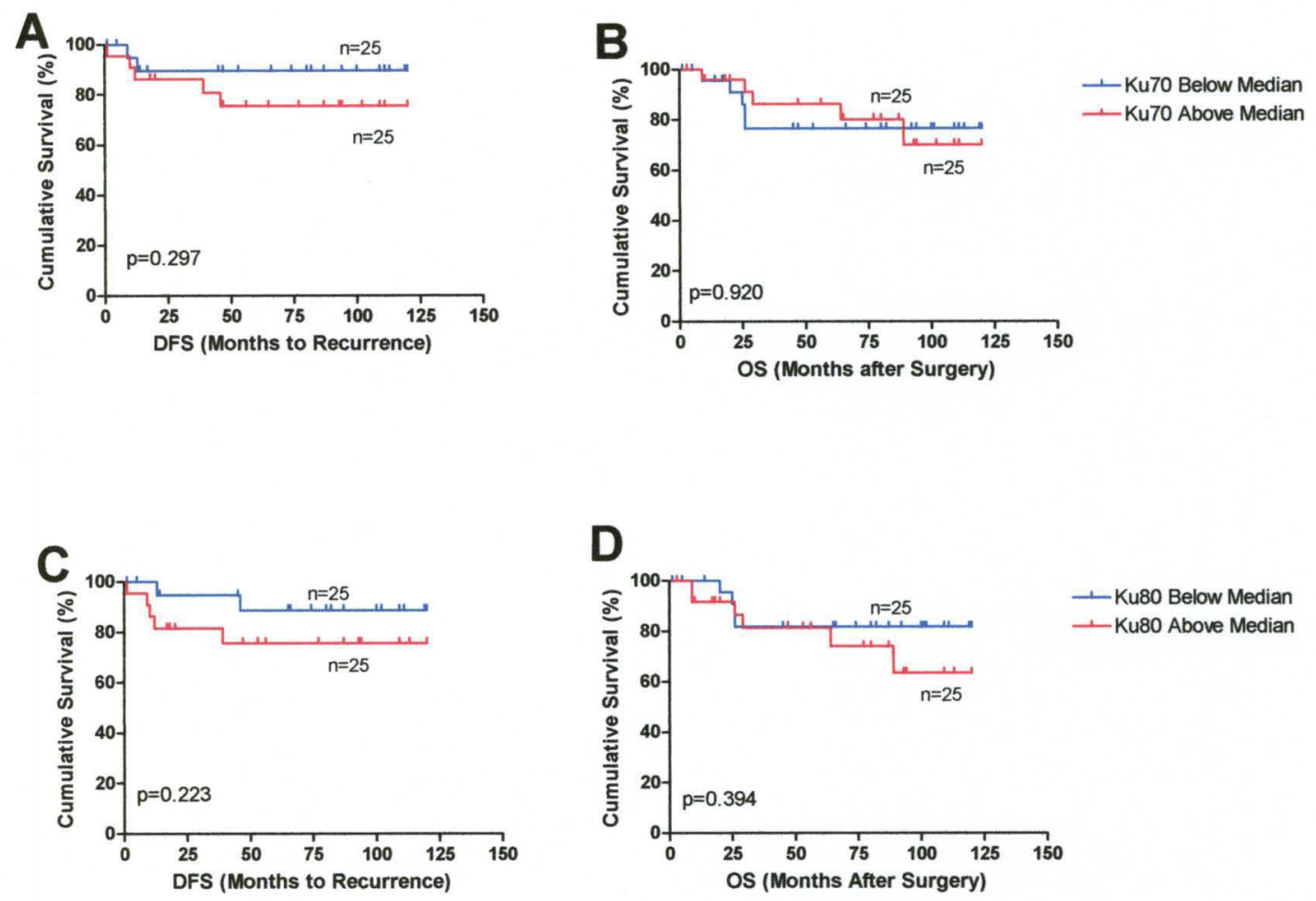

Figure 40. Disease-free and overall survival probabilities as a function of Ku70 and Ku80 protein levels. Ku70 and Ku80 protein levels were measured in previously frozen breast cancer cytosols by Western blot as described in Chapter III. Kaplan-Meier analyses were used to determine the relationship of $\mathrm{Ku} 70$ (A, B) and $\mathrm{Ku} 80$ (C, D) protein levels with DFS and OS. The patient population was divided into two groups with either Ku DNAbinding activities above or below the median value in breast tissue biopsies. These patients had breast cancers that were both ER negative and positive. P values were determined using a log-rank test. 
patient population was divided into two groups according to $\mathrm{Ku}$ protein levels either above or below the median value in breast cancers. $P$ values were determined using a logrank test. The same trend of higher Ku levels associating with lower survival probabilities was observed for DFS, although it was not statistically significant. However, there was no correlation with OS. This is most likely due to the small population size and an expanded study is warranted in a larger group of breast cancer specimens.

Disease-free and overall survival probabilities as a function of XRCC5 (Ku80) or XRCC6 (Ku70) gene expression levels were also analyzed (Figure 41). Kaplan-Meier analyses were performed using gene expression data from microarray analysis of LCMprocured carcinoma cells from 247 biopsies [200;248] to determine the influence on DFS and OS. The patient population was divided into two groups with breast carcinomas exhibiting either $\mathrm{Ku}$ gene expression levels above or below the median value. No significant correlation with survival was observed for either DFS or OS.

These data are inconsistent with the earlier clinical correlations with the DNAbinding activities as well as the studies by Saviozzi et al. and Ghezzi et al. Both of these studies measured gene expression levels by qRT-PCR instead of microarray. Because of the broad nature of microarray analysis, qRT-PCR is a more accurate method of validating gene expression data [249]. Microarray results are usually validated by qRTPCR.

Another possible explanation for the difference observed is tissue specific variability in expression. Our study focuses on breast tumors while the Saviozzi and Ghezzi studies focused on lung and colorectal tumors. Furthermore, post-translational modifications may play a role in the ability of $\mathrm{Ku}$ binding to DNA, since $\mathrm{Ku}$ has been 
XRCC5
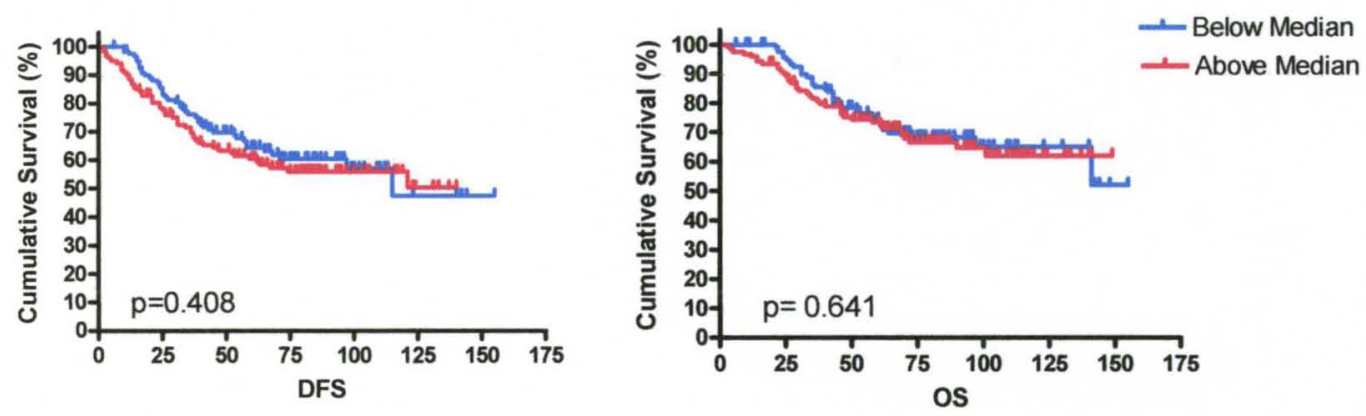

XRCC6
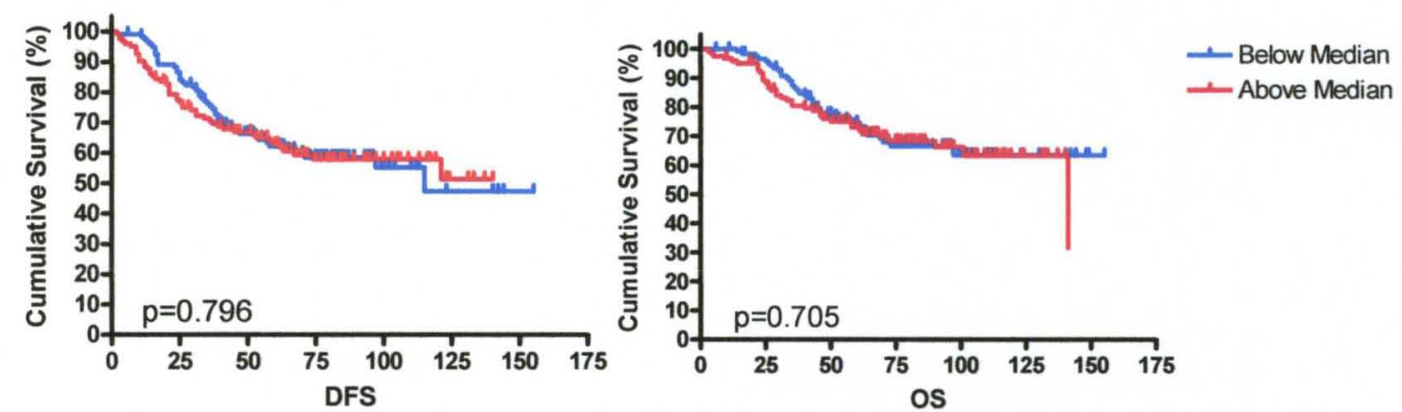

Figure 41. Disease-free and overall survival probabilities as a function of XRCC5 (Ku80) or XRCC6 (Ku70) gene expression levels in breast carcinomas. Kaplan-Meier analyses were performed using gene expression data from microarray analysis of pure populations of breast carcinoma cells procured by LCM from 247 biopsies [200;248] to determine the relationship with DFS and OS. The median value of gene expression results was used as a cutoff. $P$ values were determined using a log-rank test. 
reported to be both acetylated and phopshorylated [246;250;251]. Ku70 and Ku80 are targets of phosphorylation by DNA-PK and this phosphorylation apparently controls their localization, DNA-binding and function [251]. The C-terminal region of Ku70 is acetylated by CBP and PCAF, disrupting the Ku70-Bax interaction [250].

Correlation of Ku DNA-binding activities with survival in various sub-populations of patients

Since ER and PR expression in a primary breast cancer biopsy serve as indicators of a patient's prognosis, we combined ER/PR status with either above or below median Ku DNA-binding activity to determine the relationship with DFS and OS (Figure 42). Survival results of patients with ER-/PR- breast carcinomas accepted as those with the poorest prognosis are shown in A and B. Survival results for patients with tumors that are either ER-/PR+ or ER+/PR- breast carcinomas are shown in C and D, while those from patients with the best prognosis exhibiting breast cancers that are $\mathrm{ER}+/ \mathrm{PR}+$ are shown in $\mathrm{E}$ and $\mathrm{F}$. The median Ku DNA-binding activity of the entire population of 363 patients was used as a cutoff. A level greater than $10 \mathrm{fmol} / \mathrm{mg}$ protein by ligand binding and 15 $\mathrm{fmol} / \mathrm{mg}$ protein by enzyme immunoassay were used to distinguish between either ER or PR positive and negative samples [35]. P values were determined using a log-rank test.

A significant difference in DFS and OS was not observed between the patients with either increased or decreased $\mathrm{Ku}$ activities that also had $\mathrm{ER}+/ \mathrm{PR}+$ breast carcinomas. However, breast cancer patients with tumors that are either ER-/PR-, ER+/PR- or ER-/PR+ and exhibit above median Ku DNA-binding activities exhibited the 

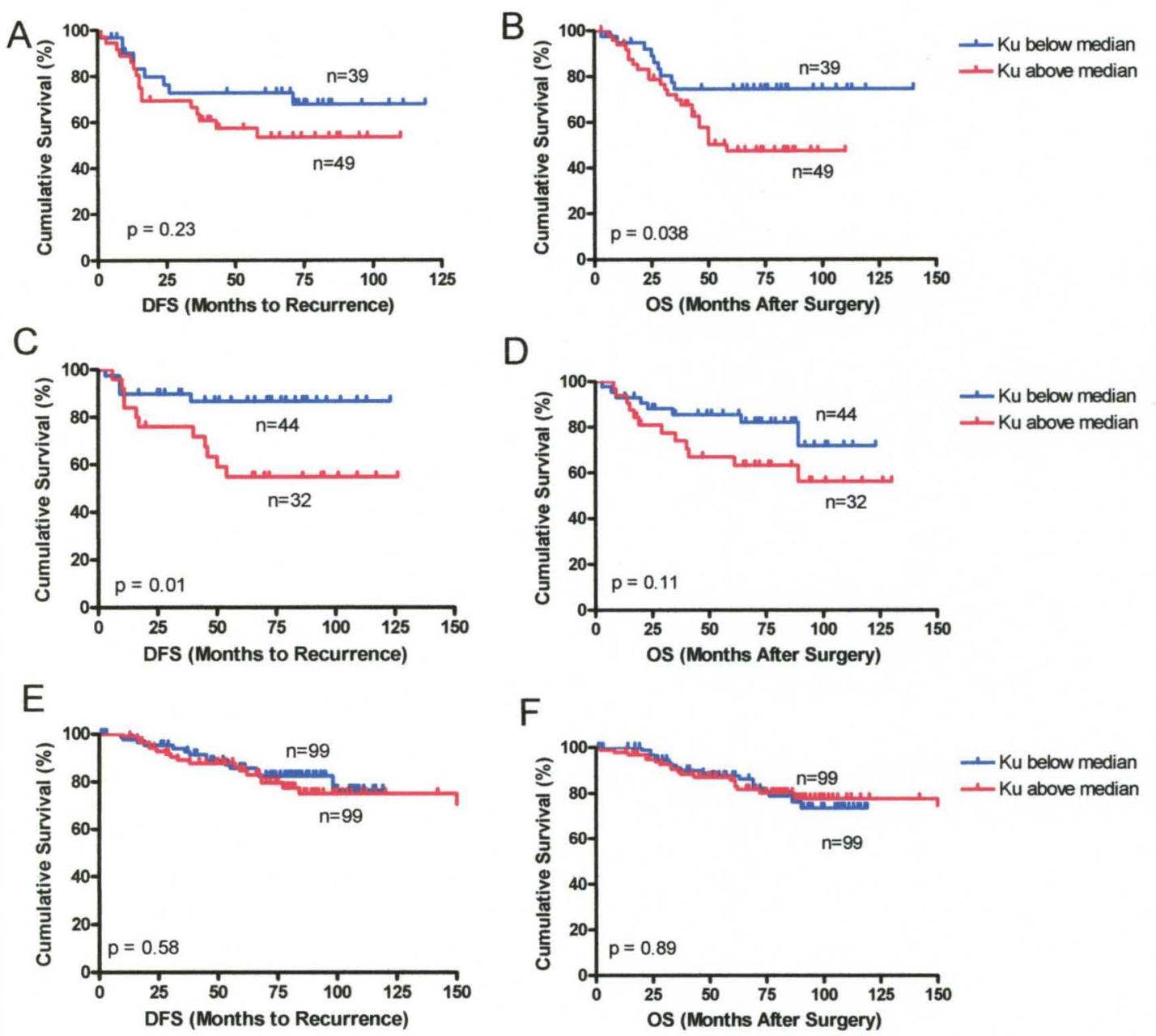

Figure 42. Disease-free and overall survival probabilities as a function of both Ku DNAbinding activity and ER/PR status of breast carcinomas. Ku DNA-binding activities were evaluated according to ER/PR status and Kaplan-Meier analyses were used to determine the relationship with DFS and OS. Survival results of patients with ER-/PR- breast carcinomas are shown in A and B. Survival results for patients with tumors that are either $\mathrm{ER}-/ \mathrm{PR}+$ or $\mathrm{ER}+/ \mathrm{PR}-$ breast carcinomas are shown in $\mathrm{C}$ and $\mathrm{D}$, while those that are $\mathrm{ER}+/ \mathrm{PR}+$ are shown in $\mathrm{E}$ and $\mathrm{F}$. The median Ku DNA-binding activity of carcinomas from the entire population of 363 patients was used as a cutoff. A level greater than 10 
fmol/mg protein by ligand binding and $15 \mathrm{fmol} / \mathrm{mg}$ protein by enzyme immunoassay were used to distinguish between ER positive and negative samples [35]. P values were determined using a log-rank test. 
poorest OS and DFS. Breast carcinomas that do not express ER or PR as well as those expressing only one of these receptor proteins are generally found to be more aggressive and less differentiated than $\mathrm{ER}+/ \mathrm{PR}+$ breast cancers [3]. Since $\mathrm{Ku}$ expression is increased in more aggressive cancers, it would be expected that $\mathrm{Ku}$ DNA-binding activity exhibits a stronger association with decreased survival in breast cancers that are ER and/or PR negative. These patients are also much less likely to respond to drugs such as tamoxifen $[25 ; 26]$.

Since nodal status is a major prognostic factor in breast cancer, we assessed the relationship between $\mathrm{Ku}$ DNA-binding activities in tissue biopsies with patient survival as a function of nodal status (Figure 43). Ku DNA-binding activities were combined with nodal status and Kaplan-Meier analysis was used to determine the relationship with DFS and OS. Survival results of patients with node negative breast carcinomas are shown in A and $\mathrm{B}$, while those for node positive breast carcinomas are shown in $\mathrm{C}$ and $\mathrm{D}$. The median $\mathrm{Ku}$ DNA-binding activity of the entire population of 363 patients was used as a cutoff. P values were determined using a log-rank test. Increased $\mathrm{Ku}$ DNA-binding activity was associated with decreased DFS in node positive patients $(p=0.046)$, however the relationship was not statistically significant in node negative patients. This also supports our observation that $\mathrm{Ku}$ DNA-binding activity in a tissue biopsy has increased relevance for predicting more aggressive cancers and increased risk of recurrence.

To confirm that these results are independent of therapy received, a subset of patients that received surgery alone without adjuvant therapy was analyzed by KaplanMeier (Figure 44). Patients with tumors exhibiting $\mathrm{Ku}$ DNA-binding activities in the 
above median group had decreased DFS $(\mathrm{p}=0.150)$ and $\mathrm{OS}(\mathrm{p}=0.003)$ probabilities. Although the $\mathrm{p}$ value for DFS was not significant, the trend of higher Ku DNA-binding activities being associated with decreased survival probabilities was observed. These results suggest that the use of Ku-binding activity as a predictor of risk of recurrence is independent of therapy received by the patient.

Because $\mathrm{Ku}$ is involved in DNA repair and certain chemotherapies induce DNA damage, we wanted to determine the clinical utility of Ku DNA-binding in a subset of patients receiving only adjuvant chemotherapy. Patients described in this population had been treated with various combinations of the DNA damaging agents doxorubicin, cyclophosphamide, methotrexate or 5-fluorouracil. Doxorubicin is an anthracycline that works by intercalating DNA, while cyclophosphamide is an alkylating agent that attaches an alkyl group to guanine bases in DNA. Methotrexate is an anti-folate that inhibits dihydrofolate reductase thereby blocking thymidine synthesis. Furthermore, 5fluorouracil is a pyrimidine analog that inhibits thymidylate synthase. Kaplan-Meier analyses were used to determine the relationship of $\mathrm{Ku}$ DNA-binding activities to disease-free and overall survival in 43 patients receiving surgery and adjuvant chemotherapy (Figure 45). All patients were without distant metastases at presentation. The median value of the Ku DNA-binding activities in cancers from the entire population of 363 patients was used as a cutoff. P values were determined using a log-rank test. Increased $\mathrm{Ku}$ DNA-binding activities were associated with decreased DFS $(\mathrm{p}=0.004)$ and OS ( $p=0.009)$ in a statistically significant manner. After 125 months, $97 \%$ of patients with breast cancers in the below median group had not developed a recurrence compared 


\section{Node Negative}
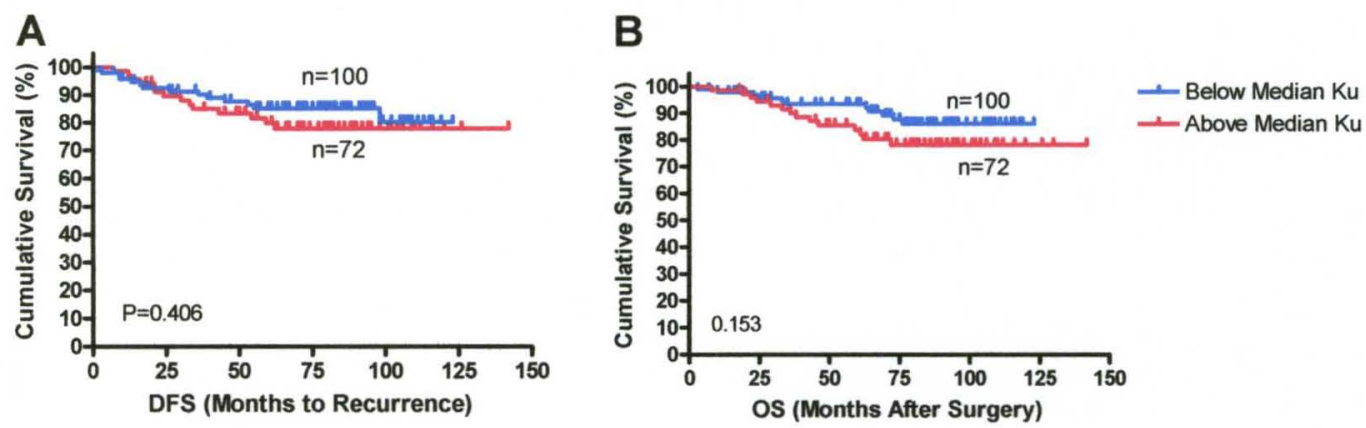

Node Positive
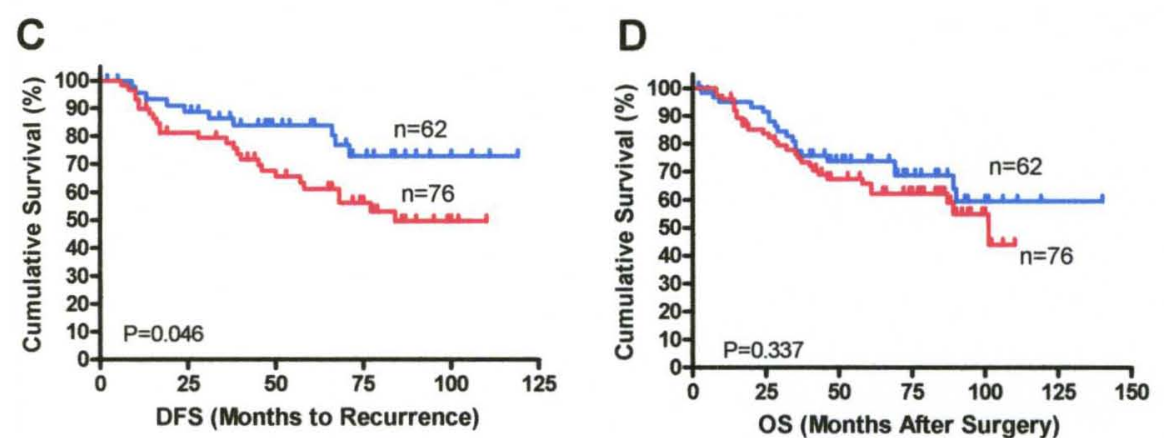

Figure 43. Disease-free and overall survival probabilities as a function of both $\mathrm{Ku}$ DNAbinding activity and nodal status of breast carcinomas. Ku DNA-binding activities were evaluated according to nodal status and Kaplan-Meier analyses were used to determine the relationship with DFS and OS. Survival results of patients with node negative breast carcinomas are shown in $\mathrm{A}$ and $\mathrm{B}$, while those for node positive breast carcinomas are shown in $\mathrm{C}$ and $\mathrm{D}$. The median Ku DNA-binding activity of carcinomas from the entire population of 363 patients was used as a cutoff. P values were determined using a logrank test. 

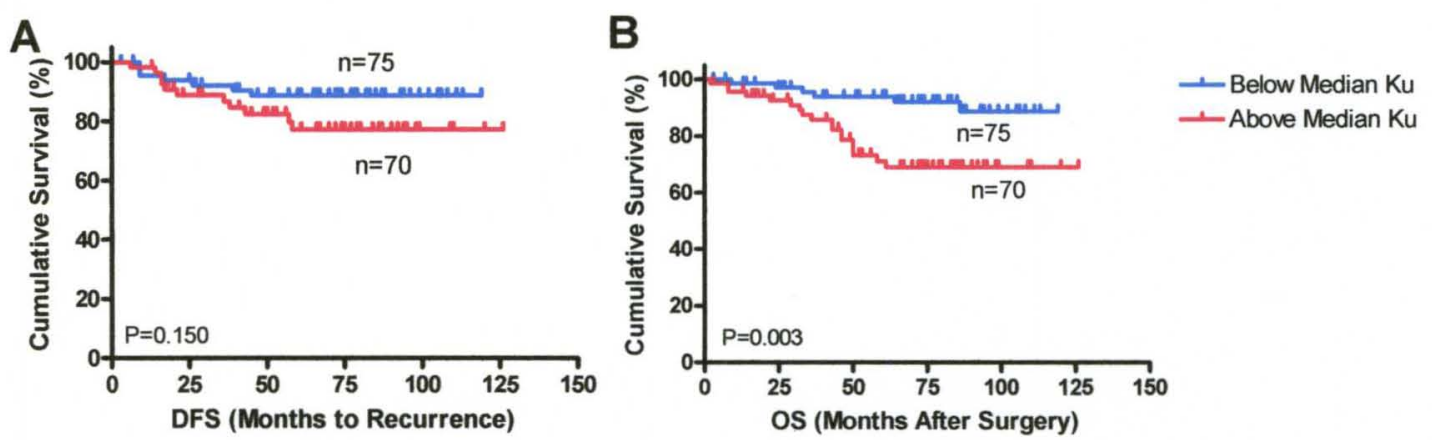

Figure 44. Disease-free and overall survival probabilities as a function of Ku DNAbinding activity in cytosols of breast cancers regardless of ER and PR status from a subpopulation of patients receiving no adjuvant therapy. Ku DNA-binding activities were measured by EMSA and Kaplan-Meier analyses were used to determine the relationship to DFS (A) and OS (B) survival. Patients received surgery only and no adjuvant therapy. The median value of the Ku DNA-binding activities of carcinomas from the entire population of 363 patients was used as a cutoff. P values were determined using a logrank test. 

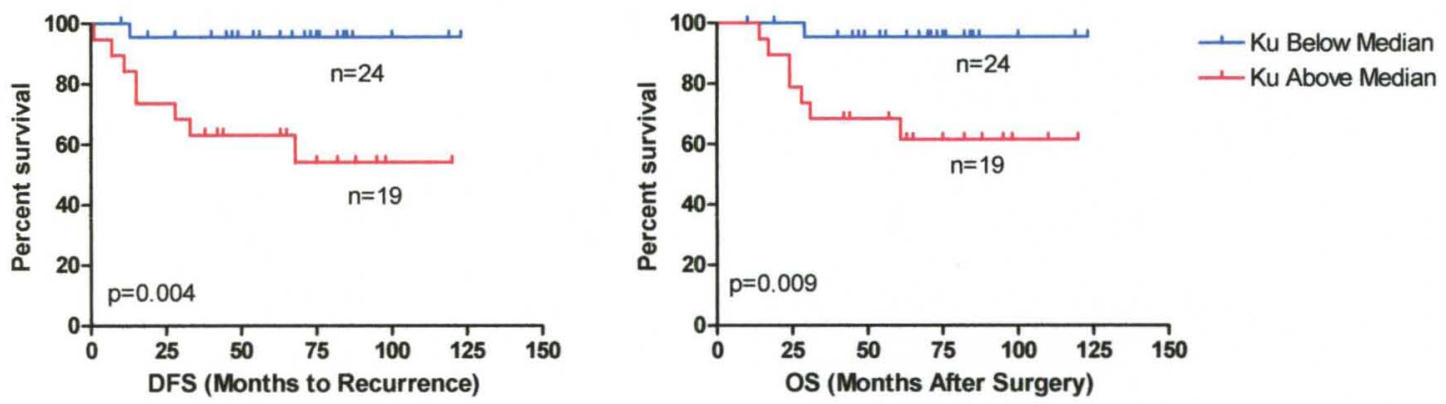

Figure 45. Disease-free and overall survival probabilities as a function of Ku DNAbinding activity in cytosols of breast cancers regardless of ER and PR status from a subpopulation of patients receiving adjuvant chemotherapy. Ku DNA-binding activities were measured by EMSA and Kaplan-Meier analyses were used to determine the relationship to DFS (A) and OS (B). Patients received surgery and adjuvant chemotherapy. The median value of the Ku DNA-binding activities of carcinomas from the entire population of 363 patients was used as a cutoff. P values were determined using a log-rank test. 
to only $55 \%$ in the above median group. A Fisher's exact test was used to determine whether a difference exists between these two groups in relation to grade and nodal status; however no significant differences were found (Table 7). The Fisher's exact test was used instead of chi-square analyses due to the small population size. Additionally, no significant difference was found in average tumor size between groups. These data underscore the importance of this research since we have shown that $\mathrm{Ku}$ DNA-binding activity in a breast tumor biopsy may predict response to chemotherapy independent of nodal status, tumor grade or tumor size.

Our results show that increased $\mathrm{Ku}$ DNA-binding activities in breast cancer tumors are associated with lower survival probabilities under a variety of clinical and tumor marker states. Several studies discussed earlier found that over-expression of $\mathrm{Ku} 70$ and $\mathrm{Ku} 80$ is associated with tumor progression in breast, lung, colorectal, skin, gastric and cervical carcinomas [238-243]. Ku levels in the majority of these studies were measured either by IHC or qRT-PCR. Additionally, only two studies measured the DNAbinding activities of $\mathrm{Ku}$ in tumor extracts $[241 ; 243]$. Both studies showed that $\mathrm{Ku}$ DNAbinding activities were increased in cancer tissue extracts compared to normal tissue extracts. Pucci et al., using breast cancer cytosolic extracts, reported $\mathrm{Ku}$ DNA-binding activities were increased 2 to 10 -fold in tumors compared to those from normal tissue [243]. However, a limitation of this study was the small population size $(n=8)$.

Parella et al. showed that an increase in DNA-binding activity was observed in both basal and squamous cell skin carcinomas compared to normal skin. The overexpression of both $\mathrm{Ku}$ proteins was also associated with an increased tumor proliferation 
Table 7. Comparison of clinical parameters between the two prognostic groups in a subset of patients receiving adjuvant chemotherapy only. Grade and nodal status were analyzed by a Fisher's exact test. For tumor size, mean \pm SEM was compared by a MannWhitney test.

\begin{tabular}{|l|c|c|c|}
\hline & Ku Below Median $(\mathrm{n}=24)$ & Ku Above Median $(\mathrm{n}=19)$ & $\mathrm{p}$ \\
\hline Grade 1 and 2 & 4 & 6 & 0.45 \\
Grade 3 and 4 & 15 & 10 & \\
\hline Node Negative & 12 & 7 & 0.54 \\
Node Positive & 12 & 11 & \\
\hline Tumor Size $(\mathrm{mm})$ & $26 \pm 2$ & $29 \pm 4$ & 0.98 \\
\hline
\end{tabular}


rate. Although our investigation did not examine Ku DNA-binding activities in normal breast specimens, our data also suggest that higher Ku activity is associated with tumor progression and metastasis. We observed a significant correlation with higher tumor grade and lymph node positive cancers, both indicators of more aggressive breast cancers.

Two of the studies discussed earlier correlated $\mathrm{Ku}$ expression levels with patient survival. Wilson et al. measured Ku70 and Ku80 protein levels by IHC in 77 cervical carcinoma biopsies [242]. Kaplan-Meier survival analysis showed that high Ku70 and Ku80 levels were associated with lower overall survival probabilities in patients receiving radiotherapy. The percent survival at 60 months for patients with tumors exhibiting high Ku70 expression compared to those with low expression was $47 \%$ and $69 \%$, respectively $(p=0.046)$. The percent survival at 60 months for patients with tumors exhibiting high Ku80 expression compared to those with low expression was 50\% and $69 \%$, respectively $(\mathrm{p}=0.087)$. Saviozzi et al. correlated Ku80 gene expression levels in non-small cell lung cancer biopsies with overall survival of 50 patients [238]. KaplanMeier survival analysis showed that high Ku80 levels in lung lesions were associated with lower overall survival probabilities. The percent survival at 60 months for patients with lung tumors with high Ku80 expression compared to those with low expression was $15 \%$ and $68 \%$, respectively $(\mathrm{p}=0.04)$. Cox regression analysis also showed that Ku80 over-expression was associated with poor prognosis (hazard ratio $=0.005)$.

The results of both these studies with different types of carcinoma are similar to our results with breast cancer which showed that DFS percentages for patients with 
tumors with high $\mathrm{Ku}$ binding activities compared to those with low activities were $67 \%$ and $79 \%$, respectively $(\mathrm{p}=0.022)$. Patients with tumors with high $\mathrm{Ku}$ binding activities compared to low exhibited OS values of $62 \%$ and $74 \%$, respectively $(\mathrm{p}=0.030)$. This work extends beyond protein expression and correlates DNA-binding activity with prognosis. Furthermore, our investigation has utilized a much larger patient population than the studies previously mentioned.

Our results also suggested that Ku DNA-binding activity in a breast tumor biopsy may predict response to chemotherapy. Over-expression of DNA repair proteins in a tumor cell potentially may promote resistance to DNA damage induced by chemotherapy and radiation leading to a less effective therapeutic outcome. Several studies have reported that $\mathrm{Ku} 70$ and $\mathrm{Ku} 80$ expression is related to resistance to radiotherapy. As discussed above, Wilson et al. measured Ku70 and Ku80 protein levels by IHC in 77 cervical carcinoma biopsies [242]. Kaplan-Meier survival analysis indicated that high Ku70 and Ku80 levels were associated with lower overall survival probabilities in patients receiving radiotherapy.

Beskow et al. also reported that cervical cancer patients resistant to radiotherapy over-express $\mathrm{Ku} 70$ and $\mathrm{Ku} 80$, as determined by IHC [252]. In addition, Komuro et al. reported similar results in patients with rectal carcinoma [253]. Ku70 and Ku80 protein levels measured by IHC significantly correlated with radiotherapy resistance while overexpression of both proteins associated with shorter disease-free survival times in patients receiving radiotherapy. Lee et al. reported that high Ku70 protein expression in nasopharyngeal carcinoma also correlated with resistance to therapy [254]. They suggested that $\mathrm{Ku} 70$ expression predicts response to radiotherapy as well as response to 
radiotherapy with concurrent chemotherapy in patients with this aggressive cancer. In breast cancer, Leifler et al. reported that low protein expression of Ku70 and Ku80 predicted a good response to radiotherapy [255]. These results suggest that tumors with high levels of Ku70 and Ku80 are able to repair damaged DNA after radio- or chemotherapy allowing them to survive and proliferate.

As documented in the preceding discussion, there is emerging evidence from studies of various types of cancer that the XRCC5 and XRCC6 genes and their protein products, Ku80 and Ku70 are correlated with a broad spectrum of clinical features and disease parameters in patients. Thus far, no common relationship has been discerned between $\mathrm{Ku} 70 / \mathrm{Ku} 80$ expression and a particular clinical behavior. To our knowledge, our results using a short, defined DNA sequence represent the first correlation between $\mathrm{Ku}$ DNA-binding activity and response to chemotherapy in breast cancer.

Resistance to cytotoxic therapy is likely only part of the reason that patients with tumors either over-expressing Ku70 and Ku80 protein levels or showing increased DNAbinding activities have shorter survival times than patients with tumors expressing lower $\mathrm{Ku}$ levels. Our results also indicated that this trend is true in patients receiving only surgical resection of the primary tumor, suggesting additional mechanisms for this difference in survival. Since NHEJ is error-prone and has been reported to cause chromosomal rearrangements, an over-expression of $\mathrm{Ku}$ may lead to increased chromosomal instability and tumor progression [256;257]. This is especially important in breast tissue because of the extensive differentiation, proliferation and apoptosis that occurs during development in utero, puberty, monthly pre-menopausal cycles and pregnancy [100-102]. These high proliferation rates enhance the likelihood of DNA 
breaks [241]. To complicate the possible mechanism further, $\mathrm{Ku}$ is also involved in telomere maintenance and apoptosis. Ku70 has been reported to be associated with telomere shortening in gastric cancer, leading to genetic instability and carcinogenesis [240]. Ku70 expression also appears to be related to suppression of apoptosis, an important mechanism in tumor suppression [258]. Over-expression of Ku70 sequesters the pro-apoptotic protein Bax from the mitochondria rendering it inactive [144;250]. These mechanistic studies provide supportive evidence for the molecular basis of the clinical correlations observed from our investigations of breast carcinoma.

\section{Summary $\&$ Conclusions}

The purpose of the investigations reported in this Chapter was to examine the clinical value of determining Ku DNA-binding activity in breast cancer tissue biopsies such as assessing risk of recurrence and overall survival as well as response to therapies. Better understanding of the relationship between $\mathrm{Ku}$ DNA-binding activity in breast cancer biopsies and breast cancer behavior will help define $\mathrm{Ku}$ as a potential prognostic biomarker.

Our results demonstrated that increased Ku DNA-binding activities measured in cytosols of breast tumor biopsies correlated with higher grade tumors, positive lymph node status and disease-free and overall survival. These results were also detected in a subset of patients that didn't receive adjuvant therapy. Most importantly, these results were also observed in patients receiving adjuvant chemotherapy, suggesting that $\mathrm{Ku}$ DNA-binding activities may be used to predict response to treatment with toxic agents. Cox regression analysis indicated that higher Ku DNA-binding activities were associated 
with an increased risk of breast cancer recurrence and decreased survival. Collectively, our results suggest that $\mathrm{Ku}$ DNA-binding activities in cytosols prepared from breast cancer biopsies may be used as potential biomarkers to improve breast cancer management. 


\section{REFERENCES}

1. Jemal A, Siegel R, Xu J, Ward E. Cancer statistics, 2010. CA Cancer J Clin 2010; 60(5):277-300.

2. Kohler BA, Ward E, McCarthy BJ, Schymura MJ, Ries LA, Eheman C et al. Annual report to the nation on the status of cancer, 1975-2007, featuring tumors of the brain and other nervous system. J Natl Cancer Inst 2011; 103(9):714-736.

3. Lester SC. The Breast. In: Kumar V, Abbas AK, Fausto N, editors. Pathologic Basis of Disease. Seventh ed. 2010. p. 1119-1154.

4. Familial breast cancer: collaborative reanalysis of individual data from 52 epidemiological studies including 58,209 women with breast cancer and 101,986 women without the disease. Lancet 2001; 358(9291):1389-1399.

5. Colditz GA, Rosner B. Cumulative risk of breast cancer to age 70 years according to risk factor status: data from the Nurses' Health Study. Am J Epidemiol 2000; 152(10):950-964.

6. Eliassen AH, Missmer SA, Tworoger SS, Spiegelman D, Barbieri RL, Dowsett M et al. Endogenous steroid hormone concentrations and risk of breast cancer among premenopausal women. J Natl Cancer Inst 2006; 98(19):1406-1415.

7. Eliassen AH, Colditz GA, Rosner B, Willett WC, Hankinson SE. Adult weight change and risk of postmenopausal breast cancer. JAMA 2006; 296(2):193-201.

8. Hamajima N, Hirose K, Tajima K, Rohan T, Calle EE, Heath CW, Jr. et al. Alcohol, tobacco and breast cancer--collaborative reanalysis of individual data from 53 epidemiological studies, including 58,515 women with breast cancer and 95,067 women without the disease. Br J Cancer 2002; 87(11):1234-1245.

9. Henderson TO, Amsterdam A, Bhatia S, Hudson MM, Meadows AT, Neglia JP et al. Systematic review: surveillance for breast cancer in women treated with chest radiation for childhood, adolescent, or young adult cancer. Ann Intern Med 2010; 152(7):444-455.

10. Venkitaraman AR. Cancer susceptibility and the functions of BRCA1 and BRCA2. Cell 2002; 108(2):171-182. 
11. de Jong MM, Nolte IM, te Meerman GJ, van der Graaf WT, Oosterwijk JC, Kleibeuker JH et al. Genes other than BRCA1 and BRCA2 involved in breast cancer susceptibility. J Med Genet 2002; 39(4):225-242.

12. Bland KI, Copeland EM. The Breast: Comprehensive Management of Benign and Malignant Diseases. Fourth ed. Philadelphia, PA: Saunders; 2009.

13. Donegan WL, Spratt JS. Cancer of the Breast. Fifth ed. St. Louis: Saunders; 2002.

14. Meijers-Heijboer $\mathrm{H}$, van den Ouweland A, Klijn J, Wasielewski M, de SA, Oldenburg $\mathrm{R}$ et al. Low-penetrance susceptibility to breast cancer due to CHEK2 $(*) 1100$ delC in noncarriers of BRCA1 or BRCA2 mutations. Nat Genet 2002; 31(1):55-59.

15. Chalhoub N, Baker SJ. PTEN and the PI3-kinase pathway in cancer. Annu Rev Pathol 2009; 4:127-150.

16. McCubrey JA, Steelman LS, Kempf CR, Chappell WH, Abrams SL, Stivala F et al. Therapeutic resistance resulting from mutations in Raf/MEK/ERK and PI3K/PTEN/Akt/mTOR signaling pathways. J Cell Physiol 2011; 226(11):27622781.

17. Rhei E, Kang L, Bogomolniy F, Federici MG, Borgen PI, Boyd J. Mutation analysis of the putative tumor suppressor gene PTEN/MMAC1 in primary breast carcinomas. Cancer Res 1997; 57(17):3657-3659.

18. Mahavni V, Sood AK. Hormone replacement therapy and cancer risk. Curr Opin Oncol 2001; 13(5):384-389.

19. Ross RK, Paganini-Hill A, Wan PC, Pike MC. Effect of hormone replacement therapy on breast cancer risk: estrogen versus estrogen plus progestin. J Natl Cancer Inst 2000; 92(4):328-332.

20. Wittliff JL, Pasic R, Bland KI. Steroid and Peptide Hormone Receptors: Methods, Quality Control and Clinical Use. In: Bland KI, Copeland III EM, editors. The Breast: Comprehensive Management of Benign and Malignant Diseases. Philadelphia, PA: W.B. Saunders Co.; 1998. p. 458-498.

21. Buller RE, O'Malley BW. The biology and mechanism of steroid hormone receptor interaction with the eukaryotic nucleus. Biochem Pharmacol 1976; 25(1):1-12.

22. Jensen EV, Jordan VC. The estrogen receptor: a model for molecular medicine. Clin Cancer Res 2003; 9(6):1980-1989.

23. Wittliff JL. Steroid receptor interactions in human breast carcinoma. Cancer 1980; 46(12 Suppl):2953-2960. 
24. Wittliff JL. Steroid-hormone receptors in breast cancer. Cancer 1984; 53(3 Suppl):630-643.

25. Fisher B, Redmond C, Brown A, Wolmark N, Wittliff J, Fisher ER et al. Treatment of primary breast cancer with chemotherapy and tamoxifen. $\mathrm{N}$ Engl $\mathrm{J}$ Med 1981; 305(1):1-6.

26. Fisher B, Redmond C, Brown A, Wickerham DL, Wolmark N, Allegra J et al. Influence of tumor estrogen and progesterone receptor levels on the response to tamoxifen and chemotherapy in primary breast cancer. J Clin Oncol 1983; $1(4): 227-241$.

27. AJCC Staging Manual. 7th Ed ed. New York, NY: Springer-Verlag; 2010.

28. Gasparini G, Pozza F, Harris AL. Evaluating the potential usefulness of new prognostic and predictive indicators in node-negative breast cancer patients. $J$ Natl Cancer Inst 1993; 85(15):1206-1219.

29. Lyman GH, Giuliano AE, Somerfield MR, Benson AB, III, Bodurka DC, Burstein $\mathrm{HJ}$ et al. American Society of Clinical Oncology guideline recommendations for sentinel lymph node biopsy in early-stage breast cancer. J Clin Oncol 2005; 23(30):7703-7720.

30. Elkin EB, Hudis C, Begg CB, Schrag D. The effect of changes in tumor size on breast carcinoma survival in the U.S.: 1975-1999. Cancer 2005; 104(6):11491157.

31. Elston CW, Ellis IO. Pathological prognostic factors in breast cancer. I. The value of histological grade in breast cancer: experience from a large study with longterm follow-up. Histopathology 1991; 19(5):403-410.

32. Colozza M, Azambuja E, Cardoso F, Sotiriou C, Larsimont D, Piccart MJ. Proliferative markers as prognostic and predictive tools in early breast cancer: where are we now? Ann Oncol 2005; 16(11):1723-1739.

33. Meyer JS, Wittliff JL. Regional heterogeneity in breast carcinoma: thymidine labelling index, steroid hormone receptors, DNA ploidy. Int J Cancer 1991; 47(2):213-220.

34. von RA. Aneuploidy as a prognostic factor in breast cancer. Med Oncol Tumor Pharmacother 1989; 6(2):117-120.

35. Hammond ME, Hayes DF, Dowsett M, Allred DC, Hagerty KL, Badve S et al. American Society of Clinical Oncology/College Of American Pathologists guideline recommendations for immunohistochemical testing of estrogen and progesterone receptors in breast cancer. J Clin Oncol 2010; 28(16):2784-2795. 
36. Mangelsdorf DJ, Thummel C, Beato M, Herrlich P, Schutz G, Umesono K et al. The nuclear receptor superfamily: the second decade. Cell 1995; 83(6):835-839.

37. Payne SJ, Bowen RL, Jones JL, Wells CA. Predictive markers in breast cancer-the present. Histopathology 2008; 52(1):82-90.

38. McGuire WL, De La Garza M, Chamness GC. Evaluation of estrogen receptor assays in human breast cancer tissue. Cancer Res 1977; 37(3):637-639.

39. Wittliff JL. Methods in Clinical Chemistry. St. Louis, MO: The C.V. Mosby Company; 1975.

40. Wittliff J, Fisher G, Durant J. Establishment of Uniformityin Steroid Receptor Analyses Used in Cooperative Clinical Trials of Breast Cancer Treatment. In: Henningsen B, Linder F, Steichele C, editors. Recent Results in Cancer Research. Heidelberg: Springer-Verlag; 1980. p. 198-206.

41. Scatchard G. The attractions of proteins for small molecules and ions. Ann N Y Acad Sci 1949; 51:660-672.

42. Leclercq G, Bojar H, Goussard J, Nicholson RI, Pichon MF, Piffanelli A et al. Abbott monoclonal enzyme immunoassay measurement of estrogen receptors in human breast cancer: a European multicenter study. Cancer Res 1986; 46(8 Suppl):4233s-4236s.

43. Jordan VC, Jacobson HI, Keenan EJ. Determination of estrogen receptor in breast cancer using monoclonal antibody technology: results of a multicenter study in the United States. Cancer Res 1986; 46(8 Suppl):4237s-4240s.

44. Pasic R, Djulbegovic B, Wittliff JL. Comparison of sex steroid receptor determinations in human breast cancer by enzyme immunoassay and radioligand binding. J Clin Lab Anal 1990; 4(6):430-436.

45. Hull DF, III, Clark GM, Osborne CK, Chamness GC, Knight WA, III, McGuire WL. Multiple estrogen receptor assays in human breast cancer. Cancer Res 1983; 43(1):413-416.

46. King RJ. Enlightenment and confusion over steroid hormone receptors. Nature 1984; 312(5996):701-702.

47. Taylor CR, Shi SR, Chaiwun B, Young L, Imam SA, Cote RJ. Strategies for improving the immunohistochemical staining of various intranuclear prognostic markers in formalin-paraffin sections: androgen receptor, estrogen receptor, progesterone receptor, $\mathrm{p} 53$ protein, proliferating cell nuclear antigen, and Ki-67 antigen revealed by antigen retrieval techniques. Hum Pathol 1994; 25(3):263270. 
48. Elledge RM, Green S, Pugh R, Allred DC, Clark GM, Hill J et al. Estrogen receptor $(E R)$ and progesterone receptor $(\mathrm{PgR})$, by ligand-binding assay compared with $\mathrm{ER}, \mathrm{PgR}$ and $\mathrm{pS} 2$, by immuno-histochemistry in predicting response to tamoxifen in metastatic breast cancer: a Southwest Oncology Group Study. Int J Cancer 2000; 89(2):111-117.

49. Layfield LJ, Gupta D, Mooney EE. Assessment of Tissue Estrogen and Progesterone Receptor Levels: A Survey of Current Practice, Techniques, and Quantitation Methods. Breast J 2000; 6(3):189-196.

50. Rhodes A, Jasani B, Balaton AJ, Barnes DM, Anderson E, Bobrow LG et al. Study of interlaboratory reliability and reproducibility of estrogen and progesterone receptor assays in Europe. Documentation of poor reliability and identification of insufficient microwave antigen retrieval time as a major contributory element of unreliable assays. Am J Clin Pathol 2001; 115(1):44-58.

51. Menard S, Tagliabue E, Campiglio M, Pupa SM. Role of HER2 gene overexpression in breast carcinoma. J Cell Physiol 2000; 182(2):150-162.

52. Klapper LN, Glathe S, Vaisman N, Hynes NE, Andrews GC, Sela M et al. The ErbB-2/HER2 oncoprotein of human carcinomas may function solely as a shared coreceptor for multiple stroma-derived growth factors. Proc Natl Acad Sci U S A 1999; 96(9):4995-5000.

53. Slamon DJ, Clark GM, Wong SG, Levin WJ, Ullrich A, McGuire WL. Human breast cancer: correlation of relapse and survival with amplification of the HER2/neu oncogene. Science 1987; 235(4785):177-182.

54. Gusterson BA, Gelber RD, Goldhirsch A, Price KN, Save-Soderborgh J, Anbazhagan $\mathrm{R}$ et al. Prognostic importance of c-erbB-2 expression in breast cancer. International (Ludwig) Breast Cancer Study Group. J Clin Oncol 1992; 10(7):1049-1056.

55. Hudis CA. Trastuzumab--mechanism of action and use in clinical practice. $\mathrm{N}$ Engl J Med 2007; 357(1):39-51.

56. Morrow M, Strom EA, Bassett LW, Dershaw DD, Fowble B, Giuliano A et al. Standard for breast conservation therapy in the management of invasive breast carcinoma. CA Cancer J Clin 2002; 52(5):277-300.

57. Osborne CK, Yochmowitz MG, Knight WA, III, McGuire WL. The value of estrogen and progesterone receptors in the treatment of breast cancer. Cancer 1980; 46(12 Suppl):2884-2888.

58. Jensen EV, Block GE, Smith S, Kyser K, DeSombre ER. Estrogen receptors and breast cancer response to adrenalectomy. Natl Cancer Inst Monogr 1971; 34:5570. 
59. McGuire WL. Endocrine therapy of breast cancer. Annu Rev Med 1975; 26:353363.

60. Wittliff JL. Specific receptors of the steroid hormones in breast cancer. Semin Oncol 1974; 1(2):109-118.

61. Cole MP, Jones CT, Todd ID. A new anti-oestrogenic agent in late breast cancer. An early clinical appraisal of ICI46474. Br J Cancer 1971; 25(2):270-275.

62. Jordan VC, Tormey DC. Antiestrogen therapy for breast cancer: current strategies and future prospects. Cancer Treat Res 1988; 39:97-110.

63. Jordan VC. Tamoxifen: a most unlikely pioneering medicine. Nat Rev Drug Discov 2003; 2(3):205-213.

64. Ward HW. Anti-oestrogen therapy for breast cancer: a trial of tamoxifen at two dose levels. Br Med J 1973; 1(5844):13-14.

65. Bezwoda WR, Esser JD, Dansey R, Kessel I, Lange M. The value of estrogen and progesterone receptor determinations in advanced breast cancer. Estrogen receptor level but not progesterone receptor level correlates with response to tamoxifen. Cancer 1991; 68(4):867-872.

66. Clark GM, Osborne CK, McGuire WL. Correlations between estrogen receptor, progesterone receptor, and patient characteristics in human breast cancer. J Clin Oncol 1984; 2(10):1102-1109.

67. Dowsett M, Houghton J, Iden C, Salter J, Farndon J, A'Hern R et al. Benefit from adjuvant tamoxifen therapy in primary breast cancer patients according oestrogen receptor, progesterone receptor, EGF receptor and HER2 status. Ann Oncol 2006; 17(5):818-826.

68. Muss HB, Case LD, Atkins JN, Bearden JD, III, Cooper MR, Cruz JM et al. Tamoxifen versus high-dose oral medroxyprogesterone acetate as initial endocrine therapy for patients with metastatic breast cancer: a Piedmont Oncology Association study. J Clin Oncol 1994; 12(8):1630-1638.

69. McDonnell DP, Wardell SE. The molecular mechanisms underlying the pharmacological actions of ER modulators: implications for new drug discovery in breast cancer. Curr Opin Pharmacol 2010; 10(6):620-628.

70. Visvanathan K, Lippman SM, Hurley P, Temin S. American Society of Clinical Oncology clinical practice guideline update on the use of pharmacologic interventions including tamoxifen, raloxifene, and aromatase inhibition for breast cancer risk reduction. Gynecol Oncol 2009; 115(1):132-134.

71. Smith IE, Dowsett M. Aromatase inhibitors in breast cancer. N Engl J Med 2003; 348(24):2431-2442. 
72. Mangelsdorf DJ, Thummel C, Beato M, Herrlich P, Schutz G, Umesono K et al. The nuclear receptor superfamily: the second decade. Cell 1995; 83(6):835-839.

73. Kuiper GG, Enmark E, Pelto-Huikko M, Nilsson S, Gustafsson JA. Cloning of a novel receptor expressed in rat prostate and ovary. Proc Natl Acad Sci U S A 1996; 93(12):5925-5930.

74. Kumar V, Green S, Stack G, Berry M, Jin JR, Chambon P. Functional domains of the human estrogen receptor. Cell 1987; 51(6):941-951.

75. Tsai MJ, O'Malley BW. Molecular mechanisms of action of steroid/thyroid receptor superfamily members. Annu Rev Biochem 1994; 63:451-486.

76. Freedman LP. Anatomy of the steroid receptor zinc finger region. Endocr Rev 1992; 13(2):129-145.

77. Evans RM, Hollenberg SM. Zinc fingers: gilt by association. Cell 1988; 52(1):13.

78. Evans RM. The steroid and thyroid hormone receptor superfamily. Science 1988; 240(4854):889-895.

79. Picard D, Kumar V, Chambon P, Yamamoto KR. Signal transduction by steroid hormones: nuclear localization is differentially regulated in estrogen and glucocorticoid receptors. Cell Regul 1990; 1(3):291-299.

80. Ylikomi T, Bocquel MT, Berry M, Gronemeyer H, Chambon P. Cooperation of proto-signals for nuclear accumulation of estrogen and progesterone receptors. EMBO J 1992; 11(10):3681-3694.

81. Montano MM, Muller V, Trobaugh A, Katzenellenbogen BS. The carboxyterminal $F$ domain of the human estrogen receptor: role in the transcriptional activity of the receptor and the effectiveness of antiestrogens as estrogen antagonists. Mol Endocrinol 1995; 9(7):814-825.

82. Peters GA, Khan SA. Estrogen receptor domains $\mathrm{E}$ and $\mathrm{F}$ : role in dimerization and interaction with coactivator RIP-140. Mol Endocrinol 1999; 13(2):286-296.

83. Skafar DF, Zhao C. The multifunctional estrogen receptor-alpha $\mathrm{F}$ domain. Endocrine 2008; 33(1):1-8.

84. Gustafsson JA. Estrogen receptor beta--a new dimension in estrogen mechanism of action. J Endocrinol 1999; 163(3):379-383.

85. Jordan VC, O'Malley BW. Selective estrogen-receptor modulators and antihormonal resistance in breast cancer. J Clin Oncol 2007; 25(36):5815-5824. 
86. Younes M, Honma N. Estrogen receptor beta. Arch Pathol Lab Med 2011; 135(1):63-66.

87. Sturgeon CM, Duffy MJ, Stenman UH, Lilja H, Brunner N, Chan DW et al. National Academy of Clinical Biochemistry laboratory medicine practice guidelines for use of tumor markers in testicular, prostate, colorectal, breast, and ovarian cancers. Clin Chem 2008; 54(12):e11-e79.

88. Klinge CM. Estrogen receptor interaction with estrogen response elements. Nucleic Acids Res 2001; 29(14):2905-2919.

89. Glass CK. Differential recognition of target genes by nuclear receptor monomers, dimers, and heterodimers. Endocr Rev 1994; 15(3):391-407.

90. Driscoll MD, Sathya G, Muyan M, Klinge CM, Hilf R, Bambara RA. Sequence requirements for estrogen receptor binding to estrogen response elements. J Biol Chem 1998; 273(45):29321-29330.

91. Nardulli AM, Romine LE, Carpo C, Greene GL, Rainish B. Estrogen receptor affinity and location of consensus and imperfect estrogen response elements influence transcription activation of simplified promoters. Mol Endocrinol 1996; 10(6):694-704.

92. Walker P, Germond JE, Brown-Luedi M, Givel F, Wahli W. Sequence homologies in the region preceding the transcription initiation site of the liver estrogen-responsive vitellogenin and apo-VLDLII genes. Nucleic Acids Res $1984 ; 12(22): 8611-8626$.

93. Dobrzycka KM, Townson SM, Jiang S, Oesterreich S. Estrogen receptor corepressors -- a role in human breast cancer? Endocr Relat Cancer 2003; 10(4):517-536.

94. Klinge CM. Estrogen receptor interaction with co-activators and co-repressors. Steroids 2000; 65(5):227-251.

95. McKenna NJ, Lanz RB, O'Malley BW. Nuclear receptor coregulators: cellular and molecular biology. Endocr Rev 1999; 20(3):321-344.

96. O'Malley BW, Kumar R. Nuclear receptor coregulators in cancer biology. Cancer Res 2009; 69(21):8217-8222.

97. Hanahan D, Weinberg RA. Hallmarks of cancer: the next generation. Cell 2011; 144(5):646-674.

98. Kwei KA, Kung Y, Salari K, Holcomb IN, Pollack JR. Genomic instability in breast cancer: pathogenesis and clinical implications. Mol Oncol 2010; 4(3):255266. 
99. Shen Z. Genomic instability and cancer: an introduction. J Mol Cell Biol 2011; 3(1):1-3.

100. Davis JD, Lin SY. DNA damage and breast cancer. World J Clin Oncol 2011; 2(9):329-338.

101. McCready J, Arendt LM, Rudnick JA, Kuperwasser C. The contribution of dynamic stromal remodeling during mammary development to breast carcinogenesis. Breast Cancer Res 2010; 12(3):205.

102. Radisky DC, Hartmann LC. Mammary involution and breast cancer risk: transgenic models and clinical studies. J Mammary Gland Biol Neoplasia 2009; 14(2):181-191.

103. Lieber MR, Gu J, Lu H, Shimazaki N, Tsai AG. Nonhomologous DNA end joining (NHEJ) and chromosomal translocations in humans. Subcell Biochem 2010; 50:279-296.

104. Rich T, Allen RL, Wyllie AH. Defying death after DNA damage. Nature 2000; 407(6805):777-783.

105. Jackson SP. Sensing and repairing DNA double-strand breaks. Carcinogenesis 2002; 23(5):687-696.

106. Khanna KK, Jackson SP. DNA double-strand breaks: signaling, repair and the cancer connection. Nat Genet 2001; 27(3):247-254.

107. van Gent DC, Hoeijmakers JH, Kanaar R. Chromosomal stability and the DNA double-stranded break connection. Nat Rev Genet 2001; 2(3):196-206.

108. Pardo B, Gomez-Gonzalez B, Aguilera A. DNA repair in mammalian cells: DNA double-strand break repair: how to fix a broken relationship. Cell Mol Life Sci 2009; 66(6):1039-1056.

109. Heyer WD, Ehmsen KT, Liu J. Regulation of homologous recombination in eukaryotes. Annu Rev Genet 2010; 44:113-139.

110. Kanaar R, Hoeijmakers JH, van Gent DC. Molecular mechanisms of DNA double strand break repair. Trends Cell Biol 1998; 8(12):483-489.

111. Li X, Heyer WD. Homologous recombination in DNA repair and DNA damage tolerance. Cell Res 2008; 18(1):99-113.

112. Feng Z, Zhang J. A dual role of BRCAl in two distinct homologous recombination mediated repair in response to replication arrest. Nucleic Acids Res 2011. 
113. Holloman WK. Unraveling the mechanism of BRCA2 in homologous recombination. Nat Struct Mol Biol 2011; 18(7):748-754.

114. Mahaney BL, Meek K, Lees-Miller SP. Repair of ionizing radiation-induced DNA double-strand breaks by non-homologous end-joining. Biochem J 2009; 417(3):639-650.

115. Li Y, Cucinotta FA. Modeling non-homologous end joining. J Theor Biol 2011; 283(1):122-135.

116. Meek K, Gupta S, Ramsden DA, Lees-Miller SP. The DNA-dependent protein kinase: the director at the end. Immunol Rev 2004; 200:132-141.

117. Weterings E, Chen DJ. The endless tale of non-homologous end-joining. Cell Res $2008 ; 18(1): 114-124$.

118. de VE, van DW, Bergsma WG, Arnberg AC, van der Vliet PC. HeLa nuclear protein recognizing DNA termini and translocating on DNA forming a regular DNA-multimeric protein complex. J Mol Biol 1989; 208(1):65-78.

119. Ristic D, Modesti M, Kanaar R, Wyman C. Rad52 and Ku bind to different DNA structures produced early in double-strand break repair. Nucleic Acids Res 2003; 31(18):5229-5237.

120. Yoo S, Dynan WS. Geometry of a complex formed by double strand break repair proteins at a single DNA end: recruitment of DNA-PKes induces inward translocation of Ku protein. Nucleic Acids Res 1999; 27(24):4679-4686.

121. Hartley KO, Gell D, Smith GC, Zhang H, Divecha N, Connelly MA et al. DNAdependent protein kinase catalytic subunit: a relative of phosphatidylinositol 3kinase and the ataxia telangiectasia gene product. Cell 1995; 82(5):849-856.

122. DeFazio LG, Stansel RM, Griffith JD, Chu G. Synapsis of DNA ends by DNAdependent protein kinase. EMBO J 2002; 21(12):3192-3200.

123. Chan DW, Chen BP, Prithivirajsingh S, Kurimasa A, Story MD, Qin J et al. Autophosphorylation of the DNA-dependent protein kinase catalytic subunit is required for rejoining of DNA double-strand breaks. Genes Dev 2002; 16(18):2333-2338.

124. Ding Q, Reddy YV, Wang W, Woods T, Douglas P, Ramsden DA et al. Autophosphorylation of the catalytic subunit of the DNA-dependent protein kinase is required for efficient end processing during DNA double-strand break repair. Mol Cell Biol 2003; 23(16):5836-5848.

125. Meek K, Douglas P, Cui X, Ding Q, Lees-Miller SP. trans Autophosphorylation at DNA-dependent protein kinase's two major autophosphorylation site clusters 
facilitates end processing but not end joining. Mol Cell Biol 2007; 27(10):38813890.

126. Smith GC, Divecha N, Lakin ND, Jackson SP. DNA-dependent protein kinase and related proteins. Biochem Soc Symp 1999; 64:91-104.

127. Weterings E, Verkaik NS, Bruggenwirth HT, Hoeijmakers JH, van Gent DC. The role of DNA dependent protein kinase in synapsis of DNA ends. Nucleic Acids Res 2003; 31(24):7238-7246.

128. Block WD, Yu Y, Merkle D, Gifford JL, Ding Q, Meek $\mathrm{K}$ et al. Autophosphorylation-dependent remodeling of the DNA-dependent protein kinase catalytic subunit regulates ligation of DNA ends. Nucleic Acids Res 2004; 32(14):4351-4357.

129. Ma Y, Pannicke U, Schwarz K, Lieber MR. Hairpin opening and overhang processing by an Artemis/DNA-dependent protein kinase complex in nonhomologous end joining and V(D)J recombination. Cell 2002; 108(6):781794.

130. Ma Y, Pannicke U, Lu H, Niewolik D, Schwarz K, Lieber MR. The DNAdependent protein kinase catalytic subunit phosphorylation sites in human Artemis. J Biol Chem 2005; 280(40):33839-33846.

131. Povirk LF, Zhou T, Zhou R, Cowan MJ, Yannone SM. Processing of 3'phosphoglycolate-terminated DNA double strand breaks by Artemis nuclease. J Biol Chem 2007; 282(6):3547-3558.

132. Bryans M, Valenzano MC, Stamato TD. Absence of DNA ligase IV protein in XR-1 cells: evidence for stabilization by XRCC4. Mutat Res 1999; 433(1):53-58.

133. Chen L, Trujillo K, Sung P, Tomkinson AE. Interactions of the DNA ligase IVXRCC4 complex with DNA ends and the DNA-dependent protein kinase. J Biol Chem 2000; 275(34):26196-26205.

134. Grawunder U, Wilm M, Wu X, Kulesza P, Wilson TE, Mann M et al. Activity of DNA ligase IV stimulated by complex formation with XRCC4 protein in mammalian cells. Nature 1997; 388(6641):492-495.

135. Gu J, Lu H, Tippin B, Shimazaki N, Goodman MF, Lieber MR. XRCC4:DNA ligase IV can ligate incompatible DNA ends and can ligate across gaps. EMBO J 2007; 26(4):1010-1023.

136. Gu J, Lu H, Tsai AG, Schwarz K, Lieber MR. Single-stranded DNA ligation and XLF-stimulated incompatible DNA end ligation by the XRCC4-DNA ligase IV complex: influence of terminal DNA sequence. Nucleic Acids Res 2007; 35(17):5755-5762. 
137. Mari PO, Florea BI, Persengiev SP, Verkaik NS, Bruggenwirth HT, Modesti M et al. Dynamic assembly of end-joining complexes requires interaction between Ku70/80 and XRCC4. Proc Natl Acad Sci U S A 2006; 103(49):18597-18602.

138. Uematsu N, Weterings E, Yano K, Morotomi-Yano K, Jakob B, Taucher-Scholz $\mathrm{G}$ et al. Autophosphorylation of DNA-PKCS regulates its dynamics at DNA double-strand breaks. J Cell Biol 2007; 177(2):219-229.

139. Yano K, Morotomi-Yano K, Wang SY, Uematsu N, Lee KJ, Asaithamby A et al. Ku recruits XLF to DNA double-strand breaks. EMBO Rep 2008; 9(1):91-96.

140. Mimori $T$, Akizuki $M$, Yamagata $H$, Inada S, Yoshida S, Homma M. Characterization of a high molecular weight acidic nuclear protein recognized by autoantibodies in sera from patients with polymyositis-scleroderma overlap. J Clin Invest 1981; 68(3):611-620.

141. Yaneva M, Arnett FC. Antibodies against Ku protein in sera from patients with autoimmune diseases. Clin Exp Immunol 1989; 76(3):366-372.

142. Downs JA, Jackson SP. A means to a DNA end: the many roles of Ku. Nat Rev Mol Cell Biol 2004; 5(5):367-378.

143. Fewell JW, Kuff EL. Intracellular redistribution of $\mathrm{Ku}$ immunoreactivity in response to cell-cell contact and growth modulating components in the medium. $\mathrm{J}$ Cell Sci 1996; 109 ( Pt 7):1937-1946.

144. Sawada M, Hayes P, Matsuyama S. Cytoprotective membrane-permeable peptides designed from the Bax-binding domain of Ku70. Nat Cell Biol 2003; 5(4):352-357.

145. Walker JR, Corpina RA, Goldberg J. Structure of the Ku heterodimer bound to DNA and its implications for double-strand break repair. Nature 2001; 412(6847):607-614.

146. Gullo $\mathrm{C}, \mathrm{Au}$ M, Feng $\mathrm{G}$, Teoh $\mathrm{G}$. The biology of $\mathrm{Ku}$ and its potential oncogenic role in cancer. Biochim Biophys Acta 2006; 1765(2):223-234.

147. Aravind L, Koonin EV. Trends Biochem Sci 2000; 25(3):112-114.

148. Aravind L, Koonin EV. Prokaryotic homologs of the eukaryotic DNA-endbinding protein $\mathrm{Ku}$, novel domains in the $\mathrm{Ku}$ protein and prediction of a prokaryotic double-strand break repair system. Genome Res 2001; 11(8):13651374.

149. Harris R, Esposito D, Sankar A, Maman JD, Hinks JA, Pearl LH et al. The 3D solution structure of the C-terminal region of Ku86 (Ku86CTR). J Mol Biol 2004; 335(2):573-582. 
150. Zhang Z, Hu W, Cano L, Lee TD, Chen DJ, Chen Y. Solution structure of the Cterminal domain of Ku80 suggests important sites for protein-protein interactions. Structure 2004; 12(3):495-502.

151. Gell D, Jackson SP. Mapping of protein-protein interactions within the DNAdependent protein kinase complex. Nucleic Acids Res 1999; 27(17):3494-3502.

152. Singleton BK, Torres-Arzayus MI, Rottinghaus ST, Taccioli GE, Jeggo PA. The $\mathrm{C}$ terminus of Ku80 activates the DNA-dependent protein kinase catalytic subunit. Mol Cell Biol 1999; 19(5):3267-3277.

153. Koike M, Ikuta T, Miyasaka T, Shiomi T. Ku80 can translocate to the nucleus independent of the translocation of Ku70 using its own nuclear localization signal. Oncogene 1999; 18(52):7495-7505.

154. Koike M. Dimerization, translocation and localization of $\mathrm{Ku} 70$ and $\mathrm{Ku} 80$ proteins. J Radiat Res (Tokyo) 2002; 43(3):223-236.

155. Weaver DT. V(D)J recombination and double-strand break repair. Adv Immunol $1995 ; 58: 29-85$.

156. Bassing $\mathrm{CH}$, Swat $\mathrm{W}$, Alt FW. The mechanism and regulation of chromosomal V(D)J recombination. Cell 2002; 109 Suppl:S45-S55.

157. Jeggo PA, Taccioli GE, Jackson SP. Menage a trois: double strand break repair, V(D)J recombination and DNA-PK. Bioessays 1995; 17(11):949-957.

158. Bailey SM, Meyne J, Chen DJ, Kurimasa A, Li GC, Lehnert BE et al. DNA double-strand break repair proteins are required to cap the ends of mammalian chromosomes. Proc Natl Acad Sci U S A 1999; 96(26):14899-14904.

159. Chai W, Ford LP, Lenertz L, Wright WE, Shay JW. Human Ku70/80 associates physically with telomerase through interaction with hTERT. J Biol Chem 2002; 277(49):47242-47247.

160. Hsu HL, Gilley D, Blackburn EH, Chen DJ. Ku is associated with the telomere in mammals. Proc Natl Acad Sci U S A 1999; 96(22):12454-12458.

161. Boulton SJ, Jackson SP. Components of the Ku-dependent non-homologous endjoining pathway are involved in telomeric length maintenance and telomeric silencing. EMBO J 1998; 17(6):1819-1828.

162. Nugent CI, Bosco G, Ross LO, Evans SK, Salinger AP, Moore JK et al. Telomere maintenance is dependent on activities required for end repair of double-strand breaks. Curr Biol 1998; 8(11):657-660. 
163. Porter SE, Greenwell PW, Ritchie KB, Petes TD. The DNA-binding protein Hdflp (a putative $\mathrm{Ku}$ homologue) is required for maintaining normal telomere length in Saccharomyces cerevisiae. Nucleic Acids Res 1996; 24(4):582-585.

164. Lalier L, Cartron PF, Juin P, Nedelkina S, Manon S, Bechinger B et al. Bax activation and mitochondrial insertion during apoptosis. Apoptosis 2007; 12(5):887-896.

165. Giffin W, Torrance H, Rodda DJ, Prefontaine GG, Pope L, Hache RJ. Sequencespecific DNA binding by $\mathrm{Ku}$ autoantigen and its effects on transcription. Nature 1996; 380(6571):265-268.

166. Li GC, Yang SH, Kim D, Nussenzweig A, Ouyang H, Wei J et al. Suppression of heat-induced hsp70 expression by the $70-\mathrm{kDa}$ subunit of the human $\mathrm{Ku}$ autoantigen. Proc Natl Acad Sci U S A 1995; 92(10):4512-4516.

167. Liu ES, Lee AS. Common sets of nuclear factors binding to the conserved promoter sequence motif of two coordinately regulated ER protein genes, GRP78 and GRP94. Nucleic Acids Res 1991; 19(19):5425-5431.

168. Hu S, Pluth JM, Cucinotta FA. Putative binding modes of Ku70-SAP domain with double strand DNA: a molecular modeling study. J Mol Model 2011.

169. Mo X, Dynan WS. Subnuclear localization of Ku protein: functional association with RNA polymerase II elongation sites. Mol Cell Biol 2002; 22(22):8088-8099.

170. Vago B, Galandiuk S, Tuckson W, Wittliff J. Detection of specific ERE-binding proteins in colon diseases. Abstracts, Austrian Society for Laboratory Medicine . 2000.

Ref Type: Abstract

171. Vago B, French A, Pepic A, Wittliff J. Specificity and distribution of EREbinding proteins in human reproductive cancers and their relationship to known prognostic factors. Abstracts, Austrian Society for Laboratory Medicine . 2000.

Ref Type: Abstract

172. Wittliff JL, Kruer TL, Andres SA, Smolenkova I. Molecular signatures of estrogen receptor-associated genes in breast cancer predict clinical outcome. Adv Exp Med Biol 2008; 617:349-357.

173. Klein-Hitpass L, Schorpp M, Wagner U, Ryffel GU. An estrogen-responsive element derived from the 5 ' flanking region of the Xenopus vitellogenin A2 gene functions in transfected human cells. Cell 1986; 46(7):1053-1061.

174. Kute TE, Heidemann P, Wittliff JL. Molecular heterogeneity of cytosolic forms of estrogen receptors from human breast tumors. Cancer Res 1978; 38(11 Pt 2):4307-4313. 
175. Horard B, Vanacker JM. Estrogen receptor-related receptors: orphan receptors desperately seeking a ligand. J Mol Endocrinol 2003; 31(3):349-357.

176. Pettersson K, Svensson K, Mattsson R, Carlsson B, Ohlsson R, Berkenstam A. Expression of a novel member of estrogen response element-binding nuclear receptors is restricted to the early stages of chorion formation during mouse embryogenesis. Mech Dev 1996; 54(2):211-223.

177. Zhang Z, Teng CT. Estrogen receptor-related receptor alpha 1 interacts with coactivator and constitutively activates the estrogen response elements of the human lactoferrin gene. J Biol Chem 2000; 275(27):20837-20846.

178. Zhang Z, Teng CT. Estrogen receptor alpha and estrogen receptor-related receptor alpha1 compete for binding and coactivator. Mol Cell Endocrinol 2001; 172(12):223-233.

179. Burbach JP, Lopes da SS, Cox JJ, Adan RA, Cooney AJ, Tsai MJ et al. Repression of estrogen-dependent stimulation of the oxytocin gene by chicken ovalbumin upstream promoter transcription factor I. J Biol Chem 1994; 269(21):15046-15053.

180. Klinge CM, Silver BF, Driscoll MD, Sathya G, Bambara RA, Hilf R. Chicken ovalbumin upstream promoter-transcription factor interacts with estrogen receptor, binds to estrogen response elements and half-sites, and inhibits estrogeninduced gene expression. J Biol Chem 1997; 272(50):31465-31474.

181. Klinge CM. Role of estrogen receptor ligand and estrogen response element sequence on interaction with chicken ovalbumin upstream promoter transcription factor (COUP-TF). J Steroid Biochem Mol Biol 1999; 71(1-2):1-19.

182. Chen H, Arbelle JE, Gacad MA, Allegretto EA, Adams JS. Vitamin D and gonadal steroid-resistant New World primate cells express an intracellular protein which competes with the estrogen receptor for binding to the estrogen response element. J Clin Invest 1997; 99(4):669-675.

183. Chen H, Hu B, Gacad MA, Adams JS. Cloning and expression of a novel dominant-negative-acting estrogen response element-binding protein in the heterogeneous nuclear ribonucleoprotein family. J Biol Chem 1998; 273(47):31352-31357.

184. Chen H, Stuart W, Hu B, Nguyen L, Huang G, Clemens TL et al. Creation of estrogen resistance in vivo by transgenic overexpression of the heterogeneous nuclear ribonucleoprotein-related estrogen response element binding protein. Endocrinology 2005; 146(10):4266-4273.

185. Chen H, Hewison M, Adams JS. Control of estradiol-directed gene transactivation by an intracellular estrogen-binding protein and an estrogen response elementbinding protein. Mol Endocrinol 2008; 22(3):559-569. 
186. Chen H, Clemens TL, Hewison M, Adams JS. Estradiol and tamoxifen mediate rescue of the dominant-negative effects of estrogen response element-binding protein in vivo and in vitro. Endocrinology 2009; 150(5):2429-2435.

187. Gray WG, Gorski J. Identification and characterization of an estrogen-responsive element binding protein repressed by estradiol. Biochemistry 1996; 35(36):1168511692.

188. Graumann K, Wittliff JL, Raffelsberger W, Miles L, Jungbauer A, Butt TR. Structural and functional analysis of N-terminal point mutants of the human estrogen receptor. J Steroid Biochem Mol Biol 1996; 57(5-6):293-300.

189. Wittliff JL, Wenz LL, Dong J, Nawaz Z, Butt TR. Expression and characterization of an active human estrogen receptor as a ubiquitin fusion protein from Escherichia coli. J Biol Chem 1990; 265(35):22016-22022.

190. Bradford AP, Conrad KE, Tran PH, Ostrowski MC, Gutierrez-Hartmann A. GHF1/Pit-1 functions as a cell-specific integrator of Ras signaling by targeting the Ras pathway to a composite Ets-1/GHF-1 response element. J Biol Chem 1996; 271(40):24639-24648.

191. Wittliff JL. Laser capture microdissection and its use in genomics and proteomics. In: Conn PM, editor. Reliable Lab Solutions: Techniques in Confocal Microscopy. Boston: Elsevier Press; 2010. p. 463-477.

192. Francis J, Babu DA, Deering TG, Chakrabarti SK, Garmey JC, Evans-Molina C et al. Role of chromatin accessibility in the occupancy and transcription of the insulin gene by the pancreatic and duodenal homeobox factor 1. Mol Endocrinol 2006; 20(12):3133-3145.

193. Sadowski HB, Gilman MZ. Cell-free activation of a DNA-binding protein by epidermal growth factor. Nature 1993; 362(6415):79-83.

194. Wittliff JL, Andres SA, Kruer TL, Kerr DA, Smolenkova IA, Erb JL. Biosensors for detecting estrogen-like molecules and protein biomarkers. Adv Exp Med Biol $2008 ; 614: 315-322$.

195. Andres SA, Kerr DA, Bumpus SB, Kruer TL, Thieman JW, Smolenkova IA et al. A three-tiered approach for calibration of a biosensor to detect estrogen mimics. Adv Exp Med Biol 2008; 614:305-313.

196. Kraus RJ, Ariazi EA, Farrell ML, Mertz JE. Estrogen-related receptor alpha 1 actively antagonizes estrogen receptor-regulated transcription in MCF-7 mammary cells. J Biol Chem 2002; 277(27):24826-24834.

197. Herr W, Sturm RA, Clerc RG, Corcoran LM, Baltimore D, Sharp PA et al. The POU domain: a large conserved region in the mammalian pit-1, oct-1, oct-2, and 
Caenorhabditis elegans unc-86 gene products. Genes Dev 1988; 2(12A):15131516.

198. Wang P, Jin T. Hydrogen peroxide stimulates nuclear import of the POU homeodomain protein Oct-1 and its repressive effect on the expression of Cdx-2. BMC Cell Biol 2010; 11:56.

199. Anderson I, Bartley CR, Lerch RA, Gray WG, Friesen PD, Gorski J. Estrogen receptor alpha requires no accessory factors for high-affinity binding to a consensus response element. Biochemistry 1998; 37(49):17287-17298.

200. Wittliff JL, Ma X, Wang W, Salunga R, Tuggle J, Stecker K. Expression of estrogen receptor-associated genes in breast cancer cells procured by laser capture microdissection. Jensen Symp Abs. 2003.

Ref Type: Abstract

201. Jin VX, Sun H, Pohar TT, Liyanarachchi S, Palaniswamy SK, Huang TH et al. ERTargetDB: an integral information resource of transcription regulation of estrogen receptor target genes. J Mol Endocrinol 2005; 35(2):225-230.

202. Kerr DA, Wittliff JL. A Five-Gene Model Predicts Clinical Outcome in ER+/PR+, Early-Stage Breast Cancers Treated with Adjuvant Tamoxifen. Horm Cancer 2011; 2(5):261-271.

203. Huang L, Harvie G, Feitelson JS, Gramatikoff K, Herold DA, Allen DL et al. Immunoaffinity separation of plasma proteins by $\operatorname{IgY}$ microbeads: meeting the needs of proteomic sample preparation and analysis. Proteomics 2005; 5(13):3314-3328.

204. Cummins TD, Barati MT, Coventry SC, Salyer SA, Klein JB, Powell DW. Quantitative mass spectrometry of diabetic kidney tubules identifies GRAP as a novel regulator of TGF-beta signaling. Biochim Biophys Acta 2010; 1804(4):653661.

205. Adkins JN, Varnum SM, Auberry KJ, Moore RJ, Angell NH, Smith RD et al. Toward a human blood serum proteome: analysis by multidimensional separation coupled with mass spectrometry. Mol Cell Proteomics 2002; 1(12):947-955.

206. Gupta V, Bamezai RN. Human pyruvate kinase M2: a multifunctional protein. Protein Sci 2010; 19(11):2031-2044.

207. Lee J, Kim HK, Han YM, Kim J. Pyruvate kinase isozyme type M2 (PKM2) interacts and cooperates with Oct- 4 in regulating transcription. Int J Biochem Cell Biol 2008; 40(5):1043-1054.

208. He W, Luo S, Huang T, Ren J, Wu X, Shao J et al. The Ku70 -1310C/G promoter polymorphism is associated with breast cancer susceptibility in Chinese Han population. Mol Biol Rep 2011. 
209. Wang HC, Liu CS, Chiu CF, Chiang SY, Wang CH, Wang RF et al. Significant association of DNA repair gene Ku80 genotypes with breast cancer susceptibility in Taiwan. Anticancer Res 2009; 29(12):5251-5254.

210. Willems P, De RK, Van den Broecke R, Makar A, Perletti G, Thierens H et al. A polymorphism in the promoter region of Ku70/XRCC6, associated with breast cancer risk and oestrogen exposure. J Cancer Res Clin Oncol 2009; 135(9):11591168 .

211. Tsuchiya N, Kamei D, Takano A, Matsui T, Yamada M. Cloning and characterization of a cDNA encoding a novel heterogeneous nuclear ribonucleoprotein-like protein and its expression in myeloid leukemia cells. J Biochem 1998; 123(3):499-507.

212. Quick Q, Skalli O. Alpha-actinin 1 and alpha-actinin 4: contrasting roles in the survival, motility, and RhoA signaling of astrocytoma cells. Exp Cell Res 2010; 316(7):1137-1147.

213. Khurana S, Chakraborty S, Cheng X, Su YT, Kao HY. The actin-binding protein, actinin alpha 4 (ACTN4), is a nuclear receptor coactivator that promotes proliferation of MCF-7 breast cancer cells. J Biol Chem 2011; 286(3):1850-1859.

214. Bustin M. Regulation of DNA-dependent activities by the functional motifs of the high-mobility-group chromosomal proteins. Mol Cell Biol 1999; 19(8):52375246.

215. Mosevitsky MI, Novitskaya VA, Iogannsen MG, Zabezhinsky MA. Tissue specificity of nucleo-cytoplasmic distribution of HMG1 and HMG2 proteins and their probable functions. Eur J Biochem 1989; 185(2):303-310.

216. Okamoto M, Hoshino T, Kitasato Y, Sakazaki Y, Kawayama T, Fujimoto K et al. Periostin, a matrix protein, is a novel biomarker for idiopathic interstitial pneumonias. Eur Respir J 2011; 37(5):1119-1127.

217. Ruan K, Bao S, Ouyang G. The multifaceted role of periostin in tumorigenesis. Cell Mol Life Sci 2009; 66(14):2219-2230.

218. Turano C, Coppari S, Altieri F, Ferraro A. Proteins of the PDI family: unpredicted non-ER locations and functions. J Cell Physiol 2002; 193(2):154-163.

219. Grillo C, Coppari S, Turano C, Altieri F. The DNA-binding activity of protein disulfide isomerase ERp57 is associated with the a(') domain. Biochem Biophys Res Commun 2002; 295(1):67-73.

220. Wang J, Dong X, Myung K, Hendrickson EA, Reeves WH. Identification of two domains of the p70 $\mathrm{Ku}$ protein mediating dimerization with p80 and DNA binding. J Biol Chem 1998; 273(2):842-848. 
221. Griffith AJ, Blier PR, Mimori T, Hardin JA. Ku polypeptides synthesized in vitro assemble into complexes which recognize ends of double-stranded DNA. J Biol Chem 1992; 267(1):331-338.

222. Wu X, Lieber MR. Protein-protein and protein-DNA interaction regions within the DNA end-binding protein Ku70-Ku86. Mol Cell Biol 1996; 16(9):5186-5193.

223. Han Z, Johnston C, Reeves WH, Carter T, Wyche JH, Hendrickson EA. Characterization of a Ku86 variant protein that results in altered DNA binding and diminished DNA-dependent protein kinase activity. J Biol Chem 1996; 271(24):14098-14104.

224. Jeng YW, Chao HC, Chiu CF, Chou WG. Senescent human fibroblasts have elevated Ku86 proteolytic cleavage activity. Mutat Res 1999; 435(3):225-232.

225. Muller C, Dusseau C, Calsou P, Salles B. Human normal peripheral blood Blymphocytes are deficient in DNA-dependent protein kinase activity due to the expression of a variant form of the Ku86 protein. Oncogene 1998; 16(12):15531560.

226. Tai YT, Teoh G, Lin B, Davies FE, Chauhan D, Treon SP et al. Ku86 variant expression and function in multiple myeloma cells is associated with increased sensitivity to DNA damage. J Immunol 2000; 165(11):6347-6355.

227. Blier PR, Griffith AJ, Craft J, Hardin JA. Binding of $\mathrm{Ku}$ protein to DNA. Measurement of affinity for ends and demonstration of binding to nicks. J Biol Chem 1993; 268(10):7594-7601.

228. Dynan WS, Yoo S. Interaction of Ku protein and DNA-dependent protein kinase catalytic subunit with nucleic acids. Nucleic Acids Res 1998; 26(7):1551-1559.

229. Falzon M, Fewell JW, Kuff EL. EBP-80, a transcription factor closely resembling the human autoantigen $\mathrm{Ku}$, recognizes single- to double-strand transitions in DNA. J Biol Chem 1993; 268(14):10546-10552.

230. Mimori T, Hardin JA. Mechanism of interaction between Ku protein and DNA. J Biol Chem 1986; 261(22):10375-10379.

231. Arosio D, Costantini S, Kong Y, Vindigni A. Fluorescence anisotropy studies on the Ku-DNA interaction: anion and cation effects. J Biol Chem 2004; 279(41):42826-42835.

232. Bakalkin G, Yakovleva T, Hurd YL, Nussenzweig A, Li GC, Terenius L. Autoantigen $\mathrm{Ku}$ in the brain. Developmentally regulated expression and subcellular localization. Neuroreport 1998; 9(9):2147-2151. 
233. Bertinato J, Schild-Poulter C, Hache RJ. Nuclear localization of $\mathrm{Ku}$ antigen is promoted independently by basic motifs in the Ku70 and Ku80 subunits. J Cell Sci 2001; 114(Pt 1):89-99.

234. Koike M, Koike A. The Ku70-binding site of Ku80 is required for the stabilization of $\mathrm{Ku} 70$ in the cytoplasm, for the nuclear translocation of Ku80, and for Ku80-dependent DNA repair. Exp Cell Res 2005; 305(2):266-276.

235. Brown KD, Lataxes TA, Shangary S, Mannino JL, Giardina JF, Chen J et al. Ionizing radiation exposure results in up-regulation of $\mathrm{Ku} 70$ via a p53/ataxiatelangiectasia-mutated protein-dependent mechanism. J Biol Chem 2000; 275(9):6651-6656.

236. Tuteja R, Tuteja N. Ku autoantigen: a multifunctional DNA-binding protein. Crit Rev Biochem Mol Biol 2000; 35(1):1-33.

237. Difilippantonio MJ, Zhu J, Chen HT, Meffre E, Nussenzweig MC, Max EE et al. DNA repair protein Ku80 suppresses chromosomal aberrations and malignant transformation. Nature 2000; 404(6777):510-514.

238. Saviozzi S, Ceppi P, Novello S, Ghio P, Lo IM, Borasio P et al. Non-small cell lung cancer exhibits transcript overexpression of genes associated with homologous recombination and DNA replication pathways. Cancer Res 2009; 69(8):3390-3396.

239. Ghezzi TL, Brum IS, Biolchi V, Garicochea B, Fillmann LS, Corleta OC. Is there any association between TACSTD2, KIAA1253, Ku70 and mutant KRAS gene expression and clinical-pathological features of colorectal cancer? Exp Oncol $2011 ; 33(1): 28-32$.

240. Hu H, Zhang Y, Zou M, Yang S, Liang XQ. Expression of TRF1, TRF2, TIN2, TERT, KU70, and BRCA1 proteins is associated with telomere shortening and may contribute to multistage carcinogenesis of gastric cancer. J Cancer Res Clin Oncol 2010; 136(9):1407-1414.

241. Parrella P, Mazzarelli P, Signori E, Perrone G, Marangi GF, Rabitti C et al. Expression and heterodimer-binding activity of Ku70 and Ku80 in human nonmelanoma skin cancer. J Clin Pathol 2006; 59(11):1181-1185.

242. Wilson CR, Davidson SE, Margison GP, Jackson SP, Hendry JH, West CM. Expression of $\mathrm{Ku} 70$ correlates with survival in carcinoma of the cervix. $\mathrm{Br} \mathrm{J}$ Cancer 2000; 83(12):1702-1706.

243. Pucci S, Mazzarelli P, Rabitti C, Giai M, Gallucci M, Flammia G et al. Tumor specific modulation of KU70/80 DNA binding activity in breast and bladder human tumor biopsies. Oncogene 2001; 20(6):739-747. 
244. Lagadec C, Romon R, Tastet C, Meignan S, Com E, Page A et al. Ku86 is important for TrkA overexpression-induced breast cancer cell invasion. Proteomics Clin Appl 2010; 4(6-7):580-590.

245. Lagadec C, Meignan S, Adriaenssens E, Foveau B, Vanhecke E, Romon R et al. TrkA overexpression enhances growth and metastasis of breast cancer cells. Oncogene 2009; 28(18):1960-1970.

246. Com E, Lagadec C, Page A, El Yazidi-Belkoura I, Slomianny C, Spencer A et al. Nerve growth factor receptor TrkA signaling in breast cancer cells involves $\mathrm{Ku} 70$ to prevent apoptosis. Mol Cell Proteomics 2007; 6(11):1842-1854.

247. McShane LM, Altman DG, Sauerbrei W, Taube SE, Gion M, Clark GM. REporting recommendations for tumor MARKer prognostic studies (REMARK). Breast Cancer Res Treat 2006; 100(2):229-235.

248. Wittliff JL, Erlander MG. Laser capture microdissection and its applications in genomics and proteomics. Methods Enzymol 2002; 356:12-25.

249. Andres SA, Wittliff JL. Relationships of ESR1 and XBP1 expression in human breast carcinoma and stromal cells isolated by laser capture microdissection compared to intact breast cancer tissue. Endocrine 2011; 40(2):212-221.

250. Cohen HY, Lavu S, Bitterman KJ, Hekking B, Imahiyerobo TA, Miller C et al. Acetylation of the $\mathrm{C}$ terminus of $\mathrm{Ku} 70$ by CBP and PCAF controls Bax-mediated apoptosis. Mol Cell 2004; 13(5):627-638.

251. Morio T, Kim H. Ku, Artemis, and ataxia-telangiectasia-mutated: signalling networks in DNA damage. Int J Biochem Cell Biol 2008; 40(4):598-603.

252. Beskow C, Skikuniene J, Holgersson A, Nilsson B, Lewensohn R, Kanter L et al. Radioresistant cervical cancer shows upregulation of the NHEJ proteins DNAPKcs, Ku70 and Ku86. Br J Cancer 2009; 101(5):816-821.

253. Komuro Y, Watanabe T, Hosoi Y, Matsumoto Y, Nakagawa K, Tsuno N et al. The expression pattern of $\mathrm{Ku}$ correlates with tumor radiosensitivity and disease free survival in patients with rectal carcinoma. Cancer 2002; 95(6):1199-1205.

254. Lee SW, Cho KJ, Park JH, Kim SY, Nam SY, Lee BJ et al. Expressions of Ku70 and DNA-PKcs as prognostic indicators of local control in nasopharyngeal carcinoma. Int J Radiat Oncol Biol Phys 2005; 62(5):1451-1457.

255. Soderlund LK, Queseth S, Fornander T, Askmalm MS. Low expression of $\mathrm{Ku} 70 / 80$, but high expression of DNA-PKcs, predict good response to radiotherapy in early breast cancer. Int J Oncol 2010; 37(6):1547-1554.

256. Gaymes TJ, North PS, Brady N, Hickson ID, Mufti GJ, Rassool FV. Increased error-prone non homologous DNA end-joining--a proposed mechanism of 
chromosomal instability in Bloom's syndrome. Oncogene 2002; 21(16):25252533.

257. Rothkamm K, Kuhne M, Jeggo PA, Lobrich M. Radiation-induced genomic rearrangements formed by nonhomologous end-joining of DNA double-strand breaks. Cancer Res 2001; 61(10):3886-3893.

258. Evan GI, Vousden KH. Proliferation, cell cycle and apoptosis in cancer. Nature 2001; 411(6835):342-348.

259. Perillo B, Sasso A, Abbondanza C, Palumbo G. 17beta-estradiol inhibits apoptosis in MCF-7 cells, inducing bcl-2 expression via two estrogen-responsive elements present in the coding sequence. Mol Cell Biol 2000; 20(8):2890-2901.

260. Wang F, Porter W, Xing W, Archer TK, Safe S. Identification of a functional imperfect estrogen-responsive element in the 5'-promoter region of the human cathepsin D gene. Biochemistry 1997; 36(25):7793-7801.

261. Flick MB, Sapi E, Kacinski BM. Hormonal regulation of the c-fms protooncogene in breast cancer cells is mediated by a composite glucocorticoid response element. J Cell Biochem 2002; 85(1):10-23.

262. Weisz A, Rosales R. Identification of an estrogen response element upstream of the human c-fos gene that binds the estrogen receptor and the AP-1 transcription factor. Nucleic Acids Res 1990; 18(17):5097-5106.

263. Hyder SM, Chiappetta C, Stancel GM. Interaction of human estrogen receptors alpha and beta with the same naturally occurring estrogen response elements. Biochem Pharmacol 1999; 57(6):597-601.

264. Okamoto K, Okazawa H, Okuda A, Sakai M, Muramatsu M, Hamada H. A novel octamer binding transcription factor is differentially expressed in mouse embryonic cells. Cell 1990; 60(3):461-472.

265. Kraus WL, Montano MM, Katzenellenbogen BS. Identification of multiple, widely spaced estrogen-responsive regions in the rat progesterone receptor gene. Mol Endocrinol 1994; 8(8):952-969.

266. Murdoch FE, Byrne LM, Ariazi EA, Furlow JD, Meier DA, Gorski J. Estrogen receptor binding to DNA: affinity for nonpalindromic elements from the rat prolactin gene. Biochemistry 1995; 34(28):9144-9150.

267. Berry M, Nunez AM, Chambon P. Estrogen-responsive element of the human pS2 gene is an imperfectly palindromic sequence. Proc Natl Acad Sci U S A 1989; 86(4):1218-1222. 
268. Glass CK, Lipkin SM, Devary OV, Rosenfeld MG. Positive and negative regulation of gene transcription by a retinoic acid-thyroid hormone receptor heterodimer. Cell 1989; 59(4):697-708.

269. Umesono K, Murakami KK, Thompson CC, Evans RM. Direct repeats as selective response elements for the thyroid hormone, retinoic acid, and vitamin D3 receptors. Cell 1991; 65(7):1255-1266. 
APPENDIX

Table 8. List of DNA sequences.

\begin{tabular}{|c|c|c|}
\hline Name & Sequence & Ref. \\
\hline $\mathrm{Bcl} 2$ & 5'-GTCCGGTCGCCAGGACCT-3' & [259] \\
\hline CTSD & 5'-GTCGATCAGCTGGGCCGGGCTGACCCCGCG-3' & {$[260]$} \\
\hline GRE & 5'-GTCAGAGGATCTGTACAGGATGTTCTAGAT-3' & [261] \\
\hline c-fos & 5'-AGCTTGGGCTGAGCCGGCAGCGTGACCCCGCATG-3' & [262] \\
\hline jun & $\begin{array}{l}\text { 5'- GTCGATCCTGAAGCAGAGCATGACCTTGAACTGAAG } \\
\text { CAGAGCAT GACCTTGAA-3' }\end{array}$ & [263] \\
\hline OCT1 & 5'-GTCATTTGCAT-3' & {$[264]$} \\
\hline OCT2 & 5'-GTCGGCGTTAAAATTCATTAAAATTCAGGCC-3' & [264] \\
\hline PR-b & $\begin{array}{l}\text { 5'-GTCATGGAGGCCAAGGGCAGGAGCTGACCAGCGCCG } \\
\text { CCCT-3' }\end{array}$ & [265] \\
\hline PRE & 5'-GTCGATCCAGAACAAACTGTTCTAGCTACG-3' & [263] \\
\hline Prolactin & 5'-GTCTCCAGGTCACCAGCTGCTTCAGATGATC-3' & [266] \\
\hline $\mathrm{pS} 2$ & 5'-GTCGATCTGCAAGGTCACGGTGGCCACCCC-3' & [267] \\
\hline Scramble-1 & 5'-GTCAGGTTTGAGGCTATATAGTGAAAGA-3' & \\
\hline Scramble-2 & $\begin{array}{l}\text { 5'-GTCTGGTCATACGAGTAAGCTGAGGATGAGCGCCG } \\
\text { AAC-3' }\end{array}$ & \\
\hline TFIID & 5'-GTCGCAGAGCATATAAGGTGAGGTAGGA-3' & [187] \\
\hline TREpal & 5'-GTCGATCGTAAGATTCAGGTCATGACCTGA-3' & [268] \\
\hline TRE-DR & 5'-GTCAGCTTCAGGTCACAGGAGGTCAGAGAG-3' & [269] \\
\hline VitA2 & 5'-GTCCAAAGTCAGGTCACAGTGACCTGATC-3' & [173] \\
\hline VitA2-HP & $\begin{array}{l}\text { 5'-TTTGCGGTCCAAAGTCAGGTCACAGTGACCTGATCGT } \\
\text { TTTTTTTCGATCAGGTCACTGTGACCTGACTTTGGACCG } \\
\text { C-3' }\end{array}$ & \\
\hline VitA2-mut & 5'-CAAAGTCAGGGCACAGTGTCCTGATC-3' & \\
\hline
\end{tabular}


Table 9. List of abbreviations.

$\begin{array}{ll}\text { aa } & \text { amino acid } \\ \text { AJCC } & \text { American Joint Committee on Cancer } \\ \text { BIR } & \text { break induced replication } \\ \text { CI } & \text { confidence interval } \\ \text { DCIS } & \text { ductal carcinoma in situ } \\ \text { DFS } & \text { disease free survival } \\ \text { dHJ } & \text { double Holliday junction } \\ \text { DLU } & \text { digital light units } \\ \text { DLU } & \text { digital light units } \\ \text { DNA-PK } & \text { dna protein kinase } \\ \text { DSB } & \text { double strand break } \\ \text { DTT } & \text { dithiothreitol } \\ \text { E2 } & \text { 17ß-estradiol } \\ \text { EIA } & \text { enzyme immunoassay } \\ \text { EMSA } & \text { electrphoretic mobility shift assay } \\ \text { ER } & \text { estrogen receptor } \\ \text { ERE } & \text { estrogen response element } \\ \text { ERE-BP } & \text { estrogen response element binding proteins } \\ \text { ERR } & \text { estrogen related receptor } \\ \text { ETOH } & \text { ethanol } \\ \text { FDA } & \text { Food and Drug Administration } \\ \text { FISH } & \text { fluorescent } \text { in } \text { situ hybridization } \\ \text { GRE } & \text { glucocorticoid response element } \\ \text { HAP } & \text { high abundant proteins } \\ \text { hnRNP } & \text { heterogeneous ribonucleoprotein } \\ \text { HRE } & \text { hormone response element } \\ \text { HRL } & \text { hormone receptor laboratory } \\ \text { HRP } & \text { horseradish peroxidase } \\ \text { IHC } & \text { immunohistochemistry } \\ \text { IRB } & \text { institutional review board } \\ \text { Kd } & \text { dissociation constant } \\ \text { LBA } & \text { ligand binding assay } \\ \text { LCIS } & \text { lobular carcinoma in situ } \\ \text { LCM } & \text { laser capture microdissection } \\ \text { LC-MS/MS } & \text { tandem liquid chromatography and mass spectrometry } \\ \text { NE } & \text { nuclear extract } \\ \text { NHEJ } & \text { nonhomologous end joining } \\ \text { NLS } & \text { nuclear localization signal } \\ \text { OS } & \text { overall survival } \\ \text { PAGE } & \text { polyacrylamide gel electrophoresis } \\ \text { PMSF } & \text { phenylmethanesulfonylfluoride } \\ \text { PR } & \text { progesterone receptor } \\ \text { REMARK } & \text { reporting recommendations for tumor marker prognostic studies } \\ \text { rhER } & \text { recombinant human estrogen receptor } \\ & \end{array}$




$\begin{array}{ll}\text { Rlx } & \text { raloxifene } \\ \text { RPA } & \text { replication protein A } \\ \text { SDSA } & \text { synthesis dependent strand annealing } \\ \text { SEM } & \text { standard error of the mean } \\ \text { SERM } & \text { selective estrogen receptor modulator } \\ \text { Tmx } & \text { tamoxifen } \\ \text { TRE } & \text { thyroid hormone response element } \\ \text { VitA2 } & \text { vitellogenin A2 } \\ \text { vWa } & \text { von Willebrand }\end{array}$




\section{CURRICULUM VITAE}

NAME: $\quad$ Traci Lynne Kruer

ADDRESS: 912 Lydia St.

Louisville, KY 40217

DOB: $\quad$ New Albany, Indiana - August 21, 1979

EDUCATION

\& TRAINING: $\quad$ B.S., Molecular Biology with Honors

Purdue University

2001

M.S., Biochemistry \& Molecular Biology

University of Louisville, School of Medicine

2011

AWARDS: Doctoral Dissertation Completion Award

School of Interdisciplinary and Graduate Studies, University of Louisville, Louisville, KY

2011

Best Poster Award Finalist

Department of Defense Era of Hope Meeting, Orlando, FL 2011

Second Place Award in Doctoral Graduate Student Poster Presentation Institute for Molecular Diversity \& Drug Design Annual Symposium, University of Louisville, Louisville, KY

2009

Third Place Award in Doctoral Graduate Student Poster Presentation Research! Louisville, Louisville, KY

2008

First Place Award in Doctoral Graduate Student Poster Presentation American Association for Clinical Chemistry Translating Proteomic Discoveries into Clinical Diagnostics Meeting, Seattle, WA 
Predoctoral Traineeship Award W81 WXWH-08-0775

Department of Defense Breast Cancer Research Program

2008

Grafton Chase Young Scientist Award \& Travel Award

Clinical Ligand Assay Society, Fajardo, Puerto Rico

2007

Graduate Fellowship

Integrated Programs in Biomedical Sciences, University of Louisville, Louisville, KY

2006

ORAL PRESENTATIONS: Expression and Clinical Significance of Novel EREBinding Proteins in Breast Tissue, Clinical Ligand Assay Society National Meeting, Fajardo, Puerto Rico, May 2007

Expression \& Clinical Significance of Novel ERE-Binding Proteins in Breast Cancer, Institute for Molecular Diversity and Drug Design Fall Fest, Louisville, KY, November, 2007

Characterization of Estrogen Response Element Binding Proteins that Predict Clinical Behavior of Human Breast Cancer, Institute for Molecular Diversity and Drug Design Fall Fest, Louisville, KY, November, 2009

Technique for Determining ERE-Binding Proteins in Cancer Biopsies to Assess Clinical Relevance, Association of Clinical Scientists Annual Meeting, Louisville, KY, May, 2011

Characterization of ERE-Binding Proteins as Clinically Relevant Biomarkers of Human Breast Cancer Behavior, Institute for Molecular Diversity and Drug Design Fall Fest, Louisville, KY, October, 2011

PUBliCATIONS: $\quad$ Andres, S.A., Kerr II, D.A., Bumpus, S.B., Kruer, T.L. Thieman, J.W., Smolenkova, I.A., Wittliff, J.L. A ThreeTiered Approach for Calibration of a Biosensor to Detect 
Estrogen Mimics. Advances in Experimental Medicine \& Biology: Oxygen Transport to Tissue XXIX. (Kang, K.A., Harrison, D.K., and Bruley, D.F., eds.) 305-313, 2008.

Wittliff J.L., Andres, S.A., Kruer, T.L., Kerr II, D.A., and Erb, J.L. Biosensors for Detecting Estrogen-like Molecules and Protein Biomarkers. Adv Exp Med Biol., Oxygen Transport to Tissue XXIX. (Kang, K.A., Harrison, D.K., and Bruley, D.F., eds.) 315-322, 2008.

Wittliff, J.L., Kruer, T.L., Andres, S.A., Smolenkova, I.A. Molecular Signatures of Estrogen Receptor-Associated Genes in Breast Cancer Predict Clinical Outcome. Hormonal Carcinogenesis V. (Li, J.J., Li, S.A., Mohla, S., H. Rochefort, H., Maudelone, T., eds.) 2008.

Kidd, L.R., Brock, G.N., VanCleave, T.T., Benford, M.L., Lavender, N.A., Kruer, T.L., Wittliff, J.L. Angiogenesisassociated sequence variants relative to breast cancer recurrence and survival. Cancer Cause and Control, 2010 Oct;21(10):1545-57. 